\title{
OPPORTUNITIES AND OBSTACLES IN THE TRANSITION TO A DISTRIBUTED NETWORK OF ROOFTOP SOLAR
}

\section{A MULTI-METHOD APPROACH}

by

Steven M. Hall

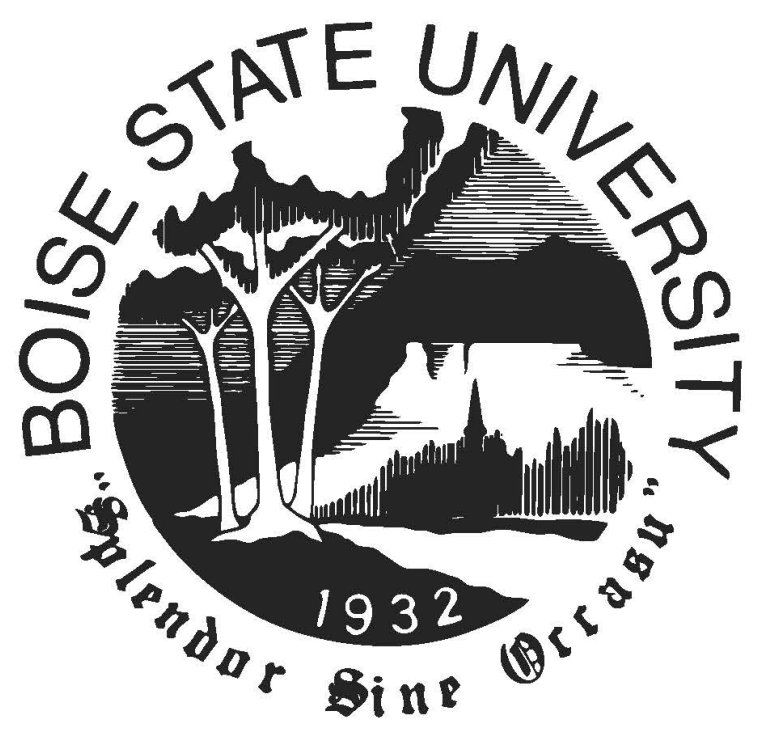

A thesis

submitted in partial fulfillment

of the requirements for the degree of

Master of Science in Economics

Boise State University

May 2020 
(C) 2020

Steven M. Hall

ALL RIGHTS RESERVED 
BOISE STATE UNIVERSITY GRADUATE COLLEGE

\title{
DEFENSE COMMITTEE AND FINAL READING APPROVALS
}

\author{
of the thesis submitted by
}

\author{
Steven M. Hall
}

Thesis Title: Opportunities and Obstacles in the Transition to a Distributed Network of Rooftop Solar: A Multi-Method Approach

Date of Final Oral Examination: $\quad 5$ March 2020

The following individuals read and discussed the thesis submitted by student Steven M. Hall, and they evaluated his presentation and response to questions during the final oral examination. They found that the student passed the final oral examination.

Michail Fragkias, Ph.D. Chair, Supervisory Committee

Kelly Chen, Ph.D. Member, Supervisory Committee

Sin Ming Loo, Ph.D. Member, Supervisory Committee

The final reading approval of the thesis was granted by Michail Fragkias, Ph.D., Chair of the Supervisory Committee. The thesis was approved by the Graduate College. 


\section{ACKNOWLEDGEMENTS}

I would like to thank my committee and the instructors who have helped me reach this point in my academic career. You are all reflected in this work. I would also like to thank the researchers, those who are cited and those whose contributions led to my increased understanding of the subject but are not cited. This is a culmination of a great deal of research and study in economics, finance, renewable energy and sustainability. I could not have accomplished this without the those who came before me, along with the help and support of my advisors, instructors, and the patience and support of my fiancè, Erin. 


\begin{abstract}
This paper investigates the feasibility and viability of providing power to Ada County, Idaho, using a distributed network of rooftop solar photovoltaic panels. Using a multi-disciplinary and multi-method modeling approach, a detailed simulation is performed where existing structures are retro-fitted with grid-tied solar photovoltaic systems using currently available technology. Feasibility is determined using simulated supply and demand per building, while viability is determined through standard financial metrics used in the energy sector. A major critique of solar energy comes from the vast amounts of space required to efficiently capture solar power, along with the inefficiencies created by transmission loss and intermittency. Under a system where structures become both producers and consumers of energy, with PV panels deployed in unused rooftop space, this paper mitigates those critiques and analyzes the results. Four case scenarios are discussed based on the perspectives of differing energy stakeholders; consumers, private firms, public utilities, and national governments.
\end{abstract}




\section{Contents}

I INTRODUCTION 1

1 The Physics of Energy 1

2 Energy Transitions and Climate Concerns 2

3 Solar Utopia 4

4 The Promise of a Distributed Network 5

5 Contributions $\quad 7$

6 Remaining Sections 7

II Literature RevieW $\quad 9$

7 Thinking in Models 9

7.1 Backcasting .......................... 9

7.2 New Reality Thinking . . . . . . . . . . . . . . . . 10

8 Simulation in Energy and Economics 11

8.1 Complex Adaptive Systems . . . . . . . . . . . . . . . . . . 11

8.2 Simulation in the Energy Sector . . . . . . . . . . . . . 11

9 Estimating Rooftop Solar Potential 12

10 Deriving and Forecasting Demand 12

11 Agent Based Modeling 14

11.1 Agent-Based Stock-Flow Consistent Transition Model . . . . . . . . . 14

11.2 Bass Diffusion . . . . . . . . . . . . . . . . . . . . . 15 
11.2.1 The Small World Network _ . . . . . . . . . . . . . . 15

11.3 Watts-Strogatz Model . . . . . . . . . . . . . . . . . . 16

11.4 Modeling Early Adopters . . . . . . . . . . . . . . . . . 16

12 Economic Evaluation of Renewable Technology 17

13 Fiscal Policy within the DSGE-VAR Framework 17

$\begin{array}{ll}\text { III Methodology } & 19\end{array}$

14 Backcasting $\quad 19$

15 System Inputs 20

15.1 Rooftop Capacity Calculations . . . . . . . . . . . . . . . 20

16 Data 20

16.1 Ada County GIS $\ldots \ldots \ldots \ldots \ldots \ldots$

16.2 Energy Information Administration . . . . . . . . . . . . 21

16.3 Weather Data . . . . . . . . . . . . . . . . . . . . 21

16.4 OpenEI US Utility Rate Database . . . . . . . . . . . . . . . . 22

17 Simulation 22

17.1 System Advisor Model (SAM) . . . . . . . . . . . . . . . 22

18 Data Validation 24

18.1 PV System Output . . . . . . . . . . . . . . . . . . . 24

18.2 Modeling Demand with MARS $\ldots \ldots \ldots \ldots \ldots$

19 Analyzing Opportunities 26

19.1 The Bass Diffusion Model . . . . . . . . . . . . . . . . 26

19.1.1 Extending the Model . . . . . . . . . . . . . . . . 27 
20 Key Evaluation Metrics 28

20.1 The Cost Function . . . . . . . . . . . . . . . . . . . 28

20.2 The Revenue Function . . . . . . . . . . . . . . . . . . . . . 29

20.3 Total Life Cycle Cost . . . . . . . . . . . . . . . . . . . . . . . 30

20.3.1 Private Firms . . . . . . . . . . . . . . . . . . . 30

20.3.2 Public Utilities . . . . . . . . . . . . . . . . . 30

20.3.3 Governments . . . . . . . . . . . . . . 31

20.4 Levelized Cost of Energy . . . . . . . . . . . . . . . . . . . . 31

20.5 Net Present Value . . . . . . . . . . . . . . . . . . . . . . . . . 32

20.6 Internal Rate of Return . . . . . . . . . . . . . . . . . . . 33

20.7 Benefit to Cost Ratios . . . . . . . . . . . . . . . . . 33

IV Distributed Network Design 35

21 Rooftop Capacity 35

21.1 Single Family Residence Capacity . . . . . . . . . . . . . . . . 35

21.2 Multi-Family Housing Capacity . . . . . . . . . . . . . . . . 36

21.3 Commercial Property Capacity . . . . . . . . . . . . . . . . . 37

21.4 Visualization of Commercial Rooftop Area . . . . . . . . . . . . . 37

21.5 Total Rooftop Capacity-Ada County . . . . . . . . . . . . . . . . 38

22 System Configuration 38

22.1 Modules and Inverters . . . . . . . . . . . . . . . . . . . . . 39

22.2 Residential-Scale Systems . . . . . . . . . . . . . . . . . 39

22.3 Commercial PV Arrangement . . . . . . . . . . . . . . . . . 39

23 Final Network Structure 40

24 Data Validation 40 
24.1 Mathematical Validation . . . . . . . . . . . . . . . 40

24.2 Visualising the Data . . . . . . . . . . . . . . 41

24.3 Moving to the Future . . . . . . . . . . . . . . . . 44

V Future Opportunities: Technical Feasibility 45

25 Feasibility for Individual Homeowners 45

25.1 Individual Homeowner Feasibility Conclusion . . . . . . . . . . . . . . 46

26 Aggregating the Network 47

26.1 Aggregate Supply . . . . . . . . . . . . . . . . 47

26.1.1 Residential Supply Potential . . . . . . . . . . . . . . 48

26.1.2 Commercial Supply Potential . . . . . . . . . . . . . . 48

26.2 Aggregate Load . . . . . . . . . . . . . . . . . . . 49

26.2.1 Residential Load Estimation . . . . . . . . . . . . . . . . 49

26.2.2 Commercial Load Estimation . . . . . . . . . . . . . 49

27 Aggregate Supply and Demand per System Type 50

28 Network Supply and Demand $\quad 51$

29 Market Area $\quad 52$

29.1 Market Supply and Demand . . . . . . . . . . . . . 53

29.2 Distributed Network Supply vs Market Area Demand . . . . . . . . . 53

30 Conclusions on Network Feasibility Opportunities $\quad 55$

31 Obstacles: Technical Feasibility 56

31.1 Intermittency . . . . . . . . . . . . . . . 56

31.2 Market Disruptions . . . . . . . . . . . . . . . . . 56

31.3 Energy Storage . . . . . . . . . . . . . . . . . . 57 
31.4 Urban Sprawl and Population Density . . . . . . . . . . . 57

31.5 The Duck Curve . . . . . . . . . . . . . . . . . . 58

31.6 Assuming Away Money . . . . . . . . . . . . . . . . . . . 60

VI Future Opportunities: Economic Viability 61

32 Adoption by Individual Homeowners at Scale 61

32.1 Costs Facing Individual Homeowners . . . . . . . . . . . . . . . . . . 61

32.2 Bass Diffusion Model Implementation . . . . . . . . . . . . . . . . . . 62

32.2 .1 The Base Case . . . . . . . . . . . . . . . . 64

32.3 Homeowner Adoption Results . . . . . . . . . . . . . . . . . 64

32.3.1 Further Adaptations . . . . . . . . . . . . . . . . . 65

32.3 .2 Incentives . . . . . . . . . . . . . . . . 65

33 Aggregate Output, Costs and Returns to Scale 66

33.1 Returns to Scale . . . . . . . . . . . . . . . . 66

33.2 Aggregate Costs . . . . . . . . . . . . . . . . 67

33.3 Aggregate System Output . . . . . . . . . . . . . . . . 67

33.4 Simulated Revenue and Profit: Distributed Rooftop Network . . . . . 68

34 The Private Firm $\quad 68$

34.1 Key Metrics . . . . . . . . . . . . . . . . . . 69

34.1.1 Total Long-Term Cost of Capital . . . . . . . . . . . . . . . . 69

34.1.2 Levelized Cost of Energy . . . . . . . . . . . . . . . . . . 69

34.1.3 Internal Rate of Return . . . . . . . . . . . . . . . . 70

34.1.4 Net Present Value for the Firm . . . . . . . . . . . . . . . . . 70

34.1.5 Break-Even Analysis . . . . . . . . . . . . . . . . . . . 70

34.1.6 Benefit to Cost Ratio . . . . . . . . . . . . . 71

34.2 Results . . . . . . . . . . . . . . . . . . . 71 
35 Investment by Public Utilities $\quad 71$

35.1 Disruptive Risk . . . . . . . . . . . . . . . . . . 72

35.1.1 Consumer Adoption . . . . . . . . . . . . . . . . 72

35.1.2 Profit Risk . . . . . . . . . . . . . . . . . . . . . . 72

36 Financial Metrics for the Public Utility 73

36.0.1 Public Utility-Revenue and Projected Profit . . . . . . . . . 73

36.0.2 Total Long Term Cost of Capital . . . . . . . . . . . . . . 74

36.0.3 Levelized Cost of Energy . . . . . . . . . . . . . . . . . . 74

36.0.4 Net Present Value . . . . . . . . . . . . . . . . . . . . . 74

36.0.5 Benefit to Cost Ratio . . . . . . . . . . . . . . . . . . 74

36.1 Public Utility Results . . . . . . . . . . . . . . . . . 75

37 Direct Government Implementation $\quad 75$

37.0.1 Levelized Cost of Energy . . . . . . . . . . . . . . . . 76

37.0.2 Government Facing Net Present Value . . . . . . . . . . . . . 76

37.1 Energy Spending as a Stimulus . . . . . . . . . . . . . . . . 77

37.1 .1 Clean Energy Jobs . . . . . . . . . . . . . . . . . . . 77

37.1.2 Government Multiplier Flow . . . . . . . . . . . . . 77

VII CONCLUSIONS

38 Further Research $\quad 80$

$\begin{array}{ll}\text { REFERENCES } & 95\end{array}$

$\begin{array}{ll}\text { APPENDIX } & 96\end{array}$

39 Simulation Data 96 
39.1 SAM Algorithm . . . . . . . . . . . . . . . . . . . . 96

40 Financial Incentives 101

40.1 Residential Renewable Energy Tax Credit . . . . . . . . . . . . . . 101

40.2 FHA Energy Efficient Mortgages . . . . . . . . . . . . . . 102 


\section{List of Figures}

1 Grid-tied Distributed Network (Author's Model) . . . . . . . . . . 6

2 Backcasting process flow (Author's Work) . . . . . . . . . . . 19

3 Photovoltaic Model Simplified Block Diagram (Gilman, 2015) . . . . 23

4 Data verification for condominium and commercial assessor data . . . 36

5 Approximately 1,136 square meters . . . . . . . . . . . . . . . . . . 38

6 Distribution of variance for calculated output versus simulated data $(\mathrm{SAM}) \ldots \ldots \ldots \ldots \ldots \ldots \ldots$. . . . . . . . . . . . . . . . . 42

7 Distribution of variance for calculated demand versus simulated data. Vertical line is distribution mean. (SAM Simulation) . . . . . . . . . 42

8 Estimated load data for Ada County versus actual load data for the Idaho Power market area . . . . . . . . . . . . . . . . . 44

$9 \quad$ Hourly Supply and Demand for Individual PV Systems. . . . . . . . . 46

10 Monthly Supply and Demand for Individual PV Systems. . . . . . . . 47

11 Micron Campus, Southeast Boise . . . . . . . . . . . . . . . 48

12 Aggregate Supply and Demand for Individual PV Systems. . . . . . . 50

13 Aggregate Supply and Demand, Distributed Rooftop Solar Network . 51

14 Idaho Power service area (Sources: Esri, DeLorme, HERE, MapmyIndia) 52

15 Market demand and Idaho Power Company net generation, 2017 . . . 54

16 Market Demand, Idaho Power Net Generation, DNRS Output . . . . 54

17 Market Demand versus Renewables, Idaho Power renewables and DNRS output combined ....................... 55

18 Hourly supply and demand during daily time periods. . . . . . . . 58 
19 (a): The probabilistic duck curve derived from California, 2012:2020 (Hou et al., 2019)(b): Impact on net loads from renewable energy sources (Denholm and Mehos, 2011) . . . . . . . . . . . . 59

20 Quarterly Depiction of the Duck Curve using EIA and Simulation Data 59

21 Agent-Based Model . . . . . . . . . . . . . . . . . . . . . . 64

22 Circular Flow: Government Spending . . . . . . . . . . . . 78 


\section{List of Tables}

1 Variables of system cost (Fumo and Rafe Biswas, 2015) . . . . . . . . 29

2 Distributed Network Configuration . . . . . . . . . . . . . . . 40

3 Validation Test: Random Draw . . . . . . . . . . . . . . . 43

4 Cost Breakdown per System . . . . . . . . . . . . . . . 62

$5 \quad$ Bass Diffusion Simulation Parameters . . . . . . . . . . . . . . . 63

6 Price Factor Analysis by PV System . . . . . . . . . . . . . . . . 63

7 Cost Breakdown per System . . . . . . . . . . . . . . 67

$8 \quad$ Projected Financials: Discount Rate Sensitivity . . . . . . . . . . . 70

$9 \quad$ Network Supply Demand with Solar Irradiance: July 15,2018 . . . 98

10 Oscar System Hourly Output: July 15,2018 . . . . . . . . . . . . . . 99

11 India System Hourly Output: July 15,2018 . . . . . . . . . . . . . . 100

12 Distributed Network-Monthly Supply, Demand and Savings . . . . . 101 


\section{PART I: INTRODUCTION}

Humankind has not woven the fabric of life. We are but one thread within it. Whatever we do to the web, we do to ourselves. All things are bound together. All things connect. Chief Seattle, 1854

\section{The Physics of Energy}

Energy is the fundamental element in economics, as well as society in general. Without the ability to leverage energy resources humanity would likely still be nomadic bands of hunter-gatherers, assuming we were able to survive at all. A shortage of reliable electrical energy is a defining characteristic of developing nations while, conversely, the presence of clean and affordable electricity are hallmarks of rich, developed nations. Energy is more than a simple input into production functions and growth models, it is an intrinsic factor that makes production itself possible (Keen, Ayres, and Standish, 2019).

As research and ideas are put forward toward policy goals and prescriptions for the future, the dynamic structure and complexity of the energy system is paramount. The energy sector is full of interdependencies, externalities, and unintended consequences that require a holistic approach and a farsighted frame of reference. Traditional estimation techniques must combine with complex systems analysis and the dynamics of sociotechnical and socioeconomic systems. The interactions between economic welfare, efficient use of resources, and mitigation of environmental degradation is paramount to both good design and good policy. Electricity production is a major contributor to environmental emissions and a

crucial factor in alleviating poverty at local and global levels (Qudrat-Ullah, 2016). 
It is imperative to find an equilibrium point between the energy needs of our planet and the constraints of the Earth's biosphere. While there are many renewable and sustainable technologies that can be used to power the planet, there are few that fit well into o ur c urrent infrastructure and have the potential to deploy rapidly at scale. Continuing progress toward sustainable growth, meeting global energy needs, and the desire to stave off an extinction level climate event requires a divide and conquer approach which can identify the best uses for each technology. The need for rapid deployment must also be a major criteria in all proposed solutions.

\section{Energy Transitions and Climate Concerns}

Climate change represents one of the major challenges faced by the planet and threatens the future of economic and socioeconomic security. Transitioning away from fossil fuels will be a major feature in any climate change mitigation plans, with residential energy consumption showing great potential for reducing fossil fuel use (Damette, Delacote, and Lo, 2018). Researchers have found it difficult to separate building energy consumption from aggregate consumption, but it is estimated that as much as $40 \%$ of global energy use can be traced to the lighting, heating and cooling of buildings (Pérez-Lombard, Ortiz, and Pout, 2008).

There is wide consensus that a low-carbon energy transition is imperative to reduce greenhouse gas emissions and fight climate change (Harvey and Orvis, 2018). The best path forward is less clear, with experts proposing everything including solar, nuclear, wind, biomass, geothermal and "all of the above" as final solutions (Araújo, 2017; Till and Chang, 2011; MacKay, 2010). Local governments and private corporations also find that clean and sustainable energy are critical for their constituents and customers. The City of Boise recently stated their goal that "100\% of the electricity used by the City of Boise's residents and businesses will be clean 
by 2023 while prioritizing affordability and access for all" (Energy, 2019). Idaho Power Corporation, the electricity provider whose service area includes Ada County, plans for a "clean today and cleaner tommorow" through increased usage of renewables from hydropower to nuclear power as well (IdaCorp, 2018a).

Climate change threatens current methods of energy generation on multiple, interacting fronts which create feedback loops and chaotic attracting systems that are virtually unpredictable. Changing climate is certain to impact agricultural performance and production, which will in turn alter energy demand as it relates not only to production but through processing, cooling and transportation of food products as well. Concurrently, increased temperatures in some regions are sure to increase cooling demand not only in the agricultural sector but also in business and residential sectors. These changes in demand response pose a significant threat to the reliability of energy generation and distribution (Ruth et al., 2015)

As the science of determining the highest and best uses for scarce resource, economics is uniquely positioned to advance clean energy goals while protecting valuable resources such as oil and natural gas. The use of oil and petroleum products is integral to the fabric of society and their vitality will remain important into the future. It must not be forgotten, though, that these are finite resources with a high likelihood of depletion in the not too distant future (MacKay, 2010). The question becomes whether burning this critical resource as fuel for electrical generation is the highest and best use. Sustainability on the planet involves preventing environmental degradation, and conserving resources which, at this point, have no close substitutes.

A major priority is to increase the amount of energy produced by solar power, in order to limit the catastrophic effects of climate change. Carbon emissions from electrical power need to fall by $80-90 \%$, so we will likely need to convert $33 \%$ of global electrical power to solar by 2050 (Sivaram, 2018; Jenkins and Thernstrom, 
2017).

\section{Solar Utopia}

Finding the equilibrium point between the energy needs of our planet and the constraints of the Earth's biosphere is an idyllic notion. The idea that we can harness the sun's energy to power society is the ultimate expression of a circular economy (Raworth, 2017). Climate change advocate Michael Shellenberger believed that technical solutions were "pretty straightforward; solar panels on every roof, and electric cars in every driveway" (Shellenberger, 2018). After spending several years working with communities and governments toward a green energy future, Shellenberger found that rooftop solar was too expensive and that the amount of land required for a commercial solar farm made it cost prohibitive and dangerous to the ecosystem. Shellenberger has since become a fierce advocate for nuclear energy.

To test the idea of the solar utopia, I take a "new reality" approach (Page, 2018), performing a large scale simulation using today's existing technology along with historical weather patterns and energy costs. There are significant and relevant limitations surrounding solar energy production at scale, many of which have been eloquently described by Shellenberger himself. If solar power truly is unable to meet our energy needs, then our time will be better served from this point forward by concentrating on solutions that are viable. This paper sets out to take the first steps toward developing and analyzing a system of solar energy that minimizes costs, maximizes output, and develops a use case that can be credibly compared with other solutions. 


\section{The Promise of a Distributed Network}

Historically energy has been produced and distributed through natural monopolies, with increasing privatization beginning in the 1990's in an attempt to encourage market forces and increase efficiency. It is widely accepted that transitioning to renewable energy will likely involve some sort of distributed network, and that such networks are "economically and technologically feasible." (Ptak et al., 2018, p. 46 ).

Two often discussed shortcomings of large-scale solar energy generation are the land footprint required to produce energy at scale (Hernandez, Hoffacker, and Field, 2014) and the transmission loss that occurs as this energy is delivered to end users (Ma et al., 2017). A common criticism of solar energy is the vast land footprint necessary to produce a large amount of energy, and this criticism is a valid one. These issues are addressed through the adoption of a distributed network of rooftop solar installations; land footprint is minimized by leveraging currently underutilized rooftop area, and transmission loss is virtually eliminated by developing a system where buildings become both producers and consumers of energy.

A distributed network of rooftop solar panels can be visualized systematically much like a distributed network of computers, a decentralized complex system, and can thus be regarded as a Systems of Systems (Kremers, Viejo, et al., 2010). Instead of a top-down hierarchical system under strict control by power generators, a distributed system allows individual agents to monitor their production and consumption with much lower barriers to entry into the energy production markets. Outside of decentralized control, in a system such as the UK where the grid is the monopoly and producers are free to enter the market (Till and Chang, 2011), higher 
levels of market freedom and choice are possible. Distributed networks also provide increased security and resilience as they are more difficult to disrupt-whether by natural or man-made disaster-as damage to a single node in the network does not disrupt the entire infrastructure.

The adoption of a distributed network allows more flexibility to enter the system and creates the opportunity for spillover effects in the development of new technologies or implementation of micro-grids. Combining smaller scale energy generation at a more local level could help to reduce costs to consumers and increase resilience in the system. However, to be free from the grid entirely will require energy storage in some form. While there are ongoing and intriguing studies of energy storage at the current moment, there are no truly scalable energy storage solutions available using current technology. The distributed network designed in this study will necessarily be a grid-tied network (Figure 1) using the net-metering system currently in place in the market area.

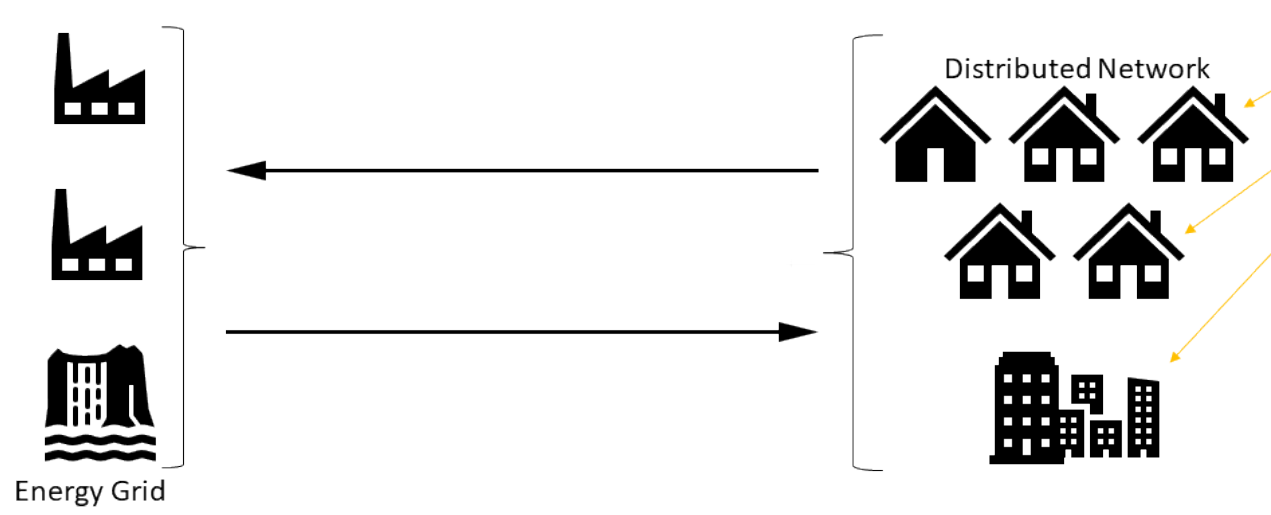

Figure 1: Grid-tied Distributed Network (Author's Model) 


\section{Contributions}

This study takes a multi-disciplinary and multi-method approach, examining the prospect of retro-fitting a distributed network of rooftop solar photovoltaic panels on currently unused rooftop area in Ada County. Others have taken a more strictly mathematical approach (Ghaith, Epplin, and R. S. Frazier, 2017; Pruckner and German, 2013), where this study explores existing rooftop spatial constraints imposed by existing roof structures.

Available rooftop area is calculated using the same technique used to determine the adequate amount of supplies needed to replace each roof, and the overall underutilized rooftop area is compared with the findings from a GIS-based national study (Gagnon et al., 2016). Six separate solar array configurations are developed based on available rooftop area using technology currently available in the market. A simulation is then performed using twenty years of actual weather and energy data, along with five additional years of simulated data to cover the stated twenty-five year lifespan of the PV panels.

Once the simulated system data has been derived, analysis is made to the extent the network is technically viable and then economically feasible for four distinct energy stakeholders; individual consumers, private firms, public utilities, and the national government.

\section{Remaining Sections}

The remainder of this paper is structured as follows. Chapter II reviews previous literature and research in the areas of energy and economics, including technical feasibility of solar energy, economic evaluation, using many-models methods, and 
fiscal policy frameworks.

Chapter III introduces the concept of backcasting, the calculation method for available rooftop area, then details the simulation software and validation methods used. Specific economic and financial metrics and data sets used in the study are also detailed.

Chapter IV details the construction of six independent solar PV systems that will aggregate to form the distributed network. Each system is built using currently existing technology and current pricing structures, while existing rooftop area is quantified and coordinated with a solar PV system based on available rooftop area.

Chapter $\mathrm{V}$ explores the technical feasibility of each system in relation to individual consumers and the network in aggregate. Energy demand is estimated at the structural level and PV panel output is simulated, developing an ecosystem where buildings become both consumers and producers of electrical energy. Aggregate supply and demand is analyzed for the distributed network and compared with current energy demand and net generation for the market area.

Chapter VI examines the economic viability of the network facing each group of stakeholders detailed above. System costs are introduced at the individual level for homeowners and at the aggregate level for large-scale investment firms, public utilities and governments. Energy output, costs and revenues are evaluated over a twenty-five year simulation which utilizes twenty years of existing data followed by five years of simulated data. Recommendations are then made for each group as to whether adoption of the network appears viable from their perspective. Chapter VII reviews the findings and direction of future research. 


\section{PART II: LITERATURE REVIEW}

\section{Thinking in Models}

\subsection{Backcasting}

Backcasting is a common approach in sustainable energy research and an increasingly utilized method in econometrics. Ahlroth and Höjer (2007) was one of the first to explore why macroeconomic models and backcasting models differed so greatly given that they deal with similar issues. They found that the main differences between the findings of the two systems stemmed from their respective baseline assumptions and the interpretations of signals about the future. Comparing sustainability and economic scenarios in Sweden they looked closely at the question of energy prices in an area with sustainable energy use. They were able to find tensions between the assumptive forecasts of the economic scenarios and the normative backcasting scenarios that only became apparent as the two were compared and conclude that assumptions and analysis from both traditions should be combined in future research.

Kapetanios and Yates (2010) investigate the measurement error in economic statistics over time using a behavioral backcasting model by measuring the variance in economic data as they are released and revised. Mulder and Biesiot (1998) looks at sustainability in terms of a sustainable development path that allows for an equal right per capita in the benefits of natural resources which adds time and space to the traditional definition of sustainability. Mulder and Biesiot also used a backcasting model to set a future target for sustainability and worked backwards to define energy use goals with an "if-then" style of analysis. 


\subsection{New Reality Thinking}

Of the many ways to perform a detailed analysis of a broad topic the two that are most often used are traditional marginal analysis, generally performed through regression, and simulation modeling. Parts and pieces of both methods are often interchangeable as simulation parameters are informed by regression or other statistical techniques. One key difference between the two is defined by Page as "The Big Coefficient vs the New Reality" (Page, 2018). Big coefficient thinking examines a problem from the perspective of how things currently exist in the world and works to make improvements at the margins. Common examples are widening roads to decrease traffic, reducing class sizes to improve test scores, or even subsidizing the adoption of one technology above others.

New Reality thinking, on the other hand, sees the world as it is and wonders what it could be. New reality thinking builds railroads and highway systems that connect a nation, public transit systems and self-driving cars that change the way we move, and energy systems that make the highest and best use of natural resources available. A parallel can be drawn in economics between "big coefficient" thinking and positive economics, while "new reality" thinking taking more of a normative approach. Both methods are important and useful, but often the biggest changes happen when we are able to envision a new reality and shape policy objectives based on reaching it. 


\section{Simulation in Energy and Economics}

\subsection{Complex Adaptive Systems}

Complex adaptive systems are those where system elements are interrelated, containing heterogeneous agents and structures, and no autonomous controls. Emergent behaviors are derived from self-organizing, autopoietic systems that cannot be easily predicted by examining individual components and introduction of new technology can influence behavior in more than one system category (Bale, Varga, and Foxon, 2015; Holland, 2003). These descriptors all fit energy systems in one form or another.

Complex adaptive systems are generally non-linear systems containing positive feedback loops, sometimes referred to in economic theory as increasing returns to scale. Simply put, as the agents interact with each other the system changes in aggregate, which prompts another reaction from the agent and evolves into a system which constantly evolves over time (Arthur, 2015). Testing for increasing returns to scale can be relatively simple; doubling factor inputs- all else held constant- and observing the effects on the outputs (Elsner, Heinrich, and Schwardt, 2015).

\section{2 $\underline{\text { Simulation in the Energy Sector }}$}

While simulation studies are relatively uncommon in economics, quite the opposite is found in the energy and engineering space. Kremers, Viejo, et al., 2010, used a complex systems approach with multi-paradigm modeling to present decentralized electrical microgrids. Kremers, Gonzalez de Durana, and Barambones (2013) present a case study of multi-agent modeling in smart microgrid applications, 
and Gonzalez de Durana and Barambones (2018) employs a multi-method approach with agent-based models embedded inside a system dynamics framework. Pruckner and German (2013) uses a hybrid system dynamics and discrete choice approach for large-scale electricity generation, while Rai and Henry (2016) model consumer energy choices in an agent-based framework to represent complexities of spatial constraints and social interaction in dealing with climate change.

\section{Estimating Rooftop Solar Potential}

Gagnon et al. (2016) explore technical potential for rooftop solar PV. They quantify the potential for the entire continental United States, generating estimates of how

much energy could be produced with the available roof space in 128 cities, including Boise, Idaho. Their study used LiDar technology and GIS techniques to estimate technical generation potential, developing the suitable rooftop area using two statistical models. One model pertains to small buildings defined as having a planar footprint area of less than 5,000 $f t^{2}$ and a second model for large systems above $5,000 f t^{2}$.

Evaluation criteria include building footprint, rooftop shading, rooftop orientation, and azimuth of the roof plane. All rooftop area that failed to meet minimum requirements were eliminated, culminating in an estimate of approximately $26 \%$ of the total available ground floor square footage suitable for rooftop solar installations.

\section{Deriving and Forecasting Demand}

Predicting energy demand, also referred to as load or peak load, on a micro-level is a difficult task that has been approached in a number of ways in previous literature. 
Early studies showed a tendency toward estimating equipment stock explicitly (Berndt, 1991), which proves difficult given the multitude of appliance and electricity consuming device configurations that may exist at the household level.

T. Ahmad et al. (2018) found through a comprehensive overview of energy demand forecasts that simulations were generally based on four classes; data-driven approaches, physics-based approaches, large scale building forecasting and hybrids of the previous three approaches. Filippini and Hunt (2012) used a stochastic demand frontier based on EIA data to estimate demand and the role played by energy efficiency; while Jun Ma and Cheng (2016b) and Jun Ma and Cheng (2016a) used GIS and big data to determine energy intensity and thereby energy use, along with a random forest approach to region energy use intensity (Jun Ma and Cheng, 2016a; Jun Ma and Cheng, 2016b).

Damette, Delacote, and Lo (2018) take a theoretical, optimization-based approach considering budget constraints and assumptions that households are able to choose their energy consumption alternatives, while Wang et al. (2018) also use a random forest approach toward hourly energy consumption predictions. The author explored determining the correct attributes and methods for predicting energy demand based on structural and spatial criteria in a previous work (Hall, 2019). Others have developed linear regression models (Ghaith, et al. 2017; Berndt, 1991), non-linear regression analysis, (Fumo and Rafe Biswas, 2015) support vector machines (M. W. Ahmad, Reynolds, and Rezgui, 2018), and complex dynamic systems (Qudrat-Ullah, 2016).

Al-Musaylh et al. (2018) compared multivariate adaptive regression splines (MARS), time series autoregressive integrated moving average (ARIMA) and support vector machine (SVM) models for forecasting end-user demand in Australia. Their findings included a distinct advantage for the MARS model, also used in this study, when trained using a large database with 0.5 to 1.0 hour time intervals. 


\section{Agent Based Modeling}

In Bale et al. (2015) the authors find agent-based modeling (ABM) as an appropriate method for the energy sector as long as clarity of purpose exists. As a bottom-up style of modeling, ABM's are especially useful in behavioral economics and simulating emergent behavior in complex systems.

\subsection{Agent-Based Stock-Flow Consistent Transition Model}

Ponta et al. (2018) consider agent based models in a stock-flow context to model sustainable transitions in the energy sector. Their investigation of the effects of feed-in tariffs on an open energy market consisting of both fossil fuel and green energy producers with renewable energy supply based on the volume of solar panels installed. The volume of installed panels was the result of capital investment decisions, measured using net-present value metrics, so the volume of space available for placement remained somewhat ambiguous. Ponta et al. found the lifespan of solar PV panels to range from twenty- to thirty-years, and chose to model lifespan at twenty years, making the further assumption that quantity of power produced per solar panel was constant over time with no diminishing output capacity. Using a total of 350 Monte Carlo simulations, the ABM model determined that feed-in tariffs were effective at spurring investment in renewable energy especially when combined with guaranteed electricity pricing. In general, the techniques employed are solid; however, important spatial and policy-level constraints may have been assumed away. 


\subsection{Bass Diffusion}

The Bass Diffusion Model (Bass, 1969) is commonly used in marketing and economics to explore consumer adoption of new technology. Boswijk and Franses (2005) uses available data to estimate parameters and add valuable extensions including social interaction. Only a fraction of most populations are willing to adopt a new technology before its use becomes ubiquitous. The benefits of a new technology are expressed in terms of costs, whether they are prices, switching costs, or costs of substitute and complimentary goods. In order for new prospects to become adopters of a technology, they are generally required to experience some sort of gain in utility through features, price, status or functionality (Sterman, 2000). In the energy sector, Bass models have been used and adapted for renewable energy adoption on large scales in India (Kumar and Agarwala, 2016) and Sterman (2000) also addresses multiple use cases for Bass Models and their derivations in his seminal work on system dynamics.

\subsubsection{The Small World Network}

Bale et al. (2015) explore the advances in modeling and complexity science as they relate to complex energy systems and how increased understanding of complex adaptive systems may lead to better technology, policy, and behavioural outcomes. Complexity is inherent in technological structures, social structures, and economic structures; all of which are at play within energy systems. Small world networks are based in graph theory, where the nodes are not explicitly required to be neighbors of one another but any given nodes are equally likely to be neighbors and most can be reached through a relatively low degree of separation. This leads to strangers possibly being linked together through factors other than geography, and direct neighbors equally likely to not be linked together as not, which lends the 
network the presumption of real-world applicability. In today's society, neighbors are less likely to know each other and far off neighbors can be easily connected electronically through methods such as social networks.

\subsection{Watts-Strogatz Model}

Watts and Strogatz identify a class of random graphs which can be classified using their clustering coefficient and average node-to-node distance. As opposed to purely random structures, this specification of the small world network finds average path lengths to be short between nodes while also having higher than expected clustering coefficients. Small world networks of this type have been widely used in biology, ecology, and in the description of neural networks and electricity grids (Watts and Strogatz, 1998).

\subsection{Modeling Early Adopters}

Araújo, Boucher, and Aphale (2019) studied early adoption and technical diffusion of clean energy technology in the electric vehicle and solar PV space in New York State. Their findings found statistically significant importance of income and home value in early adoption status, as well as finding political affiliation to be a more nuanced and less predictive indicator of early adoption. While these findings are preliminary and further research is suggested, the parameterization they suggest fits well into the randomization of early adopter status used in the agent-based model to follow in Section 32.2 . 


\section{Economic Evaluation of Renewable Technology}

The objective of economic analysis in any sector, and specifically in the energy sector, is to evaluate the information needed to make a business decision or value judgement. Analysis of technical feasibility and economic viability requires focus on each year of the project life cycle along with relevant costs. Relevant costs include direct and indirect capital costs, labor requirements, taxes and desired return on investment. Reliable data is required for a valid analysis, and the purpose or scope of the analysis is critical to providing valuable insights as well (Short, Packey, and Holt, 1995).

Several evaluation methods are fundamental to economic analysis in the energy sector, including net-present value (NPV), total life-cycle cost (TLCC), required revenue (RR), benefit to c ost ratios (B/C) and levelized cost of energy (LCOE) (Short, Packey, and Holt, 1995). These metrics are used as a means to evaluate investments in different energy technologies, but can also be used to establish the merit of investment based on incentives and risk tolerance of investors in both public and private sectors. The choice of real or nominal discount rates in this case is incidental as results point to the same conclusions using either real or nominal dollar basis (Short, Packey, and Holt, 1995).

\section{Fiscal Policy within the DSGE-VAR Framework}

Babecký et al. (2018) derived government spending and consumption multipliers of 0.76 and 0.38 , respectively, present sixteen quarters after spending occurred using a Dynamic Stochastic General Equilibrium-Vector Autoregression (DSGE-VAR) model (Babecký, Franta, and Ryšánek, 2018). They 
also found a social benefits multiplier of 0.17 using the same temporal measures. These results are prominent in the discussion of the possible role the government should play in development and implementation of the distributed solar network in Section 37. 


\section{PART III: METHODOLOGY}

\section{Backcasting}

Backcasting is accomplished by taking conditions as they currently exist and an idea of how conditions should appear in the future. Current data is used as input into a simulation engine, generating output data that is validated through comparison with expected patterns, comparison with known data points, and mathematical validation. As shown in Figure 2, once the data has passed validation it becomes an excepted proxy for the idealized future and can then be used to explore obstacles and opportunities between present and future conditions.

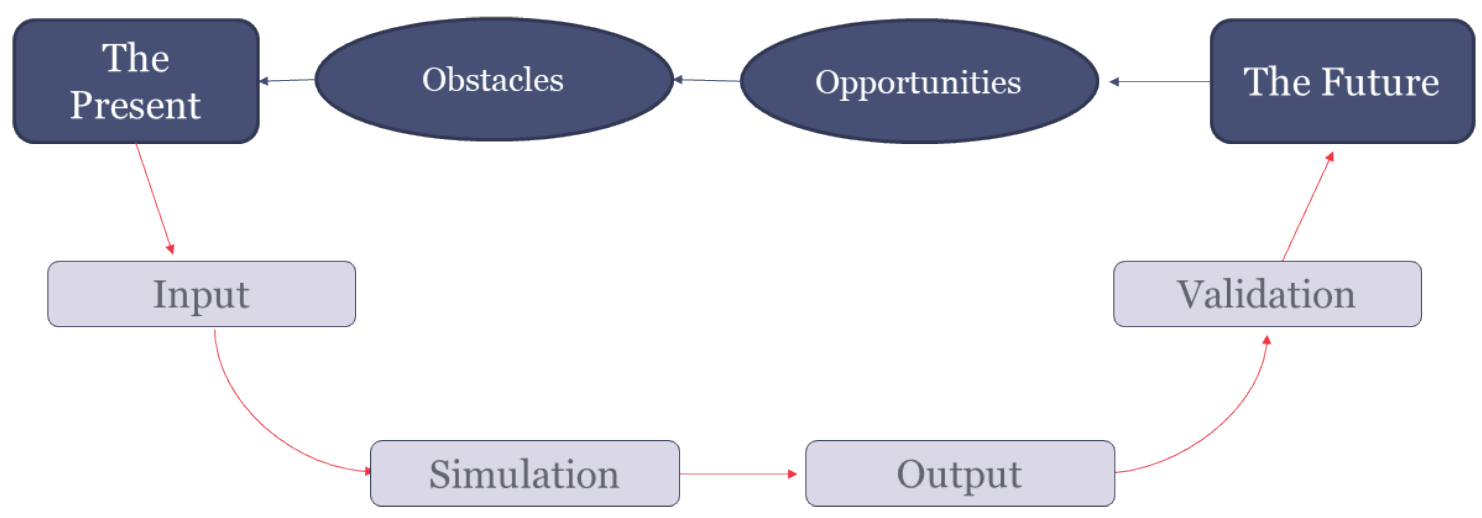

Figure 2: Backcasting process flow (Author's Work) 


\section{System Inputs}

\subsection{Rooftop Capacity Calculations}

Rooftop capacity is calculated as,

$$
Z_{i}^{\text {roof }}=0.093\left(\sum_{i=1}^{N} \sqrt{1+\frac{P_{i}}{12}} \times F_{i}^{\text {roof }} \times W^{\text {roof }} \times V^{\text {roof }}\right)
$$

Where $Z$ is final capacity in $m^{2}, P_{i}$ is the roof pitch, $F_{i}$ is the building footprint, $W_{i}$ is the setback zone required from roof edge and $V_{i}$ is the usable area constraint, all for building $i$. Usable area is constrained by existing rooftop structures along with the constraints of solar panel shading and the necessary aspect ratio for solar panel orientation.

\section{Data}

\subsection{Ada County GIS}

Ada County GIS data is leveraged to determine maximum available roof area, number of homes and commercial operations in Ada County, building footprints and spatial constraints for deployment of the distributed network (Ada County (Idaho). Assessor's Office., Ada County Highway District (Idaho), and Community Planning Association of Southwest Idaho., 0000). Ada County GIS data is used heavily in Chapter IV. 


\subsection{Energy Information Administration}

This paper uses data from the Residential Energy Consumption Survey (RECS), which collects energy-related data at the housing-unit level using a multi-stage, complex, area-probability design (EIA, 2019). A sister study, the Commercial Building Energy Consumption Survey (CBECS), supplies survey data for commercial energy use under the same format.

EIA data is also accessed for this study through their application programming interface (API). Data accessed in this manner includes net generation data for Idaho Power Corporation, market demand data for the Idaho Power Corporation service area, both containing continually updating hourly observations from 2015 through the present time. Historical revenue information for Idaho utility companies is also accessed for both commercial and residential consumers. EIA data is extensively used in Chapters V and VI.

\subsection{Weather Data}

Weather data is compiled to reflect a typical weather year for Ada County using detailed weather profiles developed from 1998-2018. An example of the weather file is included in Appendix A, table 9. The typical year is calculated through an analysis of all of the available weather profiles for the specific location which determines the best representation of typical weather conditions. Weather data is critical to the simulation process using the National Renewable Energy Laboratory's SAM software, so it is used extensively in Chapters IV, V and VI. 


\subsection{OpenEI US Utility Rate Database}

Open Energy Information (OpenEI) provides data on financial incentives and energy costs related to both renewable and fossil fuel energy production. Historical electricity rate data from OpenEI is used to infuse the simulation with actual electricity costs from 1998-2018, and to forecast costs for the remaining eight years of the final simulation period. OpenEI data is crucial to the analysis in Chapter VI.

\section{Simulation}

\subsection{System Advisor Model (SAM)}

There are many options to choose from when deciding on simulation software; output data can be generated using software packages such as $R$, AnyLogic, MatLab, or others. For this study, the System Advisor Model (SAM) from the National Renewable Energy Laboratory (NREL) was chosen. SAM is a modeling system designed for researchers, engineers, policy analysis and technology developers (Freeman et al., 2014; Blair et al., 2014). Performance and cost estimates for small and large scale energy projects are simulated using weather data and a massive database of existing photovoltaic arrays and inverters currently in production.

Photovoltaic performance estimates are modeled hourly using algorithms developed by NREL, Sandia National Laboratories, and the University of Wisconsin (Appendix 39.1). Figure 3 shows a simplified block diagram of the SAM process, where $E_{n}$ represents weather data, $I_{n}$ indicates irradiance at the array, $G_{i}$ represents irradiance after soiling and shading factors are included, and $P_{n}$ indicates power output in kilowatts. Subscripts $b, d$, and $g$ represent beam, direct and diffuse 


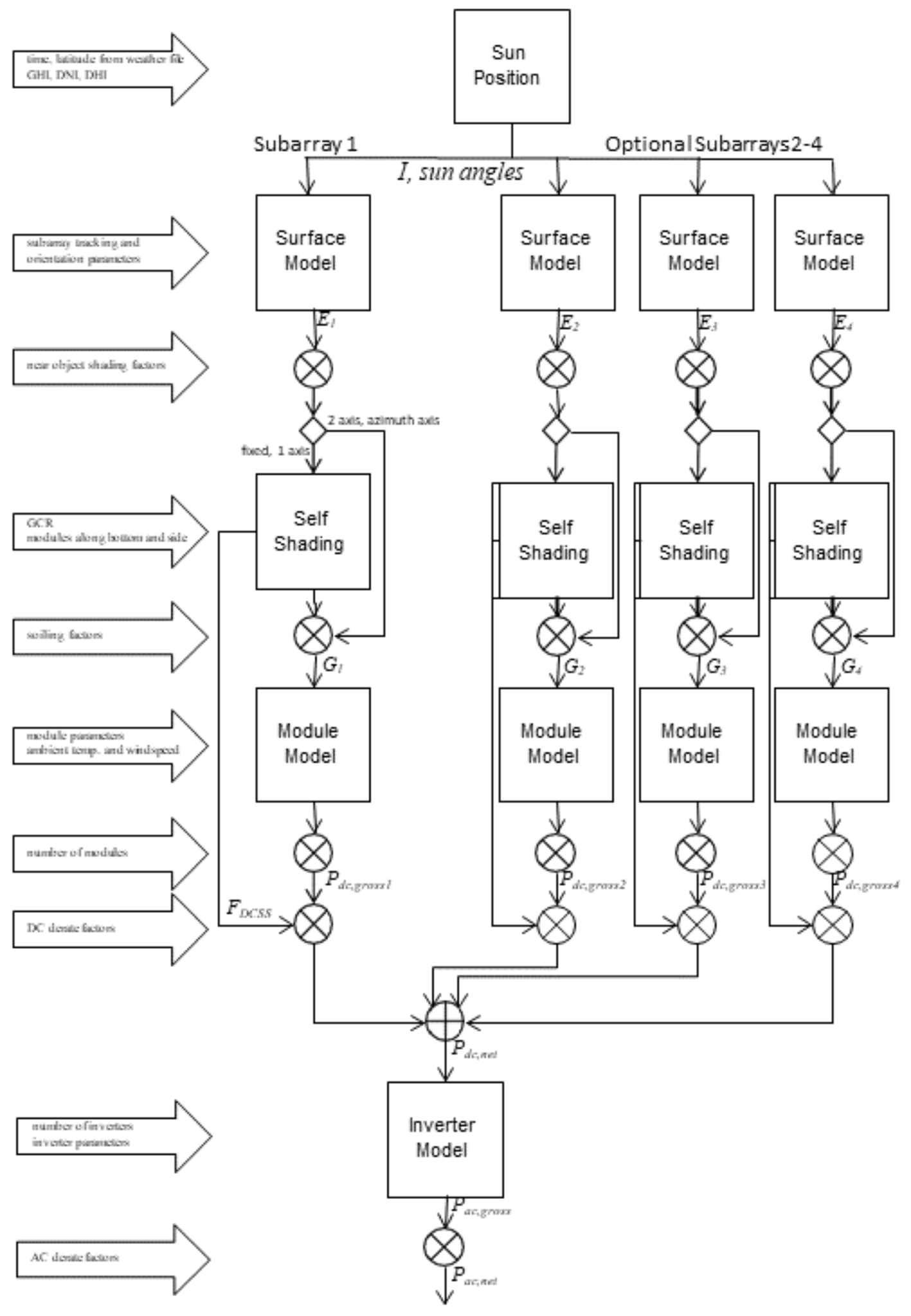

Figure 3: Photovoltaic Model Simplified Block Diagram (Gilman, 2015) 
irradiance, respectively. All network systems are designed using a singles subarray due to overall sizing restrictions and for the sake of increased simplicity. It is assumed that a more granular system design on a specific per-rooftop basis would be able to generate more energy than the current network configuration.

SAM software outputs include solar panel energy output in kilowatt-hours, solar panel system draws due to inverter power requirements and spatial conditions, electricity costs based on national utility rates, and residential load calculations based on the Residential Energy Consumption Survey (RECS) (EIA, 2019). Appendix 39 contains simulation tables for each system.

\section{Data Validation}

\subsection{PV System Output}

Maleki and Askarzadeh (2014) calculate power output from a particular solar PV panel at time $t$ using,

$$
\begin{gathered}
P_{P V}=N_{P V} \times p_{P V}(t) \\
p_{P V}(t)=I(t) \times A \times \eta_{P V}
\end{gathered}
$$

where $I$ is solar radiation, $N$ is the number of $\mathrm{PV}$ panels in an array, $A$ denotes $\mathrm{PV}$ area in $m^{2}$ and $\eta_{P V}$ is the overall efficiency of the PV panels and inverter. They assume zenith-azimuth tracking and ignore temperature effects.

Gonzalez de Durana and Barambones, 2018, adds temperature effects by using,

$$
P_{P V}=A G \eta_{P V}
$$


with

$$
\eta_{P V}=\eta_{N S T C}\left(1+\alpha\left(T_{c}-25\right)\right)
$$

where $A$ is solar panel area in $m^{2}, G$ is solar irradiation (GHI), $\eta_{N S T C}$ is the efficiency under standard test conditions, $T_{c}$ is cell temperature in Celsius, and $\alpha$ is the temperature coefficient in percentage per degree.

\subsection{Modeling Demand with MARS}

Multivariate Adaptive Regression Spline (MARS) algorithms were developed by Friedman (1991) to derive flexible regression models using existing data, including big data applications with many dimensions and difficult to estimate functional forms. The method uses a spline and knot approach with basis functions creating a step-wise functional form complete with continuous variables and continuous derivatives. The MARS model improves on standard regression spline algorithms in that additive and multi-variable interactions can be formally represented.

The MARS algorithm deploys a divide and conquer approach to forward and backward step-wise regression, considering all numerical and categorical variables (after translation to dummy variables) and their interaction with each other with an adaptive regression approach. Splines are connected together with polynomial piece-wise smoothing curves, also known as basis functions, and are flexible in handling both linear and non-linear relationships. The forward regression phase places knots at semi-random positions for each predictor to define basis functions, minimizing sum-of-squares residual errors. Basis functions act as hinges and continue to build forward until the maximum reduction in RMSE is achieved; which often results in over-fitting of the m odel. The backward regression then deletes 
redundant basis functions based on their contribution to the final RMSE (Kuhn and Johnson, 2013). In general form, the MARS model is expressed as,

$$
Y_{i}=\beta_{0}+\sum_{m=1}^{M} \beta_{m} \lambda_{m}(X)
$$

Where $\beta_{0}$ is the intercept, $\beta_{m}$ is the weight for the basis function, $\lambda_{m}$ is the basis function, which can take the form of a hinge spline or an interaction between both predictors and other basis functions. $X$ is an $n \times m$ matrix of $P$ predictors, and all functions are summed over $M$ nonconstant terms included in the model. All $\beta$ terms are estimated from the supplied data using ordinary least squares. Basis functions take the form,

$$
\max (0, x-t)\left\{\begin{array}{l}
x-t, \quad \text { if } x \geq t \\
0, \quad \text { otherwise }
\end{array}\right.
$$

Since MARS models do not impose any structure or class type on the relationship between predictors and response variables, useful models are produced with accurate predictive capabilities.

\section{Analyzing Opportunities}

\subsection{The Bass Diffusion Model}

The Bass Diffusion model is widely used in marketing and technology to determine the rate of adoption over time in regard to new technology. Like many models of complex adaptive systems, the model is strikingly simple with only three parameters in its basic form and fits well within the framework of agent-based modeling. 
The cumulative probability that a consumer will adopt new technology by time $t$ is given by a non-decreasing continuous probability distribution $(F(t))$ which approaches certain adoption as $t$ increases. The probability density function $(f(t))$ indicates the probability of adoption at time $t$. In normal form the Bass model is expressed as the differential equation,

$$
\frac{d N}{d t}=\left(p+\frac{q}{m} N(t)\right)[m-N(t)]
$$

Where $\frac{d N}{d t}$, is the hazard or survival function,

$$
\frac{d N}{d t}=\frac{f(t)}{1-F(t)}
$$

Parameter $p$ is the innovation coefficient, $q$ is the imitation coefficient, and $m$ is the total potential for adoption. The innovation coefficient is independent of of the total potential for adoption, and can be trivially replaced with a price differential (Boswijk and Franses, 2005). Imitation is also referred to modernly as "social-influence."

\subsubsection{Extending the Model}

Following Boswijk and Franses (2005) the model is altered to include randomly assigned early adopters with influence weights $(X)$ and a factor for environmental concern. Like social influence, environmental concern $(c)$ is interacted with the total potential for adoption $(m)$. Final model specification is given as,

$$
\frac{d N}{d t}=\left(p+X \frac{q}{m} N(t)+\frac{c}{m} N(t)\right)[m-N(t)]
$$




\section{Key Evaluation Metrics}

Following Brigham and Houston (2017) and Short et al. (1995) key financial indicators are measured to evaluate the incentives faced by di ering groups of stakeholders.

\subsection{The Cost Function}

Regression results, and how they are used to derive system costs, are detailed in equations 11 through 13 :

$$
\begin{aligned}
D C_{i} & =\beta_{1} N P C_{i}+\beta_{2} N P C_{i}+\beta_{3} N P C_{i}+\beta_{4} N P C_{i} \\
I C_{i} & =\beta_{5} N P C_{i}+\left(T B_{i}\right) D C_{i} * T R \\
T C_{i} & =D C_{i}+I C_{i}
\end{aligned}
$$

In equation $11, D C_{i}$ and $I C_{i}$ represent direct and indirect costs of unit $i, N P C_{i}$ is the nameplate capacity in watts of the solar module $i$, and $\beta_{1}$ through $\beta_{5}$ are cost coefficients for modules, inverters, miscellaneous system equipment, installation labor and permitting, respectively. $T B_{i}$ represents the tax basis percentage for sales tax, while $T R$ is the sales tax rate. Residential systems have a computed tax basis percentage of 0.68 , while commercial systems have a tax basis percentage of 0.85 with both systems subject to a $6 \%$ Idaho sales tax rate (Fumo and Rafe Biswas, 2015). $\beta_{1}$ through $\beta_{5}$ represent the coefficients of costs in dollars-per-watt of direct current nameplate capacity $\left(\$ / W_{d c}\right)$. All variable values are detailed in Table tab:syscostvariables, along with long term operations and maintenance costs $\left(\$ / W_{d c}\right)$ 
Table 1: Variables of system cost (Fumo and Rafe Biswas, 2015)

\begin{tabular}{|r|c|c|c|}
\hline Cost Item & Model Variable & Residential & Commercial \\
\hline Modules & $\beta_{1}$ & 0.68 & 0.35 \\
\hline Inverters & $\beta_{2}$ & 0.19 & 0.10 \\
\hline Balance of Equipment & $\beta_{3}$ & 0.36 & 0.36 \\
\hline Installation Labor & $\beta_{4}$ & 0.59 & 0.59 \\
\hline Permitting & $\beta_{5}$ & 0.10 & 0.11 \\
\hline Sales Tax Basis & $T B$ & 0.68 & 0.85 \\
\hline Sales Tax Rate & $T R$ & 0.06 & 0.06 \\
\hline Ongoing Maintenance & & 16.0 & 13.0 \\
\hline
\end{tabular}

\subsection{The Revenue Function}

The revenue function facing our distributed network can be described as,

$$
R(x)=\left(\kappa^{r}\right)\left(\mu^{r}\right)+\left(\kappa^{c}\right)\left(\mu^{c}\right)
$$

Where $\kappa^{r}$ represents annual residential system net generation, $\mu^{r}$ and $\mu^{c}$ represent average revenues per mWh and $\kappa_{i}^{c}$ represents annual commercial system net generation.

The cost function is derived by adding total fixed costs over the system life (Equation 13) to variable operations and maintenance (O \& M) costs for residential and commercial systems:

$$
C(x)=\frac{\kappa_{\text {life }}^{r}+\kappa_{\text {life }}^{c}}{T C_{\text {life }}+\Sigma_{i=1}^{5}\left(\omega^{r}\left(N P C_{i}\right)\right)+\omega^{c}\left(N P C_{i}\right)}
$$

Where $\omega^{x}$ represents maintenance coefficients for residential and commercial systems, and $N P C$ represents nameplate capacities for each of the five residential 
systems and the single commercial system. The profit function, therefore, is simply,

$$
\pi=R(x)-C(x)
$$

\subsection{Total Life Cycle Cost}

\subsubsection{Private Firms}

Total life-cycle cost (TLCC) analysis is used to evaluate investment costs and timing of returns over the project lifespan. TLCC makes no judgement as to what is an acceptable cost and does not address returns to capital or benefits to society. Only significant costs over the project life are evaluated (Short et al. 1995). Private industry is generally more interested in NPV, though there are specific variations of TLCC for government, private firms, and regulated utilities. The private firm variation is depicted as,

$$
\begin{aligned}
T L C C & =1-[(T)(P V D E P)]+\operatorname{PVOM}(1-T) \\
P V O M & =\Sigma_{n=1}^{N}\left(\frac{O \& M}{(1+d)^{n}}\right) \\
P V D E P & =\Sigma_{n=1}^{N}\left(\frac{D e p}{(1+d)^{n}}\right)
\end{aligned}
$$

Where $\mathrm{T}$ represents the prevailing income tax rate, $\mathrm{d}$ is the discount rate, PV DEP is the sum of the present values of depreciation for the investment period, and $\mathrm{PVOM}$ is the sum of the present values of operations and maintenance for the investment period.

\subsubsection{Public Utilities}

The TLCC configuration for the utility sector is slightly di erent, focusing now on the before-tax revenues required to recoup after-tax costs, formulated by, 


$$
T L C C=\frac{1-[(T)(P V D E P)]+P V O M(1-T)}{(1-T}
$$

Where all variable details are identical to Equation 17.

\subsubsection{Governments}

The total life-cycle cost of the project from a government perspective is calculated as,

$$
T L C C=\Sigma_{n=0}^{N} \frac{C_{n}}{(1+d)^{n}}
$$

Where $C_{n}$ is the cost in period $n$, including investment and $\mathrm{O} \& \mathrm{M}$ costs, and $d$ is again the discount rate.

\subsection{Levelized Cost of Energy}

Deriving the TLCC (Section 20.3) allows for a simpler calculation of levelized cost of energy (LCOE) calculated using,

$$
L C O E=\frac{T L C C}{\sum_{t=1}^{N} \frac{\kappa t}{(1+d)^{n}}}
$$

Where $\kappa_{t}$ is net generation in time period $t$, and $d$ is the discount rate in either real or nominal terms. LCOE determines the price per unit required from every unit of energy sold during the analysis period in order to recover the initial investment 
minus tax incentives.

Levelized cost of energy facing a government agency, under the assumption of a nationalized network with no profit expectations, can be expressed by,

$$
L C O E=\frac{I \times U C R F}{\bar{Q}}+\frac{O \& M}{\bar{Q}}
$$

Where $U C R F$ is the uniform capital recovery factor,

$$
\frac{d(1+d)^{n}}{(1+d)^{n}-1}
$$

and $Q$ is the average annual network output.

\subsection{Net Present Value}

Present value analysis considers the gap in time between the outlay of an investment and the returns generated by profits and cash fl ows. Investment funds are discounted by a prevailing rate, either nominal or real, which reflects the opportunity cost of using funds for one project over another (Baye and Prince, 2017). Net present value considers both the discounted net cash flows for the project life and also the initial investment. In order to approve a project an investor would expect a positive NPV based on the life cycle of the project (Brigham and Houston, 2017). The basic NVP formula is,

$$
N P V=\Sigma_{i=0}^{N} \frac{F_{n}}{(1+d)^{n}}
$$


Where $F_{n}$ is the expected cash flow at time $n, d$ is the chosen discount rate, and $N$ is the expected life cycle of the project.

\subsection{Internal Rate of Return}

Internal Rate of Return (IRR) calculates the discount rate necessary to drive net present value of the initial capital costs to zero. The IRR formula is described as,

$$
\frac{C F_{t}}{(1+I R R)^{t}}=0
$$

Where $C F_{t}$ are cash flows at time $t$, and $I R R$ is the discount rate that solves the equation. Due to the complexity involved in solving this equation for zero before computer use was widespread, IRR was estimated using a trial and error method by plugging in random values until the equation was satisfied (Baye and Prince, 2017). Using current technology, calculation of IRR is much simpler and can be accomplished with high precision.

\subsection{Benefit to Cost Ratios}

The mathematical formula for benefit-cost ratios is simply the total value of benefits $(B)$ minus to total value of costs $(C)$, both discounted to present values,

$$
B / C=\frac{\frac{B}{(1+r)^{n}}}{\frac{C}{(1+r)^{n}}}
$$

Both positive and negative externalities can be evaluated in $\mathrm{B} / \mathrm{C}$ ratios, though economic impacts and environmental concerns are difficult to quantify at local 
levels. In the scope of the current work, it is assumed that positive externalities exist in the form of carbon reduction and economic stimulus at the local level. It is also clear that extraction of rare earth minerals and disposal of solar PV systems at the end of the life cycle present significant negative externalities as well. Quantification of externalities is left to future research. 


\section{PART IV: DISTRIBUTED NETWORK DESIGN}

\section{Rooftop Capacity}

Determining the available rooftop capacity per structure is similar to the process of calculating roofing materials r equired to replace the r oof s urface. Ground floor square footage from the Ada County GIS data set is used as a proxy for building

footprint and converted from $f t^{2}$ to $m^{2}$ using Equation 1 in Section 15.1. Roof pitch $(P)$ is set to 4 , which results in a relatively standard 4-in-12 pitch (18.5 degrees) to represent the typical single family residence, and zero degrees to represent the typical flat roof structures commonly found in commercial and condominium style structures. $V$ is estimated at 0.33 , which is slightly higher than Gagnon et al. (2016) estimated due to the use of azimuth-tracking PV arrays which rotate to track the movement of the sun. This configuration is similar to that found in Maleki and Askarzadeh (2014).

\subsection{Single Family Residence Capacity}

Housing data is filtered based on the parameters needed for MARS algorithm structural demand estimation (Equation 7 in Section 18.2), which are simply the number of bedrooms, total square footage and ground floor square f ootage. After applying Equation 1, all structures with fewer than $17.4 \mathrm{~m}^{2}$ of available rooftop capacity are filtered from the sample, leaving 147,703 single family residences identified as p otential r ooftop solar installation sites with r ooftop capacities ranging from $18 \mathrm{~m}^{2}$ to $5,770 \mathrm{~m}^{2}$ and a total residential capacity of $6,084,228 \mathrm{~m}^{2}$. 


\subsection{Multi-Family Housing Capacity}

Calculating the rooftop capacity for condominiums and apartment buildings is less intuitive than the calculations for single family residences. The original data is measured in acres, but upon inspection it is clear in cases of multiple buildings occupying a single parcel, the acre measurement relates to the complex in aggregate.

For rooftop solar capacity calculation it is necessary to have the measurement of the individual building footprints, as shown in Figure 4a. Using the shapefile footprints, a new field is added to the geodatabase and the roof area is measured in $\mathrm{m}^{2}$ using the NAD Idaho Transverse Mercator geodesic map coordinates for accuracy. This condo footprint dataset provides 750 target buildings with enough rooftop area to support a residential scale solar installations and 12 buildings with potential to support a commercial-sized installation. Rooftop capacities range from $18 \mathrm{~m}^{2}$ to $1,091 \mathrm{~m}^{2}$ in cases where residential system are suited, while the additional 12 locations have capacities from $1,160 \mathrm{~m}^{2}$ to $5,770 \mathrm{~m}^{2}$. Total rooftop capacity for this building sector is $254,530 \mathrm{~m}^{2}$.

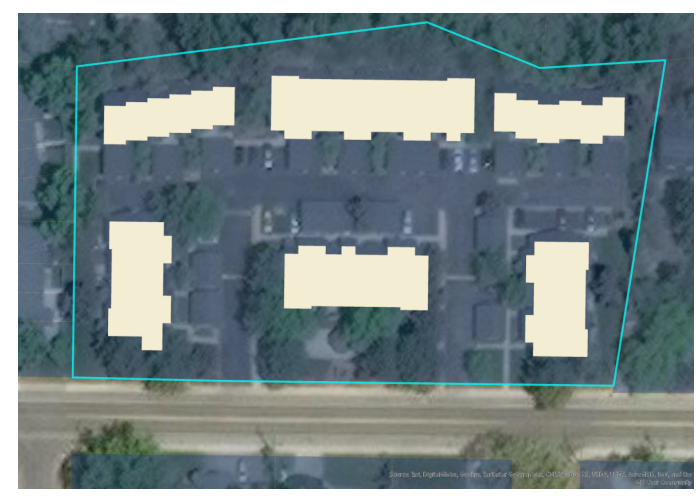

(a) Blue line represents the parcel data, which is the calculated acreage. Capacity calculation requires the building footprints individually, indicated in beige.

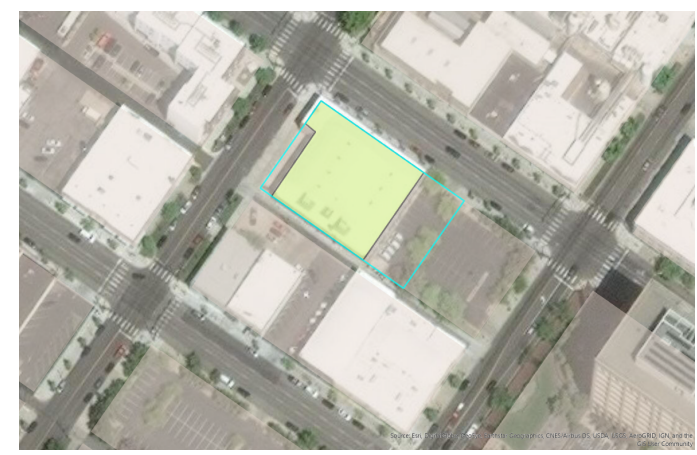

(b) Blue line is parcel boundary, filled square is calculated square meters.

Figure 4: Data verification for condominium and commercial assessor data 


\subsection{Commercial Property Capacity}

In order to be certain that the data accurately describes commercial building footprints, GIS software is used to measure building rooftop areas for data validation. Figure $4 \mathrm{~b}$ shows the shapefile parcel boundary compared to the actual measurement of the building rooftop using the Idaho Power building in downtown Boise. Multiple buildings are measured for accuracy, all returning calculated values of at least $50 \%$ less than the square footage data reported in the GIS. Calculated data are therefore considered conservative and used to calculate roof space.

Rooftop capacity is calculated using Equation 1, this time using a default assumption of zero-degree pitch to represent flat roofing surfaces. All buildings with fewer than $1,135 \mathrm{~m}^{2}$ of available rooftop area are filtered out of the data, leaving 922 commercial-grade structures. Since many commercial buildings can support well over $1,135 \mathrm{~m}^{2}$, a variable is added to measure the potential number of systems that could be installed on each building. The potential number of systems per building ranges from one to fifty-five, with a median of two. Total commercial rooftop capacity in the area is calculated at 1,018,095 $\mathrm{m}^{2}$.

\subsection{Visualization of Commercial Rooftop Area}

The mental map of a standard rooftop solar panel array between $17 \mathrm{~m}^{2}$ to $78 \mathrm{~m}^{2}$ is relatively easy to visualize, while the commercial version tends to become more difficult. A validation of the size and scope of these commercial rooftop arrays is developed by placing a rectangle of the correct size on a map for easy reference. A system of this size stretches between the hash marks and just past the 35-yard line of Bronco Stadium as shown in Figure 5a. Figure 5 places the system measurements on top the Idaho Power building in downtown Boise, also used in Figure 4b. 


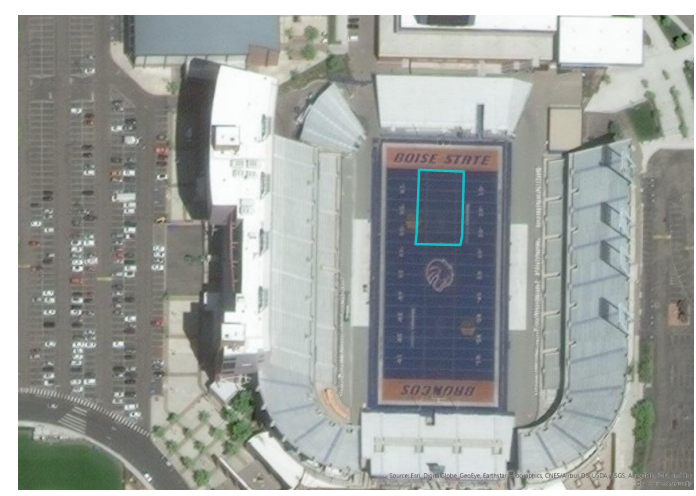

(a) 1,136 $\mathrm{m}^{2}$ imposed on Bronco Stadium

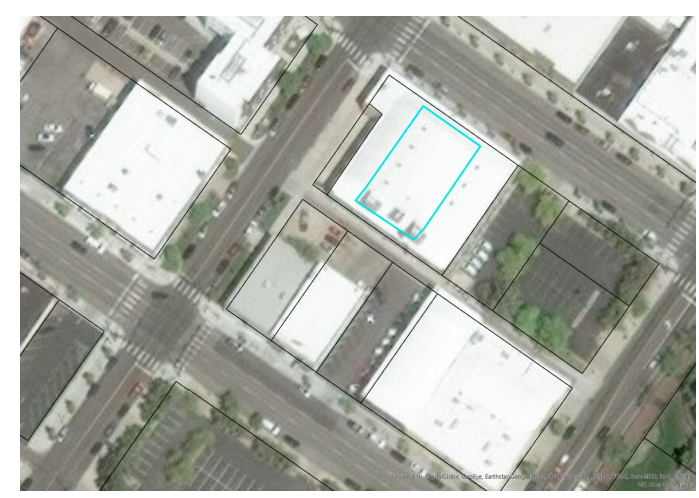

(b) Rooftop capacity of Idaho Power office building with $1,136 \mathrm{~m}^{2}$ installation.

Figure 5: Approximately 1,136 square meters

\subsection{Total Rooftop Capacity-Ada County}

This analysis shows that Ada County contains just over 32 million $m^{2}$ of total rooftop area, $7,356,853 \mathrm{~m}^{2}$ of which have adequate area to be retro-fitted as part of the distributed rooftop solar network.

\section{System Configuration}

The major contribution of this study, and any simulation study, is modeling a future environment based on projections and current data (see Figure 2). In the case of this work, care is taken to build a simulation environment using materials that are currently in production and could be implemented with a short time lag. It is also critical that the simulation produces reliable data and reflects the objectives of the solar utopia discussed in Section 3. 


\subsection{Modules and Inverters}

Module selection is based on performance and sizing data from the California Energy Commission (CEC) Performance Module database in SAM, keeping with the standard of modeling with commercially available products (c. 2019). The CEC database stores module parameters for thousands of commercially available solar arrays, and calculates energy-to-electricity conversion efficiency using the California Energy Commission New Solar Homes Partnership Calculator with a six-parameter single diode circuit model. Inverters were selected from the CEC Inverter database using loss efficiency and compatibility with the chosen modules. Modules and inverters were chosen to maximize net energy generation based on the spatial constraints detailed in Section 21.

\subsection{Residential-Scale Systems}

Residential properties, both single and multi-family, are fitted with systems based on their spatial rooftop constraints. System sizes and outputs, tagged with the phonetic descriptors shown in Table 2, range from $17.4 \mathrm{~m}^{2}$ through $78.3 \mathrm{~m}^{2}$ and from $3 \mathrm{kw}$ to $16.1 \mathrm{kw}$ nameplate capacities.

\subsection{Commercial PV Arrangement}

The commercial-grade system deploys a large scale array of 696 solar modules with three inverters and nameplate capacity of $179.58 \mathrm{kw}$. Ada County contains 922 buildings that can support at least one commercial-grade installation, with a maximum of 588 and median of two. There are 8,479 remaining commercial buildings that cannot support the major commercial solar power station, but that 
do have the potential to support one or more of the residential systems. Capacity for these smaller buildings range from 18 to 1,127 square meters with a median of 100 square meters, and are added to the system configuration to which they belong.

\section{Final Network Structure}

Table 2: Final Distributed Rooftop Solar Network system structure

\begin{tabular}{ccllcc}
\hline Tag & Output & Module & Inverter & Area $\left(m^{2}\right)$ & Deployed \\
\hline Uniform & $3 \mathrm{kw}$ & SPR-X20-255 & SMA:SB3800TL & 17.4 & 21,108 \\
\hline Tango & $6 \mathrm{kw}$ & SPR-X21-335 & SMA:SBS6.0 & 26.1 & 34,984 \\
\hline Oscar & $7.5 \mathrm{kw}$ & SPR-X21-335 & Fonius:IG Plus V & 34.3 & 57,244 \\
\hline Papa & $10 \mathrm{kw}$ & SPR-X21-335 & NGT: Solis 10K US & 48.9 & 41,214 \\
\hline India & $16.1 \mathrm{kw}$ & SPR-X21-335 & AEI: AE-3TL-16 & 78.3 & 22,313 \\
\hline Alpha & $179.58 \mathrm{kw}$ & SPR-E19-310-COM & SMA: STP 60-US & $1,135.2$ & 21,868 \\
\hline
\end{tabular}

System configurations for all six systems, five residential and one commercial, are detailed in Table 2. In total, Ada County has rooftop area capable of supporting 177,788 solar panel arrays. Final output capacities in hourly, monthly and yearly time frames are simulated using SAM software and detailed in Chapters V and VI.

\section{Data Validation}

\subsection{Mathematical Validation}

Data output from the SAM software is validated mathematically and visually to ensure that the simulation bears a close resemblance to expectations. One hundred random samples are drawn from the simulation data for validation testing, with 
randomization drawing both 10 years and ten system configurations which results in a total data pool of 87,600 observations. Simulated supply data is validated mathematically using equation 5 , while demand data is validated using the MARS algorithm from equations 7 and 8 . Output and demand are calculated for each of the ten test data sets before ten random samples are drawn from each to make the final validation set of 100 observations. For example, the random year generator draws 2011 and the random system generator draws system Papa. Simulated data for the Papa system is pulled from SAM, output and demand are calculated manually and compared to the supply and demand variables in the simulated data. Calculated values greater than zero are selected and ten random observations are compiled into a master validation data set. Table 3 displays 25 randomly drawn examples from the master validation data set.

Variance in output calculated versus simulation data ranges from effectively zero to .0265 , distribution of variance is shown in Figure 6 . Individual building demand is more difficult to accurately calculate, which accounts for the larger distribution of values exhibited in Figure 7. Based on these results, the simulated data is considered valid compared with mathematically calculated values.

\section{$24.2 \quad$ Visualising the Data}

Another method for data validation is to visualize the data and compare simulated results to actual data and expected trends. Figure 8 shows estimated aggregate loads for Ada County as compared to actual EIA data for the Idaho Power market area for the year 2017. The simulated data follows the expected trends, increasing in the summer months and decreasing in the winter, with expected differences in market area represented by the space between the two curves. The EIA data exhibits steeper slopes during the ramp up into summer and the decline into winter, 


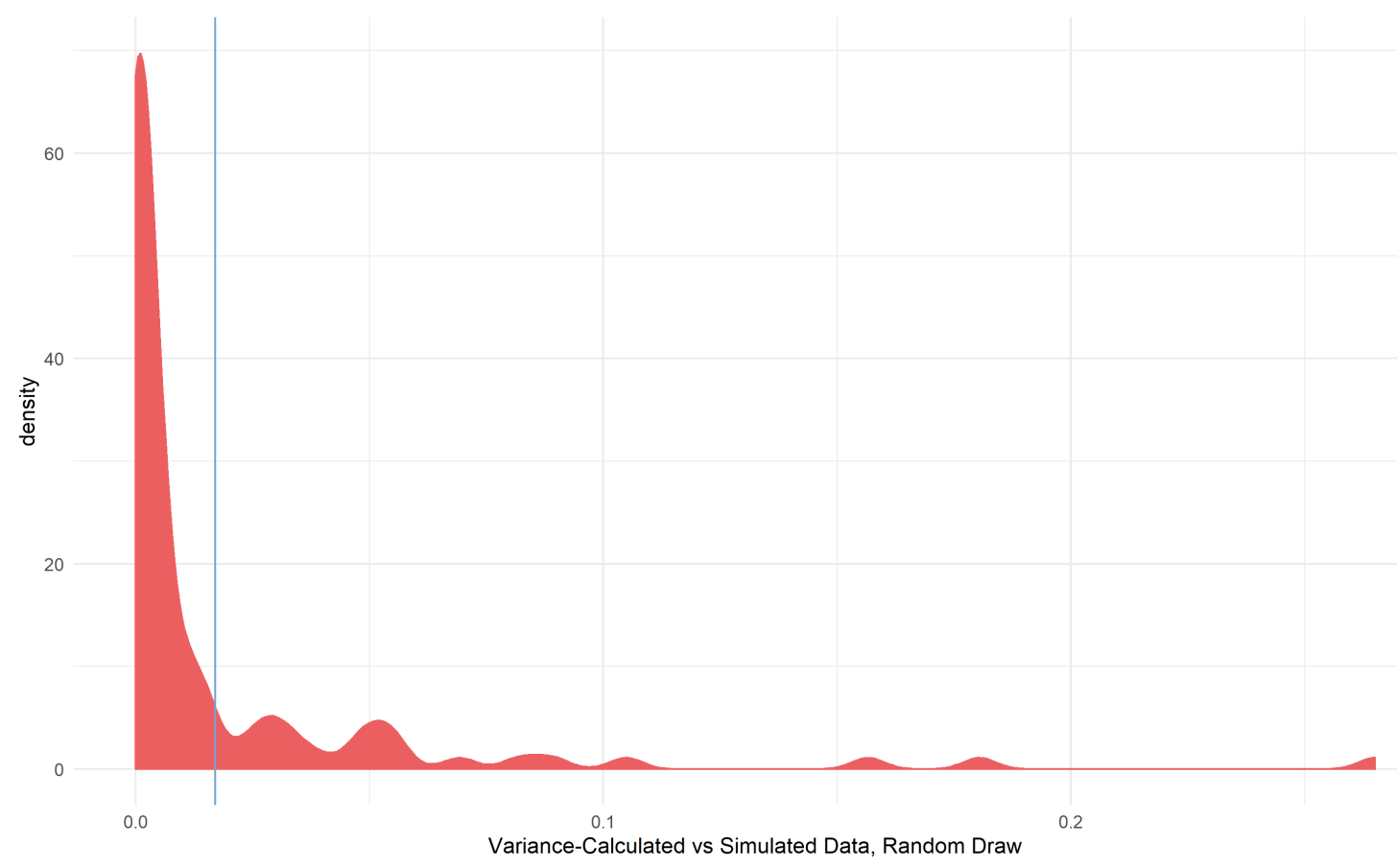

Figure 6: Distribution of variance for calculated output versus simulated data (SAM)

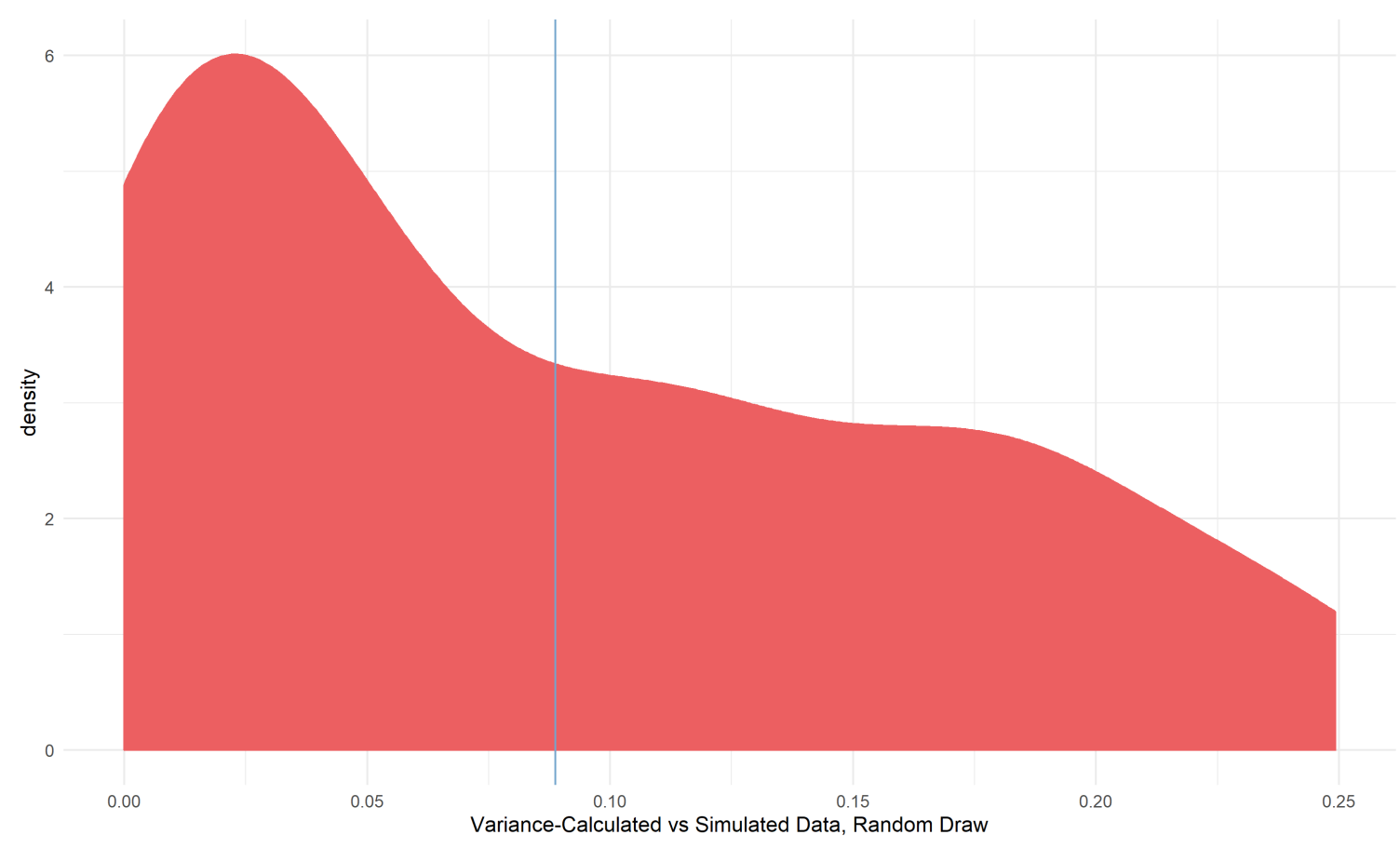

Figure 7: Distribution of variance for calculated demand versus simulated data. Vertical line is distribution mean. (SAM Simulation) 
Table 3: Validation Test: Random Draw

\begin{tabular}{ccccccccc}
\hline & Date & Year & Supply & Demand & O.Val & O.Var & D.Val & D.Var \\
\hline \hline 1 & Oct 21, 09:00 am & 1998 & 9.102 & 1.027 & 9.251 & 0.006 & 0.310 & 0.128 \\
2 & Sep 21, 02:00 pm & 2000 & 5.208 & 2.567 & 5.669 & 0.053 & 1.646 & 0.212 \\
3 & May 25, 11:00 am & 2015 & 2.999 & 1.609 & 3.216 & 0.012 & 1.788 & 0.008 \\
4 & Mar 10, 06:00 pm & 2009 & 0.174 & 1.590 & 0.177 & 0.00000 & 0.752 & 0.176 \\
5 & Nov 18, 12:00 pm & 2009 & 1.657 & 0.820 & 1.647 & 0.00002 & 0.391 & 0.046 \\
6 & Jan 26, 02:00 pm & 2004 & 2.955 & 0.871 & 2.891 & 0.001 & 1.759 & 0.197 \\
7 & May 31, 05:00 pm & 2001 & 5.784 & 3.509 & 6.222 & 0.048 & 3.168 & 0.029 \\
8 & Jun 11, 07:00 pm & 2016 & 0.800 & 3.200 & 0.803 & 0.00000 & 3.578 & 0.036 \\
9 & Sep 9, 10:00 am & 2001 & 2.669 & 1.146 & 2.866 & 0.010 & 1.725 & 0.084 \\
10 & Mar 26, 12:00 pm & 2011 & 3.419 & 0.868 & 3.359 & 0.001 & 1.029 & 0.007 \\
11 & Feb 28, 05:00 pm & 2001 & 3.179 & 1.654 & 3.036 & 0.005 & 1.868 & 0.011 \\
12 & Jun 23,07:00 pm & 2004 & 2.039 & 5.292 & 2.133 & 0.002 & 5.770 & 0.057 \\
13 & Mar 21, 12:00 pm & 2004 & 7.800 & 0.812 & 8.249 & 0.051 & 1.808 & 0.248 \\
14 & Aug 20,03:00 pm & 2009 & 3.618 & 4.896 & 4.055 & 0.048 & 5.183 & 0.021 \\
15 & Dec 23, 03:00 pm & 2001 & 0.774 & 0.645 & 0.751 & 0.0001 & 0.840 & 0.010 \\
16 & Jul 9, 10:00 am & 2011 & 7.887 & 1.802 & 8.535 & 0.105 & 1.488 & 0.024 \\
17 & Nov 13, 12:00 pm & 1998 & 0.325 & 0.869 & 0.364 & 0.0004 & 1.212 & 0.029 \\
18 & Mar 18, 10:00 am & 2001 & 1.754 & 0.893 & 1.766 & 0.00004 & 0.022 & 0.190 \\
19 & Apr 24, 12:00 pm & 2000 & 5.951 & 1.046 & 6.308 & 0.032 & 0.369 & 0.115 \\
20 & Sep 27, 04:00 pm & 2011 & 4.820 & 4.275 & 5.147 & 0.027 & 3.542 & 0.134 \\
21 & Apr 21, 12:00 pm & 2016 & 2.968 & 1.024 & 3.213 & 0.015 & 0.504 & 0.067 \\
22 & Jul 31, 05:00 pm & 2004 & 3.687 & 5.496 & 4.023 & 0.028 & 5.607 & 0.003 \\
23 & Mar 12,02:00 pm & 2004 & 7.589 & 0.812 & 7.914 & 0.026 & -0.032 & 0.178 \\
24 & Sep 5, 10:00 am & 2001 & 6.714 & 0.987 & 7.110 & 0.039 & 1.986 & 0.249 \\
25 & Feb 9, 11:00 am & 2004 & 7.236 & 0.919 & 7.150 & 0.002 & 1.550 & 0.100 \\
\hline \hline
\end{tabular}

Random sample of 25 out of 100 validations 
which can be explained by the inclusion of agriculture and industry in the EIA data where the simulated data only includes residential and agriculture. Finally, a

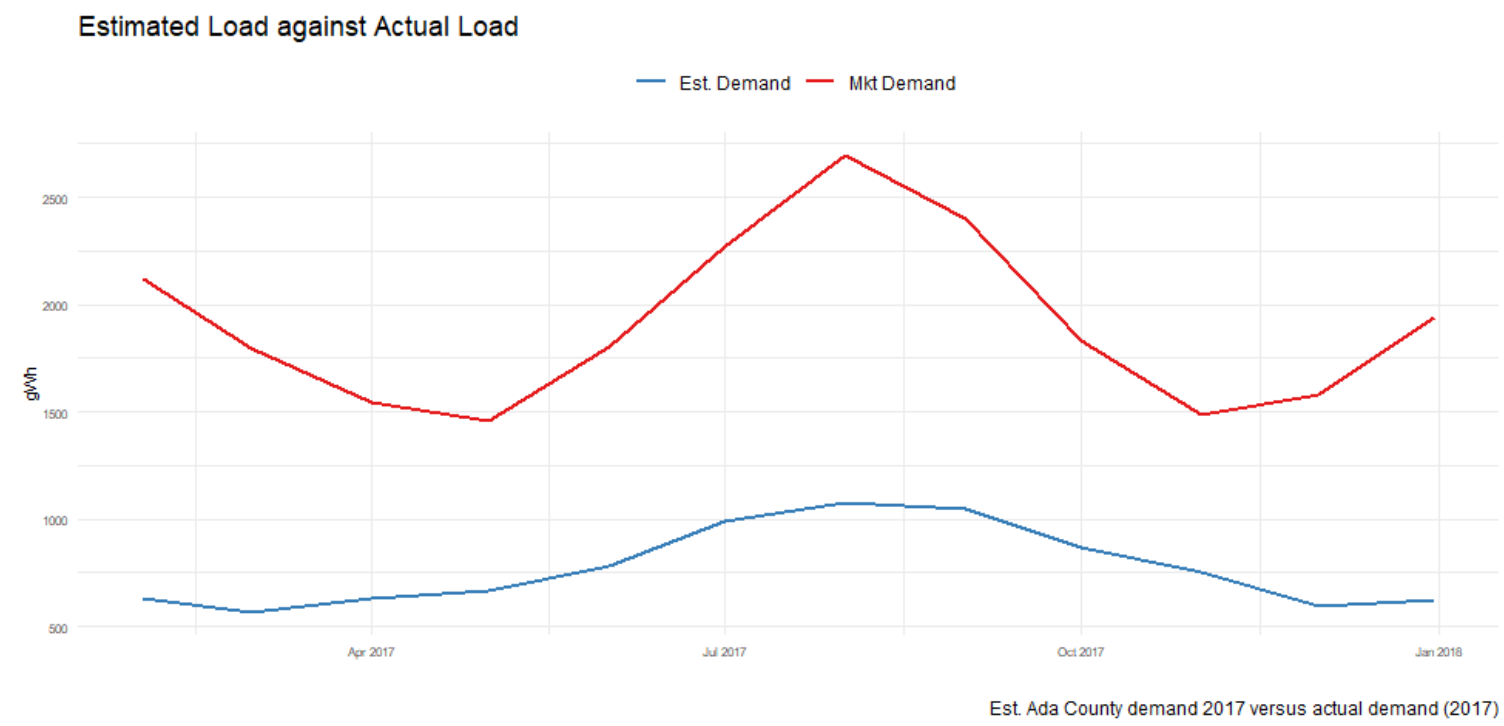

Figure 8: Estimated load data for Ada County versus actual load data for the Idaho Power market area

statistical comparison between simulation data and actual demand data for 2017 is conducted. EIA data from the 2017 Residential Electrical Consumption Survey (EIA, 2019) shows Idaho Power market area consumers use an average of $944 \mathrm{kWh}$ per month. The simulated data set for the same time period shows an average monthly consumption of 1,076 kWh per household. It appears that the simulated data may overestimate demand for the area, which is an acceptable result.

\subsection{Moving to the Future}

Based on visual and mathematical validation, the simulated data derived from SAM is considered a valid representation of reality. This represents the final step in the backcasting process, SAM data is considered an acceptable representation of our desired future. Armed with the simulation data we can now begin to explore the opportunities and obstacles between our current conditions and future possibilities. 


\section{PART V: FUTURE OPPORTUNITIES: TECHNICAL FEASIBILITY}

\section{Feasibility for Individual Homeowners}

A major aspect of determining the technical feasibility of the network is the interaction between production and consumption of energy on a per-structure basis. The distributed network will allow individual buildings to become producers and consumers of energy, both on the individual level and in the aggregate as all PV systems are linked in the network. Figure 9 compares hourly supply and demand for each individual PV system, showing that in most cases the ability of the system to supply energy on an hourly basis exceeds the demand. Notably, the smaller structures with less available rooftop capacity run large power deficits, while the larger buildings surplus for the majority of the time. Commercial structures (Figure 9-Alpha) clearly consume more energy than they are able to produce.

Using average monthly output, as opposed to hourly, the picture begins to change, as shown in figure 10 . The small Uniform and Tango systems $\mathrm{r}$ un a deficit for the entire year, with Uniform barely reaching an equilibrium point in the spring and Tango producing a small surplus during the same time period. The Oscar system produces a surplus in the second quarter of the year and maintains a mild deficit during the third and fourth quarters. Only the Papa and India systems produce a surplus for nearly the entire year (Figure 10(Papa and (India)). The commercial Alpha system unsurprisingly is in deficit for the entire year as well.

Each system requires grid energy to operate for at least a portion of the year, but energy savings are realized annually for each stakeholder. The owner of a small home is likely to experience an annual savings of $\$ 629$ in electrical charges using 


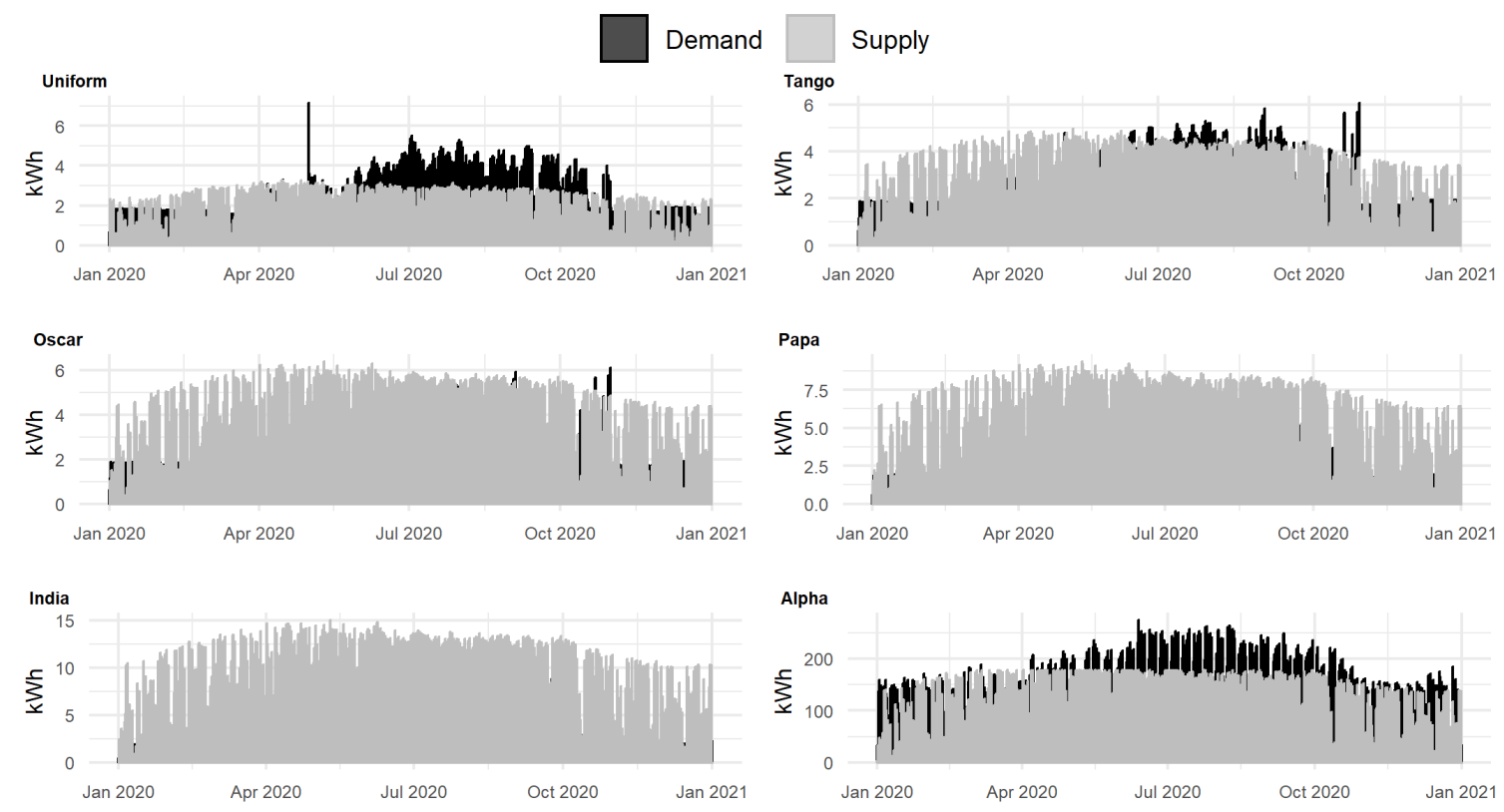

Figure 9: Hourly Supply and Demand for Individual PV Systems.

the small Uniform system, while large homes with higher rooftop capacity could expect to save $\$ 1,214$. Large-scale commercial buildings could reduce their energy costs by $\$ 18,818$ annually as well. An essential question regarding individual adoption is the upfront cost and the payback period, which are addressed in section 32 , Table 4 .

\subsection{Individual Homeowner Feasibility Conclusion}

It is clear that PV systems are technically feasible using existing technology for individual homeowners with at least $17.4 \mathrm{~m}^{2}$ of available rooftop area. All systems produce energy cost savings over time, along with the possible goodwill premium of reducing their grid energy consumption. Incentives exist for homeowner adoption of the network, but questions still arise surrounding whether consumer adoption without additional outside incentives will generate the full distributed network of 


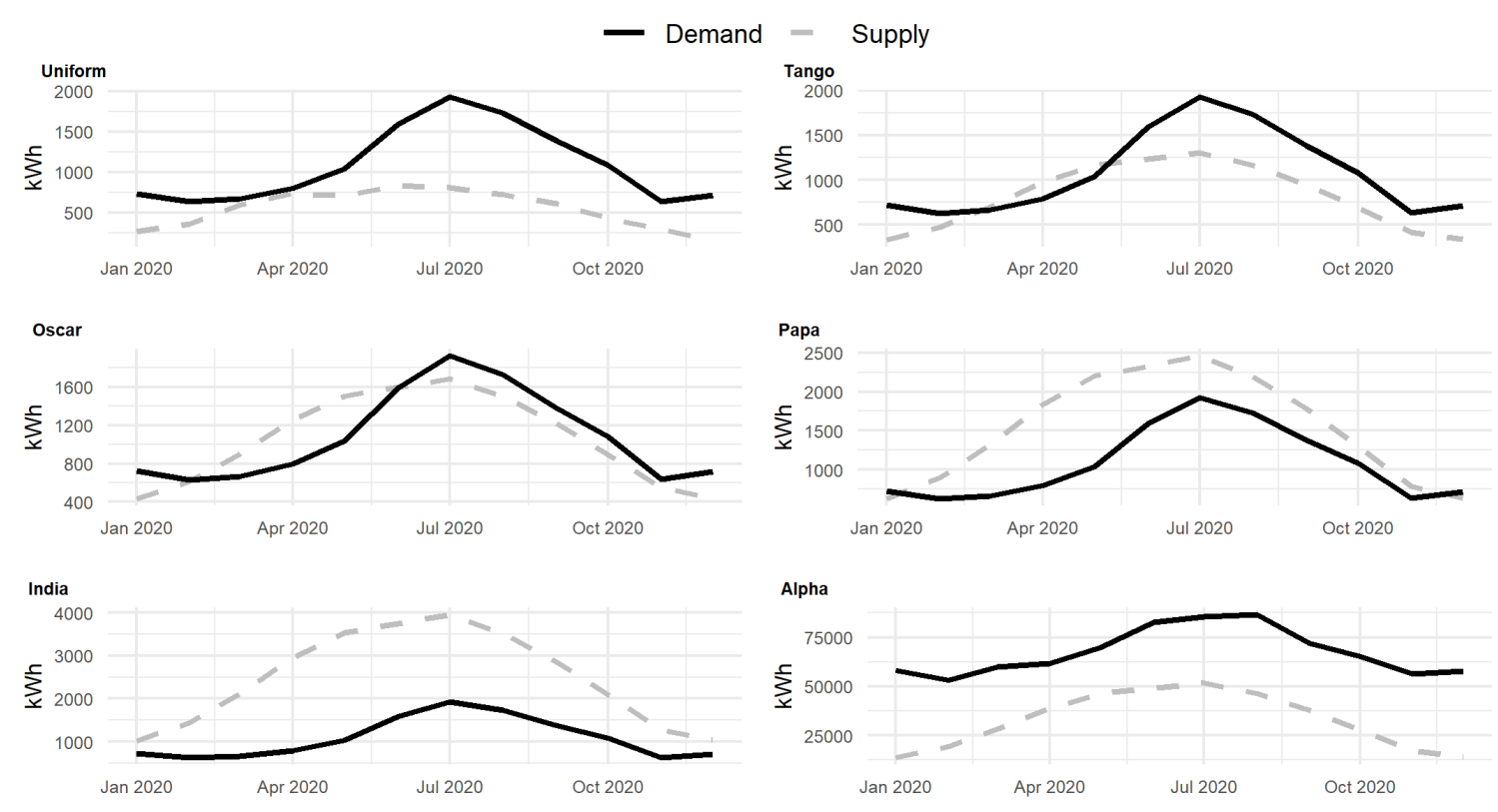

Figure 10: Monthly Supply and Demand for Individual PV Systems.

rooftop solar organically and at the necessary scale.

\section{Aggregating the Network}

In energy literature, both in engineering and economics, common terms are used interchangeably. From this point forward the terms load, consumption and demand will all be used to express the idea of energy consumed and the terms output, production and supply are all used to express the amount of energy produced.

\subsection{Aggregate Supply}

The task now becomes aggregating all six individual systems into a single distributed network. In their annual 10-k reports, Idaho Power reports units of energy produced and consumed in thousands $m W h$, which is equivalent to a gigawatt hour (Delloite, 2019). Data from the Energy Information Administration on 
demand and net generation are also reported in megawatt-hours, so the aggregate solar output potential from the SAM simulation is adjusted to fit those conventions.

\subsubsection{Residential Supply Potential}

From the Ada County GIS data analysis in Chapter IV, we know that available rooftop area allows for the deployment of a vast array of PV panels of each type across the region. Calculated deployment levels are detailed in Table 2. Scaling the output of the network becomes the relatively trivial task of multiplying each system by the deployment volume, which results in aggregate residential supply across the system.

\subsubsection{Commercial Supply Potential}

Aggregating

the Alpha commercial-grade systems is a less straight forward process than the residential-style systems. Commercial structures contain some of the aspects of multi-family condominium-style structures due to their vertical

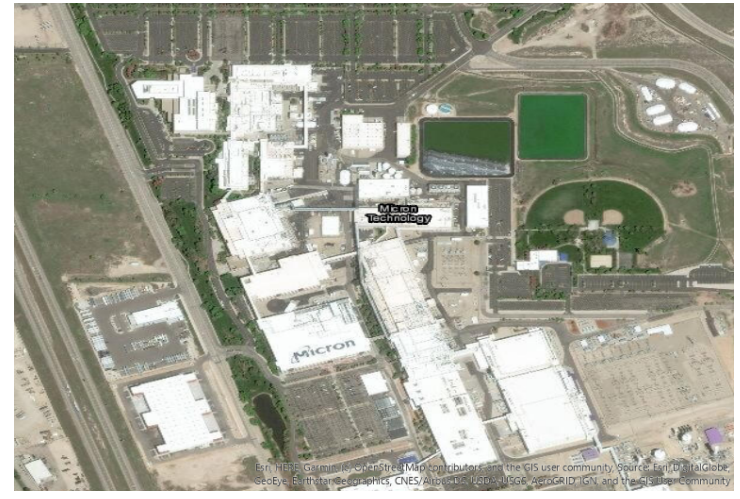

Figure 11: Micron Campus, Boise, ID occupying a single building footprint.

Some commercial structures represented in the data also consume little or no energy, parking garages and storage facilities may fit this description. While there are only 922 structures in Ada County capable of supporting a commercial-grade structure due to the large expanse, many buildings can support multiple systems.

Referring back to Figure 5, a central business district structure such as the Idaho Power building in downtown Boise has the potential to support a single Alpha 
system. On the other end of the spectrum, a campus such as Micron's in Southeast Boise has the potential to support 588 Alpha systems (Figure 11). Potential for multiple deployments range from 1 to 588 with a median of 2 and a total deployment possibility of 21,868 .

\subsection{Aggregate Load}

\subsubsection{Residential Load Estimation}

Calculating aggregate load requires inclusion of structures that consume energy but do not have the rooftop capacity to generate their own supply; there are 5,688 structures in Ada County that fit this s pecification. Based on their average square footage, these properties are included in the load profile for the Uniform system. Condominium-style structures contain multiple single dwellings within the same building footprint which must be accounted for separately in load estimation. There are 2,866 individual condominium-style dwellings in the sample which are added to the load profile for the Tango system based on their size and estimated energy usage.

\subsubsection{Commercial Load Estimation}

Determining system load in the commercial sector is also more challenging than the residential sector. As mentioned, some structures have large footprints with little to no energy usage while others display extremely high energy usage. Commercial estimates use the same methods described in Sections 10 and 18.2, using the commercial version of the Commercial Buildings Energy Consumption Survey (CBECS) from the EIA. While this likely leads to an overestimation of commercial building load, that seems a more acceptable outcome compared to underestimating. A key assumption at this point, in the absence of more granular data on energy usage per building, is that all 8,440 commercial structures in the data set consume 
energy at the estimated commercial level.

\section{Aggregate Supply and Demand per System Type}

As in Section 25, it is relevant to examine the supply potential of each individual system in aggregate across the network area compared to the aggregate loads for each system size before moving on to examining production and consumption from the entire network together. Section 28 will aggregate all systems together into a full distributed network.
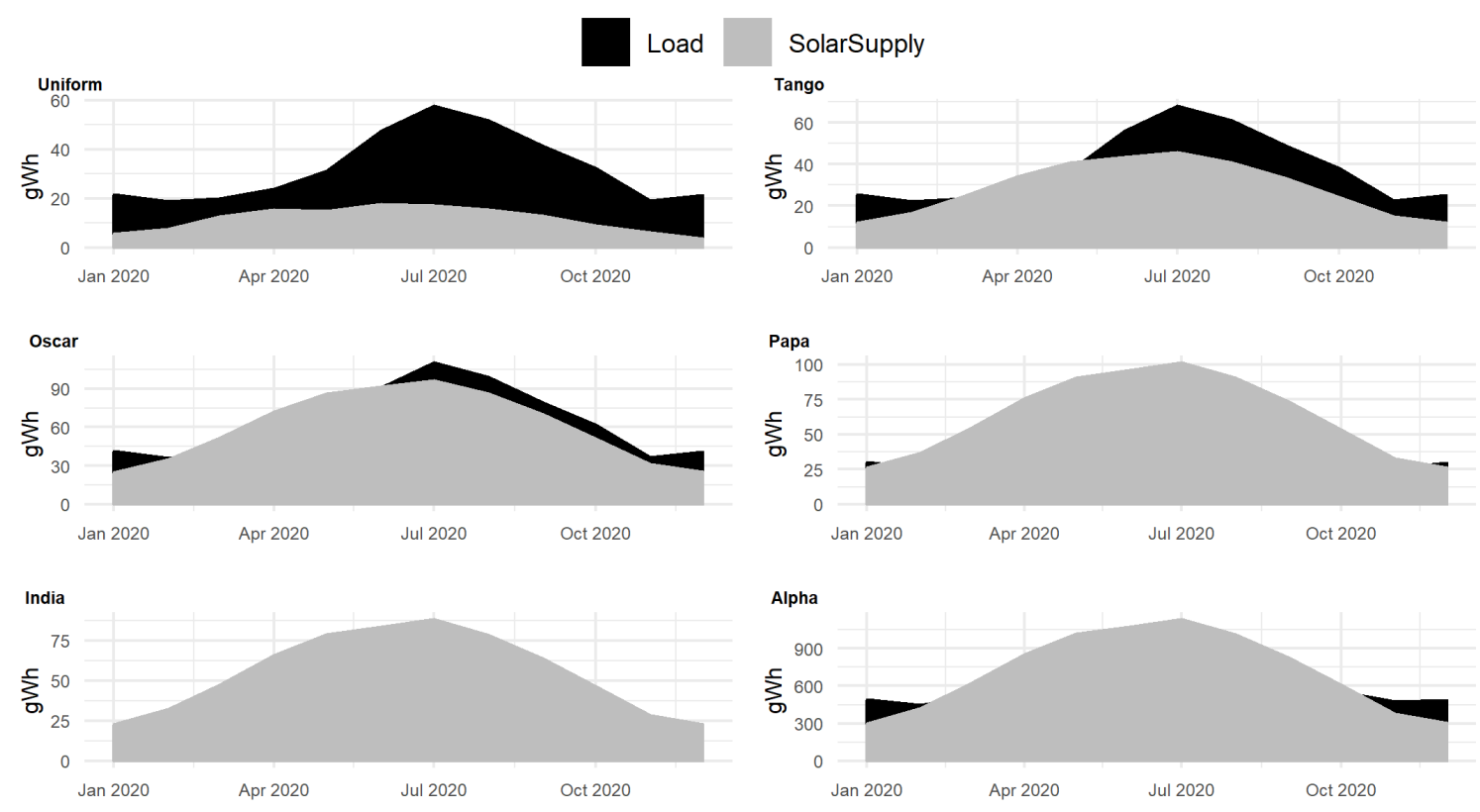

Figure 12: Aggregate Supply and Demand for Individual PV Systems.

As shown in Figure 12, each individual system performs as expected when scaled to the all available rooftop area. The Uniform system falls short of load at all points during the typical model year, with surpluses increasing as the systems grow larger. Interestingly, the Alpha system generates surplus energy for nearly the entire calendar year even though the individual system measured in figures 9 and 10 displayed a constant deficit. Based on the r esults from Section 32, these aggregate 


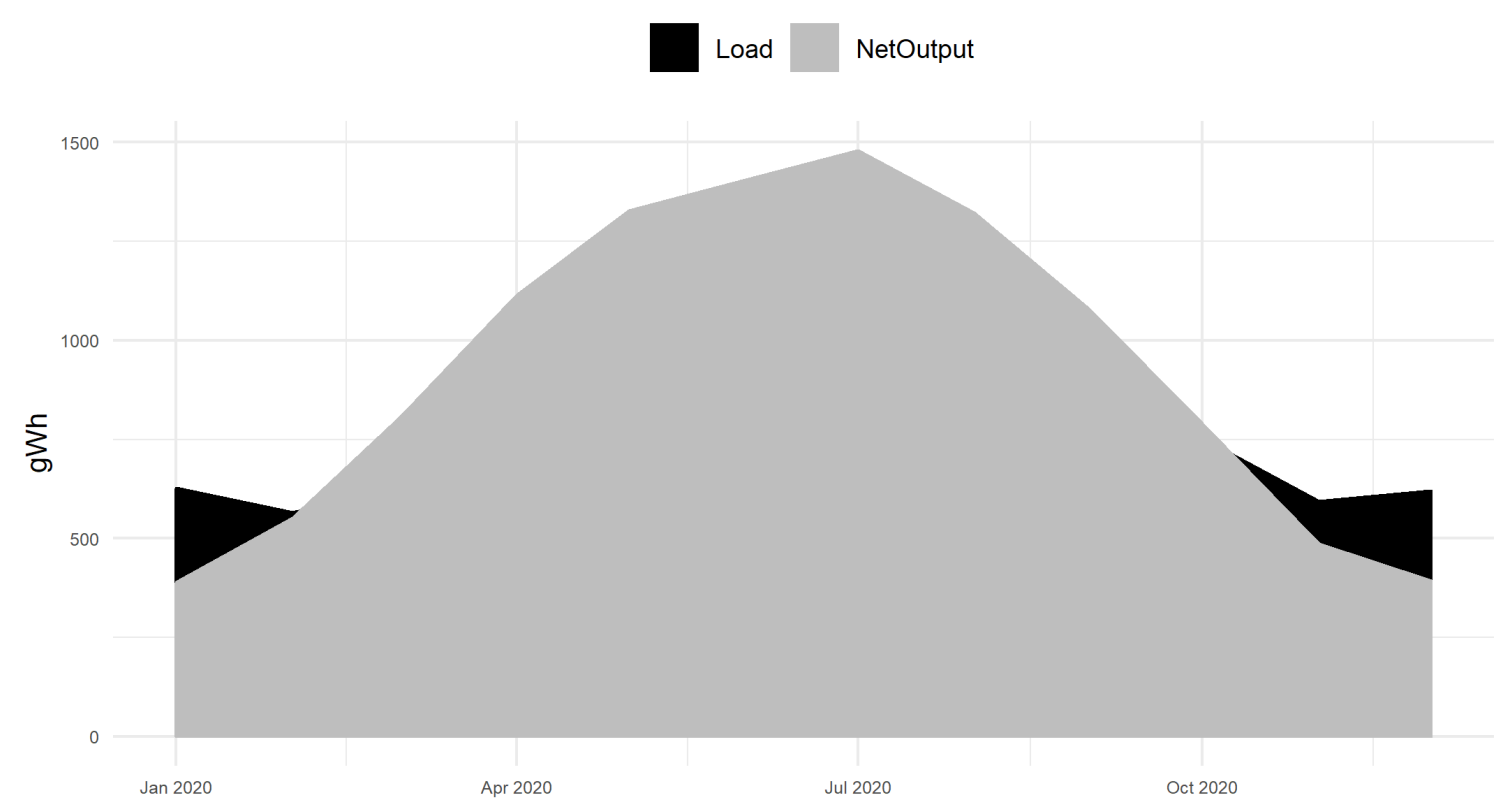

Figure 13: Aggregate Supply and Demand, Distributed Rooftop Solar Network

results are expected.

\section{Network Supply and Demand}

Finally, all six systems are aggregated together to form the full Distributed Network of Rooftop Solar (DNRS). The full network displays surplus energy generation for the majority of the year, only falling into deficit during the winter months of January, February, November and December. Figure 13 and Table 12 detail the final aggregation results. In a typical model year, calculated in SAM based on average weather patterns from 1998 through 2018, the DNRS produces a surplus of 1,915 gWh, or $20 \%$ of estimated Ada County demand. Stated differently, enough solar energy strikes Ada County rooftops each year to more than meet Ada County demand. It is clear that on average annually there is surplus energy generated in the spring, summer and fall but a shortage during the winter months. In the absence of a suitable energy storage solution, the network will still rely on grid energy, which is 
covered more in Section 31.3.

\section{Market Area}

The extent of the Idaho Power Corporation market area covers twenty-five counties in Idaho and three in Oregon, with a 2016 census population of 1.4 million (Figure 14. The area spans 24,000 square miles and includes 558,000 retail customers, roughly 465,000 of whom are residential customers (Delloite, 2019). Figure 14 shows the extent of the market area and population breakdown as a percentage of the total. Although Ada County comprises a small portion of the land mass in the area, it is the most populous county in the region and represents roughly $37 \%$ of the Idaho Power market.

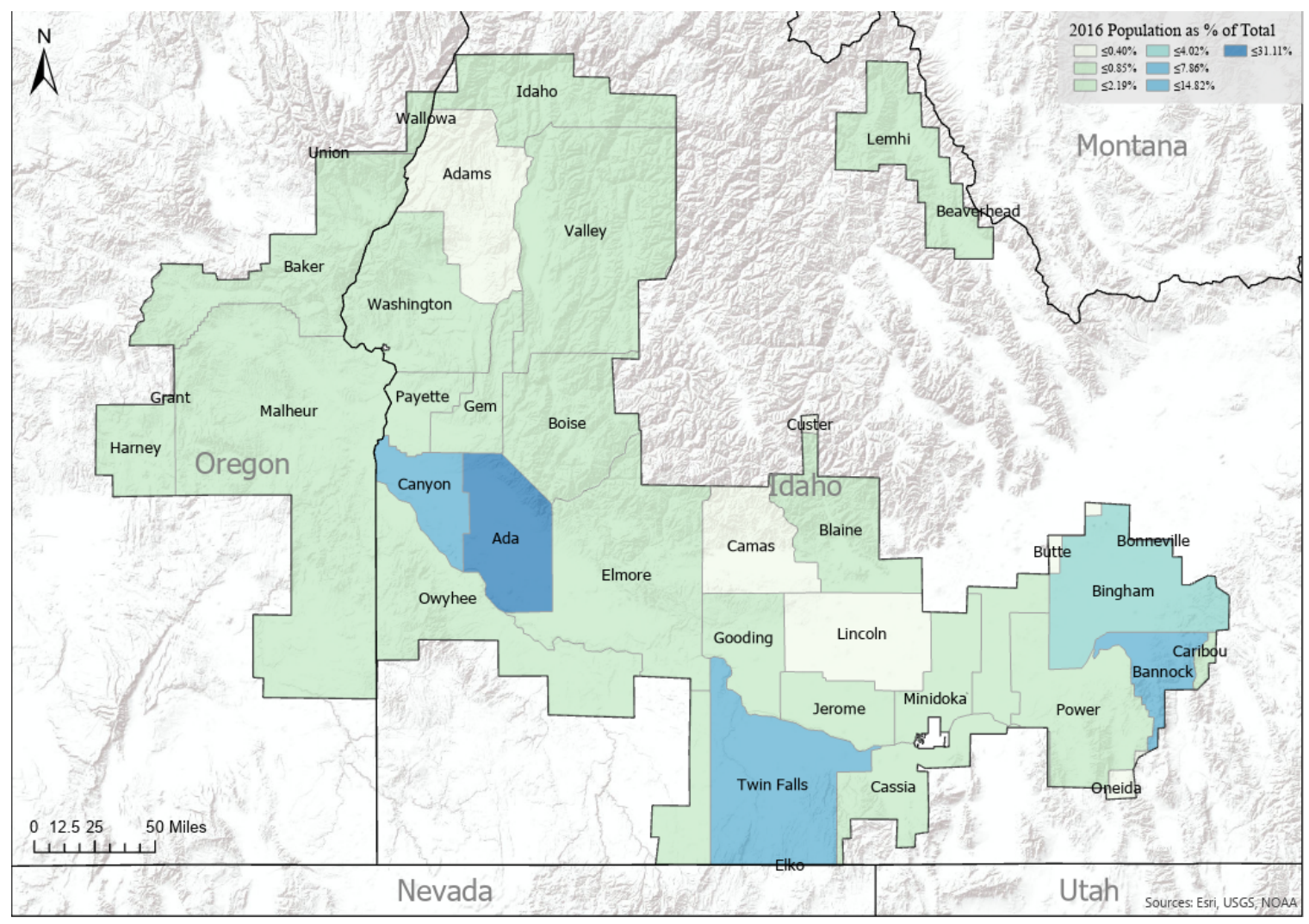

Figure 14: Idaho Power service area (Sources: Esri, DeLorme) 
The simulation model developed in this paper estimates 186,017 residential households and 8,440 commercial businesses in Ada County. This represents $40 \%$ of the households in the Idaho Power service area which is a realistic estimate of the distribution of customers within the area.

\subsection{Market Supply and Demand}

Energy Information Administration data provides net generation from Idaho Power-owned facilities on an hourly basis, as well as hourly operating system demand for the service area. Idaho Power Corporation net generation and demand data for 2017 is converted to monthly averages, after interpolating two missing values for each data set in July and December using cubic interpolation. Results are displayed in Figure 15. Due to the high levels of hydropower generated by the utility the supply curve follows the expected trajectory with a surplus of output during the spring runoff months and a marked decrease toward the end of the year. Demand needs above the net generation curve represent energy purchases made by the utility, which are reflected in the 10-K s tatement for 2017.

\subsection{Distributed Network Supply vs Market Area Demand}

Figure 16 combines the DNRS output with the demand and net generation curves shown in Figure 15. Comparing DNRS energy output to market area demand, it is clear that the DNRS does not produce enough energy to meet the demand for the entire market area. The DNRS does produce enough energy to meet $48 \%$ of market area demand on average, with a minimum of $17.3 \%$ in January and a maximum of $76 \%$ of market demand in April.

A common goal in the sustainability and renewable energy arena is to replace 


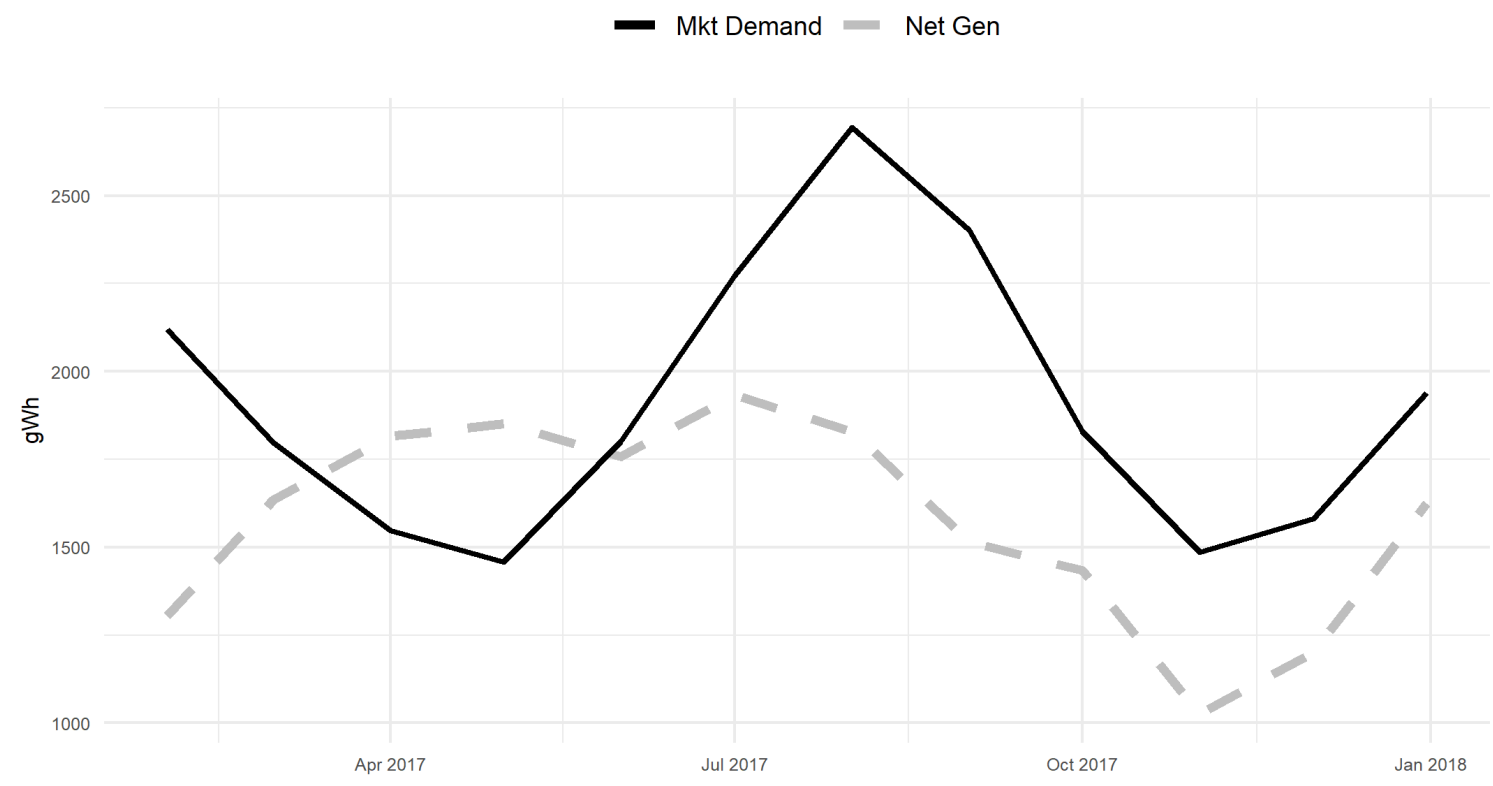

Figure 15: Market demand and Idaho Power Company net generation, 2017

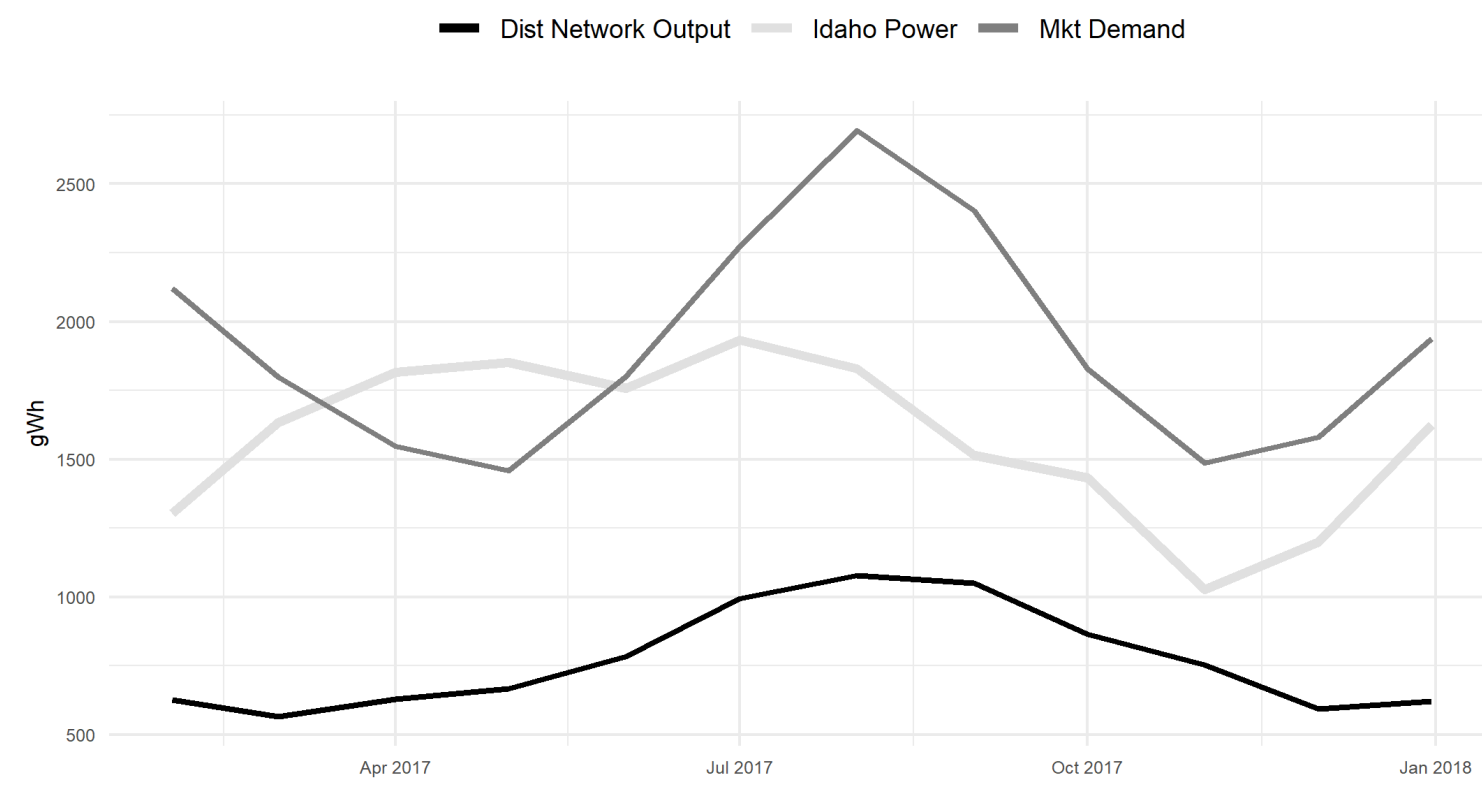

Figure 16: Market Demand, Idaho Power Net Generation, DNRS Output 
fossil fuels with renewable energy. Figure 17 combines the current renewables included in Idaho Power net generation and the output from the DNRS and compares them against total market area demand. This combination creates a larger spring surplus of energy, but is still unable to close the deficit in supply during the summer and fall months. This speaks to the enormous demand the public utility faces even in a relatively small market area, and sheds light on how complicated and complex the transition to renewable energy becomes at scale.

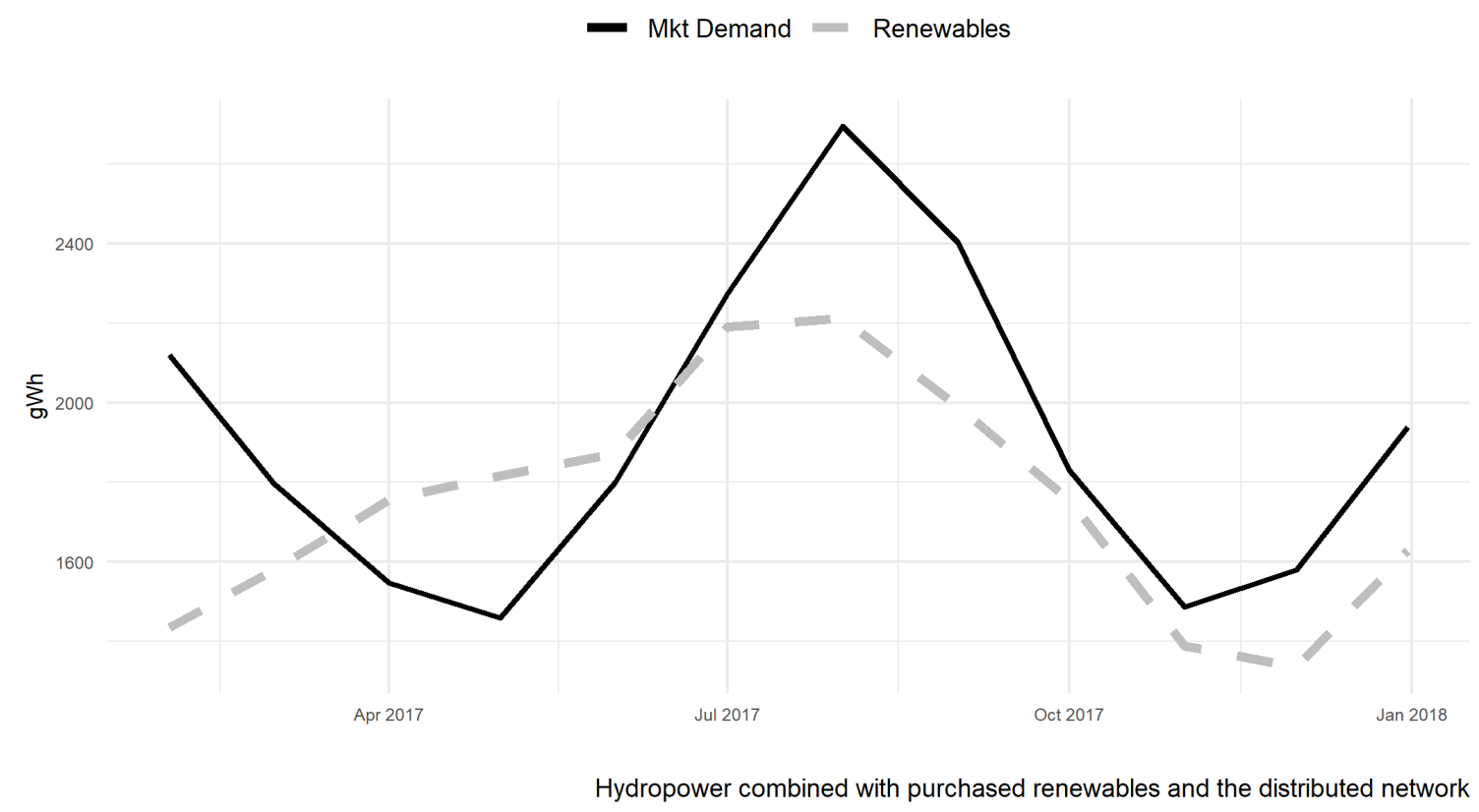

Figure 17: Market Demand versus Renewables, Idaho Power renewables and DNRS output combined

\section{Conclusions on Network Feasibility Opportunities}

This section has demonstrated the technical feasibility of the DNRS. It is clear from this analysis that enough sunlight hits unused rooftop space in Ada County to provide more than enough energy to meet demand. Considering that the neighboring county, Canyon, shares similar spatial attributes and and identical 
weather profile it is relatively easy to imagine that the unused rooftop area in these two counties could collect enough solar energy to power the entire Idaho Power service area. While this is a positive outcome, reaching these future opportunities is not without obstacles.

\section{Obstacles: Technical Feasibility}

\subsection{Intermittency}

Inspecting the data at a closer level obstacles emerges. As shown graphically in Figure 18, a discussion of solar energy is never complete without a discussion on intermittency. Just as the hourly data in Figure 9 masked shortages which appeared in the monthly average data in Figure 10, both the annual and monthly averages mask a deficit that occurs daily. Household energy demand is always well above zero, while output from the solar arrays is actually negative at night. This is due to the energy needs of the inverter and is the main flaw when comparing an inverter-powered energy source like solar to the turbine-powered energy sources that currently supply the energy grid. The turbine can keep spinning as long as heat exists while the PV panels can only generate energy while the sun is shining.

\subsection{Market Disruptions}

Figure 18 illuminates another obstacle as more intermittent energy sources enter the grid. For many days throughout the year, supply and demand curves from the network are not in equilibrium. Since the energy grid as it exists today is one of the few real-world examples of an equilibrium system, this creates a problem in the energy market. Energy is traded on the trading floor of most public utilities based 
on demand for the next minute, hour, week, month and year. Energy bought and sold in real-time, meaning that if supply and demand are not in equilibrium the system will crash. All areas of daily surplus in Figure 18 create risks in the market and uncertainty in the price of energy. Excess energy cannot be stored and therefore must be sold in the energy markets. If supply exceeds demand, the price likely falls and, in extreme cases, the energy could even be given to another market at either no cost or at a loss.

\section{$31.3 \quad$ Energy Storage}

Energy storage is necessary to solve the problems in Section 31.1 since green energy sources are intrinsically intermittent, the ability to store energy in times of surplus for use in times of deficit is critical (Mazhari et al., 2009). While residential storage is under intense research, and becoming less of a niche market (Journal, 2018), at this point there is not a solution that can fit with the distributed network model at scale. Idaho represents a special case due to the high volume of hydroelectric power available. If waterfall-style batteries are being considered as technically feasible storage solutions (Denholm and Margolis, 2007; Denholm and Hand, 2011), it seems a valid assumption that some form of technical solution can be managed that balances the grid and the distributed network (IdaCorp, 2018b).

\subsection{Urban Sprawl and Population Density}

It is also clear from the data that urban sprawl becomes an asset in this situation. As populations become more dense and more people are consuming energy inside a smaller building footprint, the ability to generate ample amounts of energy diminishes. This is evidenced partly in the supply and demand charts for the 


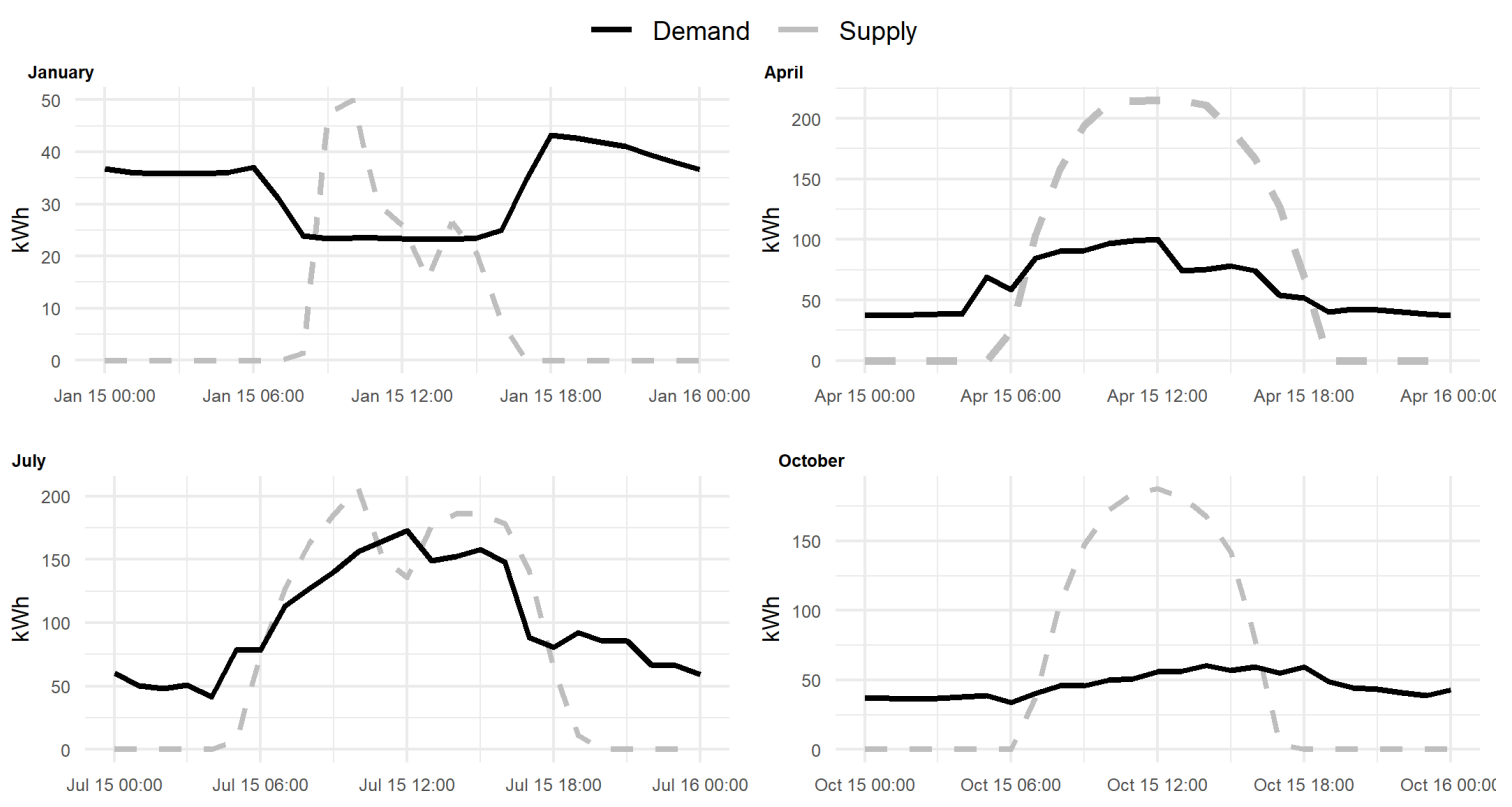

Figure 18: Hourly supply and demand during daily time periods.

Uniform, Tango and Alpha systems, structures with small footprints and multiple floor struggle to meet demand.

\subsection{The Duck Curve}

The Duck Curve is a common problem in renewable energy, and particularly relating to solar networks. The problem arises as solar modules hit their peak performance during the afternoon, resulting in higher levels of energy produced and a reshaping of the net-load curve. This creates a significant issue regarding peak loads occurring in the middle of the day, generally, and violent ramp up requirements as solar power diminishes during the evening hours as shown in Figure 19. As Figure 20 shows, during the peak afternoon times net loads from the utility fall as expected. The problem is the steep ramp from the local minima to peak evening energy use, in order to meet that demand the utility must be able to quickly provide ramp up production and most forms of energy generation do not 


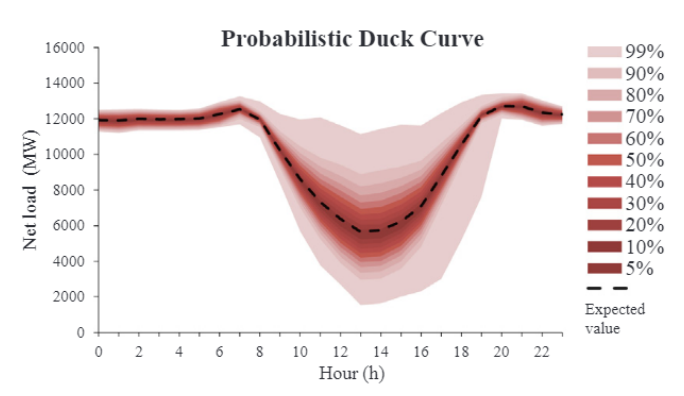

(a)

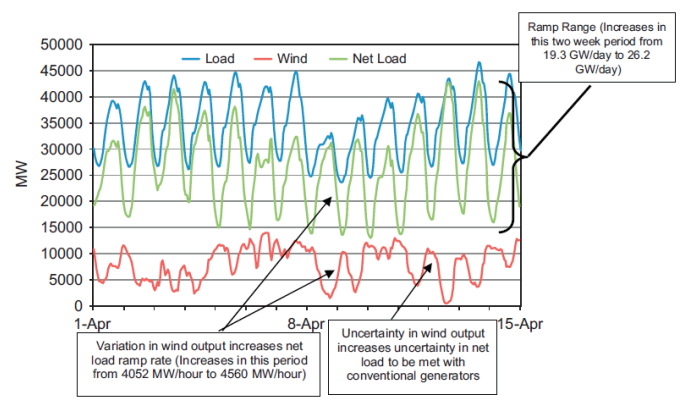

(b)

Figure 19: (a): The probabilistic duck curve derived from California, 2012:2020 (Hou et al., 2019)(b): Impact on net loads from renewable energy sources (Denholm and Mehos, 2011)

perform optimally as they are turned down and then ramped back up. Some studies suggest that the ramp in the duck curve uses more energy, and thereby produces more carbon, than running the power plant at peak load 24 hours per day. The concept is similar to idling your car and then accelerating from a red light; more fuel is used to reach cruising speed than is needed to maintain cruising speed. Hou
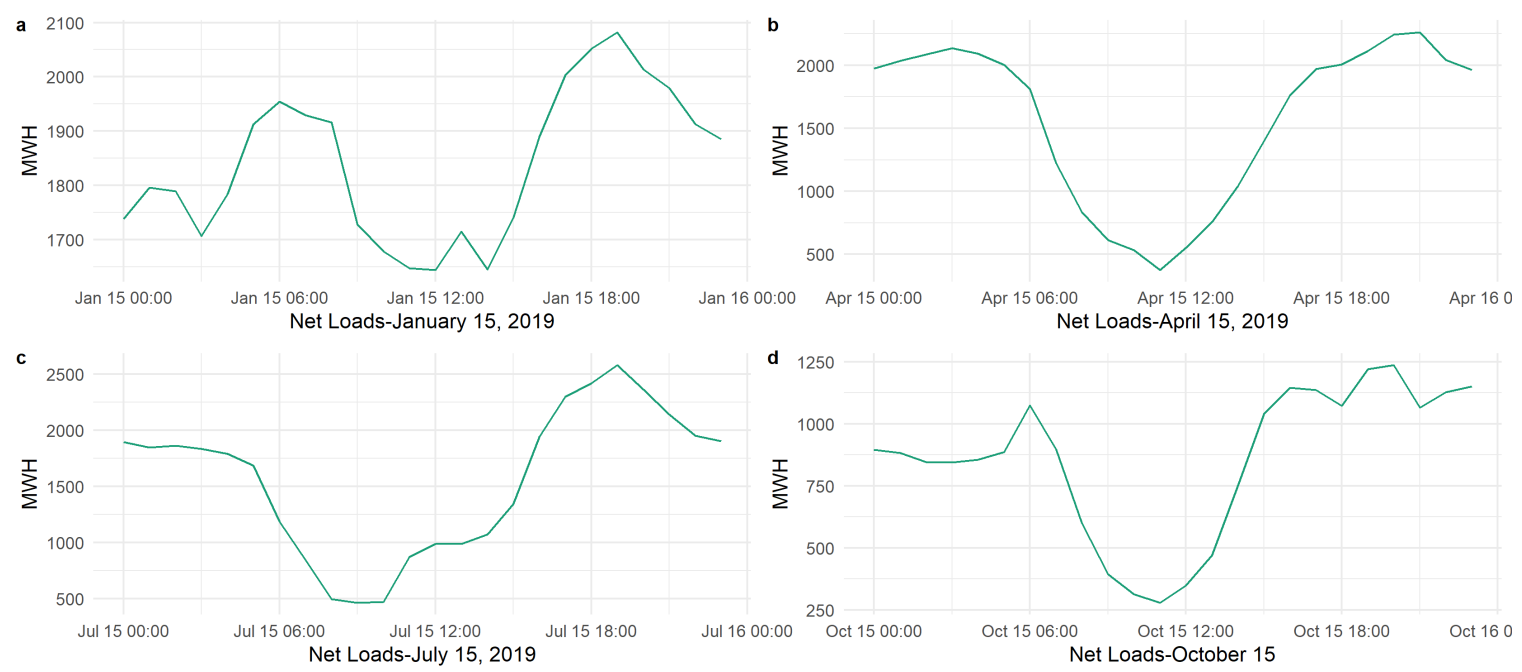

Figure 20: Quarterly Depiction of the Duck Curve using EIA and Simulation Data

et al. (2019) find a method for estimating probability of the peak regulation and ramping requirements and show that with flexible resources utilities should be equipped to accommodate intermittent renewable energy sources, while others question whether the duck curve is even a legitimate concern (The Duck Curve- 
Debunking Renewable Energy Myths, Part 1, 2016). As more solar energy is added to the system stability is likely to decrease, which could likely lead to the utility employing an Internet-of-Things approach and seeking the ability to cut off excess solar energy from reaching the grid. As a complex system, it is clear that a myopic viewpoint could lead to unintended consequences.

\subsection{Assuming Away Money}

Up to this point we have operated under the implicit assumption that money was no object. In chapter VI that assumption is relaxed as the financial aspects of the network are analyzed. 


\section{PART VI: FUTURE OPPORTUNITIES: ECONOMIC VIABILITY}

\section{Adoption by Individual Homeowners at Scale}

In Chapter V it was determined that implementation of the distributed network by individual homeowners was technologically feasible. Generation capacity and energy savings in comparison to fully grid-based energy were enough to incentivize adoption by homeowners, without considering factors such as upfront cost and inertia. This section adds price factors to the model and investigates the likelihood of widespread consumer adoption using an adapted Bass model with price factoring, early adopter status, environmental concern, and social influence. The concern is whether consumers, left to their own devices, would be likely to adopt rooftop solar in a high enough volume to create the network organically. If consumers are not likely to adopt widespread use of rooftop solar, it will be necessary for private firms, public utilities or the government to incentivize adoption to reach the penetration levels of renewable energy needed to stave off an extinction-level climate event.

\subsection{Costs Facing Individual Homeowners}

Individual system costs include direct and indirect capital costs, ongoing maintenance, and capital financing that may be required. When investigating the incentives for firms, utilities and governments the capital financing assumption is relaxed and installer margins and overhead are removed from total costs under the assumption that these groups possess greater market power. The cost function for all sectors is detailed in Equations 11 through 13, the only difference being inclusion 
of financing installer overhead and in capital costs for consumers. In both cases, installer overhead should not be confused with installer labor, labor costs are included in all scenarios. Refer to Section 20.1 for a complete breakdown of financial parameters.

\begin{tabular}{rccccccc} 
Table 4: Direct(DC), Indirect(IC), Total(T C) and Ongoing Costs for each system. \\
System & $D C(\$)$ & $I C(\$)$ & $T C(\$)$ & O \& M $($ Yr1 $)$ & Payback $(Y r s)$ & LCOE $(\$ / k W h)$ & NPV $(\$)$ \\
\hline Uniform & 10,053 & 766 & 10,820 & 68 & 14.4 & 0.1083 & -997 \\
Tango & 12,979 & 1,066 & 14,045 & 101 & 12.6 & 0.0685 & 2,938 \\
Oscar & 16,331 & 1,370 & 17,701 & 148 & 12.0 & 0.0798 & 1,831 \\
Papa & 23,330 & 1,957 & 25,288 & 211 & 16.9 & 0.0782 & $-2,612$ \\
India & 32,501 & 2,935 & 35,436 & 338 & $25+$ & 0.0782 & $-11,031$ \\
Alpha & 314,298 & 39,774 & 354,072 & 3,686 & 17.4 & .0506 & $-44,572$ \\
\hline
\end{tabular}

With the exception of the India system, payback periods are less than the expected system life of twenty-five years and real levelized cost of energy is at or below current market rates. Net present value, however, is negative for all systems except Oscar and Tango. When making the decision to install solar panels, however, the average consumer is not likely to calculate net present value or levelized cost of energy. The two main decision points facing consumers are upfront costs and inertia. The decision facing the consumer involves taking responsibility for infrastructure attached to their own residence, when the alternative is to simply pay the electric bill and energy is provided at the flip of a switch. This type of inertia, behaviorally, is intuitively diffeult to overcome.

\subsection{Bass Diffusion Model Implementation}

The Bass Diffusion Model provides insight into how likely individual consumers are to take the actions necessary to implement the distributed network. The Bass Model is implemented in NetLogo using Equation 9 and an early adoption matrix from Section 11.4. Price factor differentials are derived for each PV system from the 
SAM simulation data, adopter status is assigned at random for each individual with weights derived from Araújo et al. (2019) and sensitivity analysis is performed on $q$ and $c$ through behavior space experimentation in NetLogo. Each model is simulated in ten instances with $q$ and $c$ values ranging from 0 (no social influence or environmental concern) to 0.33 (one-third of the population is highly influenced and/or highly concerned). Parameters for the simulation are detailed in Table 5. Price factors are derived from the ratio of solar energy costs and grid

Table 5: Bass Diffusion Simulation Parameters

\begin{tabular}{c|l|l} 
Parameter & Value & Derived \\
\hline Early Adopters & Political Affiliation, Home Value, Income & Random \\
$p$ & Price differential $\left(\frac{\text { Solar }}{\text { Grid }}\right)$ & (SAM Data) \\
$q$ & Social Influence & Sensitivity Range \\
$c$ & Environmental Concern Level & Sensitivity Range \\
$w$ & Adopter Weight & From Araújo et al 2019 \\
\hline
\end{tabular}

energy costs exhibited by the SAM simulation. The average Price Factor across all residential systems is -0.091 , meaning that the average cost of grid energy is approximately $9.1 \%$ higher than the overall cost of the solar network; price factors for each individual system are detailed in Table 6 .

Table 6: Price Factor Analysis by PV System

\begin{tabular}{lccc}
\hline TagName & Price.Factor & Adoptions & Percentage \\
\hline \hline India & 0.28 & 1,680 & 100 \\
Oscar & -0.278 & 277 & 16 \\
Papa & -0.078 & 1003 & 59 \\
Tango & -0.18 & 539 & 32 \\
Uniform & -0.07 & 1,020 & 60 \\
Cumulative Mean & -0.06 & 1,057 & 62 \\
\hline \hline
\end{tabular}

Calculated based on typical model year data, 1998:2018 


\subsubsection{The Base Case}

According to theory, a typical rational actor would be expected to adopt solar energy technology as long as the price differential was in his favor (Rai and Henry, 2016). As a base case the small world network is set to disregard the early adopter matrix, along with a population that is moderately concerned about the environment (0-15\%) and influenced by their society at at standard $25 \%$. A $10 \%$ price advantage to the solar network results in $100 \%$ adoption rates over an average time frame of 14 years, while a $15 \%$ price differential incentivizes full adoption in an average of nine years. This model imitates a more discrete-choice basis, using price as the major incentive for action and implies that the convenience of existing grid-based energy creates a strong inertia regardless of the energy source (Wilensky and Rand, 2015).

\subsection{Homeowner Adoption Results}

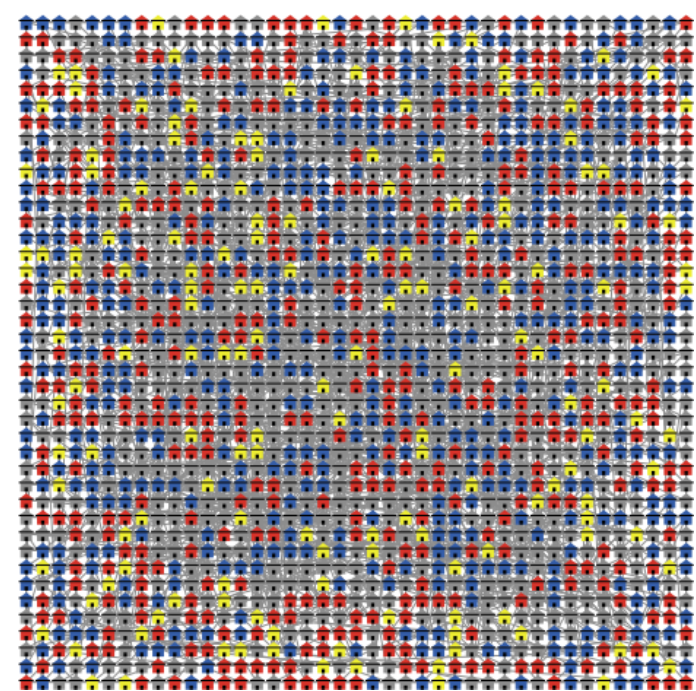

(a)

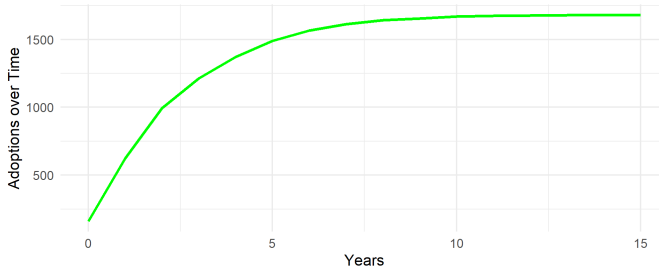

(b)

Figure 21: (a)Small-world network with early adopters (b)Adoption results using the India configuration with $q=0.3, c=0.13$, and $p=0.28$ 
The Bass experiments tend to validate previous findings in this study, and throw doubt on the idea that left to their own devices consumers will adopt a widespread network of rooftop solar organically. Tango and Oscar systems provide clear incentives with short payback periods and positive net present values, with those two systems representing $52 \%$ of the overall deployment. The larger systems, those shown in Figure 10 to operate in constant surplus, show the longest payback periods and lowest net present values of all residential systems due to their high upfront costs. In order to maintain viability these two large systems must be included in the network. Table 6 also details the experiment results over a 10-year simulation period.

\subsubsection{Further Adaptations}

Once the feasibility and viability of the network have been established, there are some interesting areas of future agent-based models. Government actors can incentive adoption at the national level through a variety of means, some of which are discussed briefly in the following section, and dis-incentivize adoption on the local level through homeowner's associations and public utilities commissions (Barker, 2018). It is also clear that the local population is changing and with these changes are likely to come changes in attitude and reactions to monetary incentives. As environmental concern increases the adoption rate should also increase; and the effects of climate change could alter both output and demand in the future as well.

\subsubsection{Incentives}

A policy that may provide incentives for some homeowners to adopt the system may be offering below market rate mortgage refinancing which includes energy upgrades. When seen as a portion of a 15- or 30-year mortgage, the perceived costs of the systems are reduced for consumers. Government intervention raises considerable 
questions that are addressed in Section 37 and Chapter VII. It is still unclear, however, if there could ever be a large enough adoption rate to establish a distributed solar network without business or government assistance. While the deployment of such a system is technologically feasible, it fails in terms of viability at this point. If time is truly of the essence, deployment of the distributed network will require intervention from private firms, public utilities, the government, or a combination of all three.

\section{Aggregate Output, Costs and Returns to Scale}

\subsection{Returns to Scale}

As discussed in Section 8.1, a complex adaptive system, and therefore a good candidate for simulation modeling, can be identified by calculating returns to scale. Tables 10 and 11 in Appendix 39 show simulated solar output for the Oscar and India systems. As shown in Equations 5 and 2, holding atmospheric conditions and panel efficiencies constant, solar panel area can be varied to increase or decrease production. The Oscar system has $34.3 \mathrm{~m}^{2}$ of area, while the India system has 78.3 $m^{2}$, so the area increases from Oscar to India by 128\%. The solar outputs for Oscar and India on July 15, 2018 were $53.69 \mathrm{kWh}$ and $125.81 \mathrm{kWh}$, holding all other variables constant. Increasing panel area by $43.81 \%$ results in an increase in output of $134 \%$, therefore exhibiting increasing returns to scale and suggesting that energy markets are indeed complex adaptive systems. 


\subsection{Aggregate Costs}

Cost curves facing private firms, public utilities or the government differ slightly from those facing individual consumers. Considering economies of scale, it is trivial to assume that installer overhead will disappear from the equation as any entity with enough market power to accomplish the build-out of the network will have considerable negotiating power.

Table 7: Direct, Indirect, Total and Ongoing Costs for each system (USD).

\begin{tabular}{cccccccc} 
System & $D C$ & $I C$ & $T C$ & O\& M & Units & Network Cost & Annual O\&M \\
\hline Uniform & 6,488 & 621 & 7,110 & 57 & 21,108 & $150,067,804$ & $1,204,000$ \\
Tango & 9,761 & 935 & 10,695 & 85 & 34,984 & $374,160,699$ & $3,001,907$ \\
Oscar & 12,811 & 1,277 & 14,038 & 112 & 57,244 & $803,566,542$ & $6,447,048$ \\
Papa & 18,302 & 1,752 & 20,054 & 160 & 41,214 & $826,515,379$ & $6,631,168$ \\
India & 29,284 & 2,804 & 32,088 & 257 & 22,313 & $715,970,151$ & $5,744,259$ \\
Alpha & 314,297 & 39,774 & 354,071 & 2806 & 21,868 & $7,742,828,717$ & $61,366,681$ \\
\hline Total & & & & & $10,613,109,292$ & $84,395,063$ \\
\hline
\end{tabular}

Table 7 details the direct and indirect costs across the network for the deployment of each individual system and the aggregate costs of all systems. Annual operating and maintenance expenses are also included, totalling $\$ 84.3$ million annually. The total price tag for the network is $\$ 10.6$ billion with a projected lifetime of 25 -years, which brings the total costs including operations and maintenance to $\$ 12.7$ billion.

\section{3 $\quad \underline{\text { Aggregate System Output }}$}

System output is simulated with SAM over the 25-year life cycle of the network with a PV panel degradation rate of $5 \%$ annually. Annual output begins in year two, assuming that the first year is required for construction, with an annual estimated output of 11.1 million mWh. Total lifetime output of the network is estimated at 262,466,218 $\mathrm{mWh}$ of output, for a cost per $\mathrm{mWh}$ including upfront and 
O\&M costs of $\$ 48.47$ per $\mathrm{mWh}$. Average revenue per $\mathrm{mWh}$ in Idaho from 2001 through 2018 was $\$ 79.18$ for residential consumers and $\$ 64.57$ for commercial customers. According to the IdaCorp 10-k statements, average revenue per $\mathrm{mWh}$ ranged from $\$ 96.57$ to $\$ 97.08$ with an average of $\$ 97.88$ in the residential sector and from $\$ 75.21$ to $\$ 77.66$ with an average of $\$ 76.11$. The average revenue across all sectors and time spans is $\$ 81.00$ per $\mathrm{mWh}$.

\subsection{Simulated Revenue and Profit: Distributed Rooftop Network}

Profits and revenues are simulated using retail price of electricity data from 2001 through 2018 matched with weather data across the same period. In order to simulate the entire life cycle of the network an additional five years of retail price data is required which is estimated using the trend of the moving average of the past 20 years. With 25-years of simulated data it is possible to now estimate the outcomes for the final three scenarios in this study; the private firm (Section 34), the public utility (Section 35), and the national government (Section 37).

\section{The Private Firm}

Private sector investment is driven almost exclusively by profit motives, which finds private sector decision makers interested in not only revenues and costs but cash flows and present values discounted based on risk and alternative investment opportunities. Annual network revenue is estimated to be $\$ 11.14$ million in the first year with a roughly $5 \%$ reduction each following year as solar PV panels degrade. Total revenue for the 25-year life cycle of the network is $\$ 20.03$ billion against a total cost of $\$ 12.7$ billion, for a projected 25 -year profit of $\$ 7.3$ billion. This represents a positive although basic, back-of-envelope style calculation; discounted 
values and standard investment metrics are explored below.

\subsection{Key Metrics}

Capital investment analysis depends on the key metrics discussed in Section 20 just as much as pure profit and loss figures over time. Investment in the distributed network of rooftop solar requires a large up-front capital investment of $\$ 6.98$ billion at the beginning of year zero along with a labor cost of $\$ 3.63$ billion, resulting in a total upfront capital investment of $\$ 10.6$ billion. The model assumes a 25 -year straight-line depreciation schedule with no salvage value, $\$ 84.4$ million in maintenance and operating expense beginning in year two, and a $25 \%$ federal income tax rate. All scenarios use the average expected inflation rate of $1.7 \%$, calculated over the past decade, and a reference nominal discount rate of $5 \%$. Table 8 in Section 34.1.4 performs a sensitivity analysis on the discount rate.

\subsubsection{Total Long-Term Cost of Capital}

Total long-term cost of capital facing the private firm is $\$ 9.83$ billion, reflecting the after-tax costs to the investor or firm. This suggests a tax savings for the firm during the project life cycle of nearly $\$ 3$ billion.

\subsubsection{Levelized Cost of Energy}

The Levelized Cost of Energy for this project is $\$ 54.77$, meaning that every $\mathrm{mWh}$ of energy generated by the network will need to be sold for at least $\$ 54.77$ in order to recoup the investment. Given the average retail cost of energy in Idaho from 2016 through 2018 of $\$ 87.00$ per $\mathrm{mWh}$, this indicates a profit incentive for the firm in the long run. 


\subsubsection{Internal Rate of Return}

IRR for this project is calculated at $-0.77 \%$. As shown in the sensitivity analysis to follow, this indicates that a discount rate of $4.20 \%$ will generate a positive net present value.

\subsubsection{Net Present Value for the Firm}

Table 8: Projected financials with nominal discount rate sensitivity analysis (\$millions)

\begin{tabular}{cccccccccc}
\hline Year & O\&M & $\pi$ & Dep & NTI & Fed $_{T} a x$ & $F_{n}$ & $4 \% F_{p v}$ & $5 \% F_{p v}$ & $6 \% F_{p v}$ \\
\hline 1 & 0.00 & 659.2 & 424.5 & 234.7 & 37.6 & 600.6 & 587.2 & 581.7 & 576.2 \\
\hline 2 & 84.4 & 634.1 & 424.5 & 125.2 & 31.3 & 518.4 & 495.7 & 486.3 & 477.2 \\
\hline 3 & 84.4 & 611.3 & 424.5 & 102.3 & 25.6 & 501.3 & 468.8 & 455.5 & 442.7 \\
\hline$\ldots$ & & & & & & & & & \\
\hline 25 & 84.4 & 989.8 & 0.00 & 905.5 & 226.4 & 679.1 & 333.1 & 262.2 & 206.9 \\
\hline Total & $2,109.9$ & $20,027.3$ & $10,613.1$ & $7,728.8$ & $1,932.2$ & $5,372.1$ & 242.8 & -928.3 & $-1,924.8$ \\
\hline
\end{tabular}

Table 8 details cash flow information for the first three study years, the final study year and summations for all parameters, including sensitivity analysis using nominal discount rates of $4 \%$ (2.3\% real), $5 \%$ (3.2\% real), and $6 \%$ ( $4.2 \%$ real). This results in net present values of $\$ 242.8$ million, $-\$ 928.3$ million and $-\$ 1.92$ billion, respectively. Clearly the appeal of the investment varies greatly depending on the discount rate required by the firm.

\subsubsection{Break-Even Analysis}

Break-even analysis shows that without including any finance charges the firm will break-even in terms of gross revenue in approximately 18 years, and in terms of free cash flow in approximately 22 years. This leaves three to seven years of pure profit with little or no unexpected expense and provides further incentive for the private sector. 


\subsubsection{Benefit to Cost Ratio}

The $\mathrm{B} / \mathrm{C}$ ratio for the distributed network is 5.26 , meaning the benefits outweigh the costs by that factor. This factor is derived using only pure costs, no social costs or benefits are included at this point, which is a channel for future research.

\subsection{Results}

While the initial capital investment is large, a private firm could certainly make the business case for deploying the DNRS. As long as the firm was seeking an investment with high fixed cost and limited future uncertainty coupled with long term profitability and an overall $4 \%$ return on investment. Since this investment is hedged against the uncertainty of increasing fuel costs, this represents a stable investment during times of disruption and change.

\section{Investment by Public Utilities}

The public utility faces some of the same decision metrics as the private firm, but there are also some significant differences. As the regulated monopoly, the public utility enjoys market power within the confines of the Public Utilities Commission (PUC), and also has production capacity that is unmatched by any independent

power producer (IPP). Even with these advantages, the utility faces disruptive risk from increased adoption by individual consumers and risks to their overall profits and business model. 


\subsection{Disruptive Risk}

\subsubsection{Consumer Adoption}

Consumers are not likely en masse to trade flipping a switch to receive virtually unlimited energy with near-perfect uptime for paying high upfront costs to install solar panels. Regardless of the adoption probability at scale, as more rooftop solar is incrementally installed in an area it can create friction between the utility and their customer base (Sowell, 2019; Stokes and Breetz, 2018). As the utility wades through these issues they are relying on market tests in Hawaii and California to determine best practices, while at the same time pushing for separate rate classes for grid energy users and solar energy producers (Barker, 2018), which places increasing friction points between the public utility and their customers. Increasing adoption also introduces uncertainty and erratic behavior into the grid, including the dreaded "duck curve," explored in detail in Section 31.5.

\subsubsection{Profit Risk}

Considering the financial analysis conducted in Section 34, there is a speculative risk of one or more private firms entering the market and developing a DNRS. This may be considered an outside chance given the level of investment, but cautionary tales of entrenched industries not taking outside risk seriously are abundant. One needs not think any further than New York taxicab medallion values cratering due to Uber, or Blockbuster video not seriously evaluating the threat posed by RedBox and Netflix. As the incumbent utility, you do not want to be the taxi cab when Uber comes to town. The potential $\$ 17$ billion in total 25 -year revenue captured by a private firm entering the Idaho market would come directly from the bottom line of the IdaCorp 10-k statement. While the public utility currently enjoys annual 
revenues of $\$ 1.18$ billion and a customer base of 536,350 residential and commercial clients (Delloite, 2019), the loss of nearly the entire Ada County market and $\$ 659$ million in annual revenue would be devastating. Under current structures, grid maintenance costs would likely also remain under the purview of the public utility, and the excess energy from the distributed network could realistically impact wholesale energy markets and cause additional wholesale losses for the utility.

\section{Financial Metrics for the Public Utility}

Most of the market analysis tools used in section 34 also apply to regulated utilities. The utility faces an identical net present value as any other IPP entering the market with the caveat that a major producer such as Idaho Power may have additional market power and economies of scale stemming from their established workforce and customer base. Public utilities not only possess large financial assets but also have the ability to lobby for favorable market conditions with Public Utility Commissions and have an existing infrastructure and the ability to bundle energy for sale on the wholesale markets. Controlling the grid also allows the utility to develop more revenue, and operating and maintenance costs may also be reduced due to economies of scale; as long as revenues remain undisturbed as discussed in Section 35.1.2.

\subsubsection{Public Utility-Revenue and Projected Profit}

Under the assumption of a $20 \%$ decrease in up-front costs due to market power and already existing economies of scale, the projected revenues for the distributed network are $\$ 17.7$ billion over the life cycle of the project. From the public utilities view, however, this is not new revenue but simply a change in the energy source used by their current customer base. A complete analysis would require existing revenues and costs from current energy generation, which are not available at a 
granular enough level to determine if this is a positive or negative investment.

\subsubsection{Total Long Term Cost of Capital}

Total long-term cost of capital is $\$ 9.72$ billion which, like the private firm, indicates a substantial tax savings over the life of the project.

\subsubsection{Levelized Cost of Energy}

Levelized cost of energy for the public utility is $\$ 53.65$ per $\mathrm{mWh}$, which is less than the average derived from the IdaCorp 10-k statement of $\$ 87$ (Delloite, 2019). This suggests profitability over the long term, and the ability to compete on pricing if necessary to protect market share.

\subsubsection{Net Present Value}

Net present value facing the firm, using the same sensitivity analysis as the private sector, is $-\$ 726$ million using the reference case with a low of $\$ 470.1$ million and a high of $\$ 1.74$ billion based on a $20 \%$ capital expense reduction due to economies of scale and a total up-front capital investment of $\$ 10.61$ billion. Annualized required revenue $(\mathrm{RR})$ to recoup the investment at $5 \%$ ROI is $\$ 567.8$ million, which is well under the projected annual revenue of $\$ 659.2$ million.

\subsubsection{Benefit to Cost Ratio}

Finally, the benefit cost ratio facing the public utility is 6.83 , so the benefits of the project are significantly higher than the costs based on the model assumptions. 


\subsection{Public Utility Results}

Financial metrics all seem to indicate that the distributed network is a viable investment for the public utility. As mentioned in section 36.0.1, in terms of the public utility this analysis represents more of a horizontal rather than vertical move. The utility company currently captures the revenue base covered in the simulation and granular profitability information is not available to make a more accurate assessment. The public utility is, however, incentivized to invest resources into the distributed network if for no other reason than a preemptive protection of current profits and revenue.

\section{Direct Government Implementation}

When considering a major public investment, the concerns facing a sovereign government with control over its own currency are vastly different than those facing private firms and public utilities. There are things that arguably belong in the free market, and there are things that government must do. Where financial markets and private firms are skewed toward profitability and shareholder value, governments can focus on long term solutions and the common good (Tirole and Rendall, 2017). Where private firms must consider tax as a burden, sovereign governments are able to use tax receipts and incentives as agents for growth (Mitchell, 2019).

Governments can create private and public-private incentives through creative use of fiscal policy, spurring investment pools that allow multiple private investors to operate a portfolio and diversified risk (Sivaram, 2018). Governments can also allow for special subsidies and tax code treatments for renewable energy investments, as well as providing a financial structure to lure private sector 
investment in a project at lower cost and less risk. And, finally, the public sector is able to offset massive costs with economic growth and focus on national and global economic benefits; as the issuer of the currency and the protector of the public good government may be the only reasonable investor in large scale projects such as the interstate highway system, or the distributed solar network (Kelton, 2011).

\subsubsection{Levelized Cost of Energy}

Levelized cost of energy facing the government is $\$ 65.17$, meaning the government would need to sell each $\mathrm{mWh}$ of energy for $\$ 65.17$ to recoup the initial investment, operations and maintenance costs over the life of the project. This is another indicator that government development of the network could produce more efficient outcomes compared to the regulated monopoly or private industry.

\subsubsection{Government Facing Net Present Value}

Net Present Value from the governmental perspective doesn't include depreciation, which is a tax reducing measure, and it is clear that the federal government is the collector of tax not the payer. Therefore, NPV is the net present value of the net revenue stream under the assumption that a government agency is directly collecting the revenue. This results in a nationalized energy market, which is a controversial issue in the United States, but may hold some merit due to the importance of clean and stable electricity to the common good. Based on these assumptions, the NPV faced by the government ranges from 1.48 billion to $-\$ 945.8$ million using the same sensitivity metrics employed in analysis of the private firm and the public utility. Under the assumption of the nationalization of the distributed network, the economies of scale from Section 36 is relaxed since a new government agency would likely not have an operations and maintenance workforce in place. Considering capital investment in the distributed network as government investment results in 
an increase in GDP of $\$ 7.1$ billion in 4-years, while classifying labor consumption adds $\$ 1.4$ billion to GDP over the same 4-year period.

\subsection{Energy Spending as a Stimulus}

\subsubsection{Clean Energy Jobs}

Possibly more than any financial metric, local and national government offfials are typically focused on job creation. Wei, Patadia, and Kammen (2010) study jobs created per unit of energy and find that non-fossil fuel based technologies create more jobs per unit than found in the fossil fuel industry. While averaging one-time employment factors such as plant construction, or solar panel installation, over the project lifetime and adding operations and maintenance workers, they find that solar PV creates more jobs per unit than any other renewable sector. Pollin et al. (2008) proposed a jobs program shortly after the GFC to build the low-carbon economy and found the $\$ 100$ billion in government investment would spark increased jobs in six different clean energy sectors. Their analysis, and the U.S. Bureau of Economic Analysis, estimated that total job creation nationally due to their program would nearly reach 2 million over a 12-month period and create a more productive stimulus channel than the bank bailouts or fossil-fuel subsidies taking place both then and now. Idaho legislators could possibly extrapolate up to $10 \%$ of this job growth based on the $10 \%$ of green jobs investment funding represented by the distributed network.

\subsubsection{Government Multiplier Flow}

Governmental development of the distributed network, in the absence of profit motives and required returns on investment, not only appears to make better economic sense than the other options investigated; spending by the government 
also works as a stimulus and includes multiplier effects.

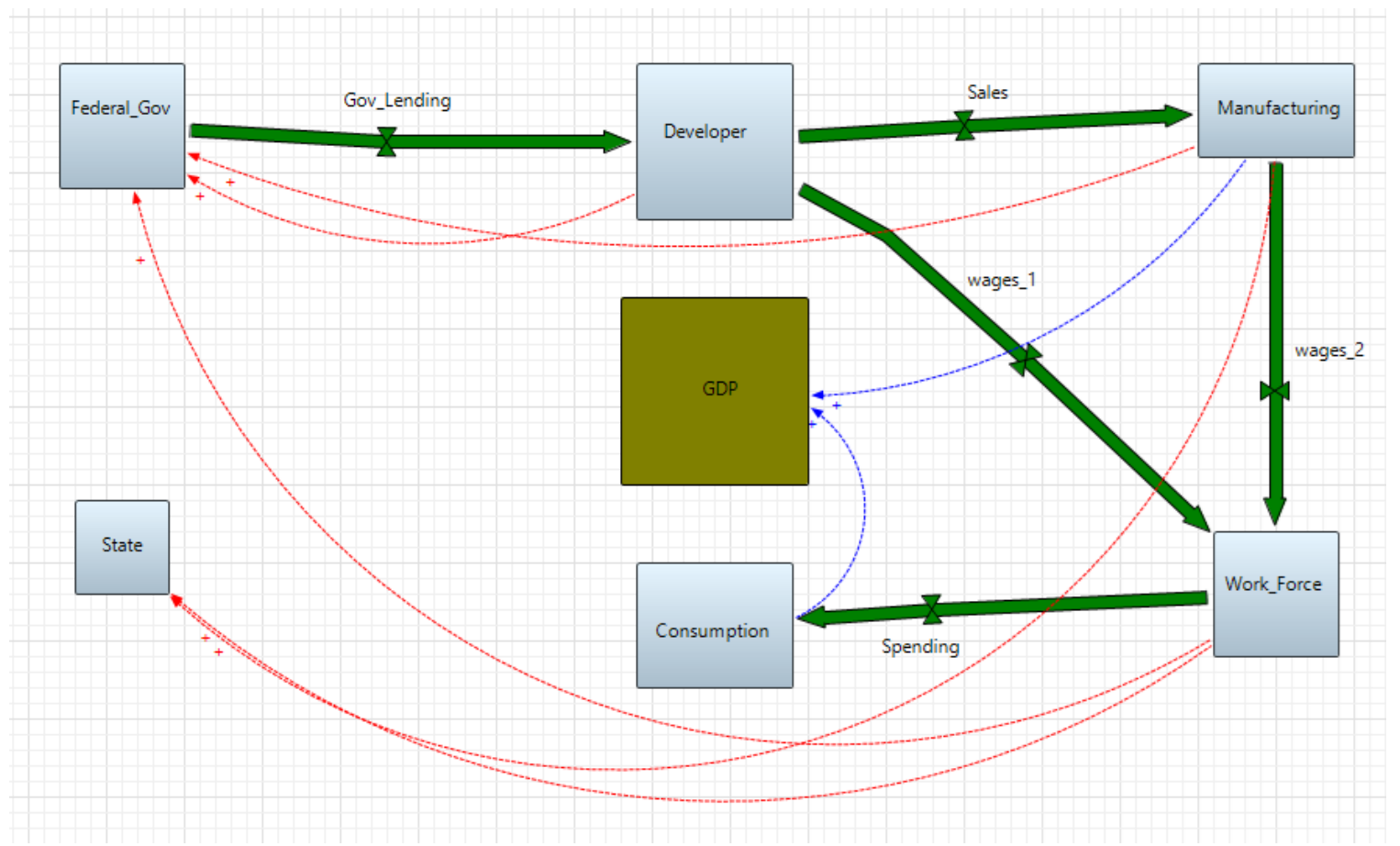

Figure 22: Circular Flow Diagram for Government Spending 


\section{PART VII: CONCLUSIONS}

We have this handy fusion reactor in the sky called the sun. You don't have to do anything. It just works. It shows up every day and produces ridiculous amounts of power. Elon Musk, 2015

The main questions of this study revolve around the technical feasibility and economic viability of a distributed network of rooftop solar. At this point, the answers to both questions are affirmative. Most residential applications are able to generate more net energy than they use, although intermittency issues still exist that would require the system to be grid-tied, or the addition of battery storage. It is technologically feasible to retro-fit existing structures with solar panels and capture energy that is currently being reflected or absorbed using current technology. More than 11,000 mWh of energy strike rooftops in Ada County annually, which represents enough wasted energy generated in unused space to more than power all homes and businesses in the county. Energy generated from 2016-2018 using hydroelectric plants, coal plants and natural gas plants totalled $12,175,13,688$, and $13,364 \mathrm{mWh}$, respectively; so the rooftop solar network has the ability to replace coal and partially replace natural-gas fired power plants.

An all-hands on deck approach will be required to solve our energy needs and environmental concerns moving forward. The complexity, scope, and magnitude of the electrical grid, even restricted to an area as relatively small as Ada County, is tremendous. The DNRS appears to have the technical potential and the necessary profit motive to warrant further investigation. In order to spark large-scale adoption government will likely need to be involved. Government financing, at the very least, offers the resources, incentives, and the monetary ability to develop the system. The question then turns to government's role in the energy sector. Given the importance 
of energy systems to the economic and security concerns of the United States, it seems rational that a nationalized energy system could be considered a public good just as the public highway system. Returning to the Gagnon et al. (2016) model from chapter I, the 128 cities used in that study could be analyzed in this same fashion and retro-fitted with solar technology through government funding at a rough estimated cost of $\$ 1.28$ trillion, or the equivalent of the Iraq war.

There are options that could be taken on a governmental level short of a quasi-nationalization of the electrical grid. Lobel and Perakis (2011) propose subsidizing private consumers to adopt new solar technologies, and there are likely a multiplicity of schemes that could accomplish increased adoption by individual homeowners. The consequences of these programs are often accompanied by cascade effects as utilities struggle to adapt grid dependencies to these changing conditions. Hawaii and California both provide recent examples of supply-side issues creating tensions between utilities and consumers (Cole and A. W. Frazier, 2018), and the Idaho PUC has heard complaints from consumers who feel they should be protected from free market effects driving down the price Idaho Power is willing to pay for their excess energy (Sowell, 2019).

\section{Further Research}

The question still remains whether solar is the most economically and environmentally ecient option. The social costs of the distributed network also must be investigated, including the mining of rare earths for solar array construction and the disposal process once the life cycle of the arrays have been exhausted. As new energy storage technology becomes available this model should be adapted to reflect storage possibilities and possible disconnection from the energy grid. Safety, security, and resilience issues can be explored in greater detail to 
determine if the distributed network characteristics provide a level of resilience high enough to offset more of the costs.

Another viable, and relatively carbon-free, solution appears in the nuclear energy sector. Since nuclear power is generated through a turbine system, as opposed to the inverter system found in solar, nuclear technology is more than capable of replacing dirty fuels and can be more or less plugged right in to the current grid. Energy density, regardless of whether it is measured in building footprint or megawatt-hours per dollar, is considerably higher. The aggregate capital costs of the distributed network are estimated at $\$ 6.9$ billion for a lifetime estimated output of 262,000 mWh. Two Westinghouse AP1000 reactors were grid-activated in 2018 in China with estimated 60-year life cycles and 3,400 $\mathrm{mWh}$ capacity each, at a final construction cost of $\$ 7.3$ billion (US) (Sanmen Nuclear Power Station 2019). Power output from the twin nuclear plants, assuming full nameplate capacity, is 1.49 billion mWh. A similar project in Georgia is scheduled to come online in 2020 with an estimated cost of $\$ 25$ billion, and while that difference in cost is worth investigating either option far outpaces the distributed network in terms of energy density for both land footprint and cost per mWh. Exploring the advantages and disadvantages of small modular reactors, and how they compare to the distributed network, is another fascinating area of study.

Even as future research is required, the hope is that this study has made one thing clear -providing energy to Ada County through a distributed network of rooftop solar installations is both technologically feasible and economically viable. At this point, the choice to continue burning our valuable and scarce fossil fuels for electricity generation in the face of copious amounts of clean renewable energy is just that - a choice. 


\section{References}

Ada County (Idaho). Assessor's Office., Ada County Highway District (Idaho), and Community Planning Association of Southwest Idaho. (0). Ada County GIS data. English. Boise, ID. URL: http://www .adacountyassessor .org/download/ (visited on $01 / 30 / 2020)$.

Ahlroth, Sofia and Mattias Höjer (Sept. 2007). "Sustainable energy prices and growth: Comparing macroeconomic and backcasting scenarios". en. In: Ecological Economics. Sustainability and Cost-Benefit Analysis 63.4, pp. 722-731. ISSN: 0921-8009. DOI: 10.1016/j.ecolecon.2007.05.002. URL: http://www.sciencedirect.com/science/article/pii/S0921800907002789 (visited on 03/03/2020).

Ahmad, Muhammad Waseem, Jonathan Reynolds, and Yacine Rezgui (Dec. 2018). "Predictive modelling for solar thermal energy systems: A comparison of support vector regression, random forest, extra trees and regression trees". In: Journal of Cleaner Production 203, pp. 810-821. ISSN: 0959-6526. DOI:

10.1016/j.jclepro.2018.08.207. URL:

http://www.sciencedirect.com/science/article/pii/S0959652618325551 (visited on $03 / 07 / 2019$ ).

Ahmad, Tanveer et al. (Apr. 2018). "A comprehensive overview on the data driven and large scale based approaches for forecasting of building energy demand: A review". In: Energy and Buildings 165, pp. 301-320. ISSN: 0378-7788. DOI:

10.1016/j.enbuild.2018.01.017. URL:

http://www.sciencedirect.com/science/article/pii/S0378778817329225 (visited on $03 / 07 / 2019$ ). 
Araújo, Kathleen M (2017). Low carbon energy transitions: turning points in national policy and innovation. English. OCLC: 959610826. ISBN: 978-0-19-936255-4.

Araújo, Kathleen, Jean Léon Boucher, and Omkar Aphale (Apr. 2019). “A clean energy assessment of early adopters in electric vehicle and solar photovoltaic technology: Geospatial, political and socio-demographic trends in New York". en. In: Journal of Cleaner Production 216, pp. 99-116. ISSN: 0959-6526. DOI: 10.1016/j.jclepro.2018.12.208. URL: http://www.sciencedirect.com/science/article/pii/S0959652618339283 (visited on $02 / 14 / 2020)$.

Arthur, W. Brian (2015). Complexity and the economy. Oxford ; New York: Oxford University Press. ISBN: 978-0-19-933429-2.

Babecký, Jan, Michal Franta, and Jakub Ryšánek (Nov. 2018). "Fiscal policy within the DSGE-VAR framework". en. In: Economic Modelling 75, pp. 23-37. ISSN: 02649993. DOI: 10.1016/j.econmod.2018.06.005. URL: https://linkinghub.elsevier.com/retrieve/pii/S0264999317319077 (visited on $01 / 10 / 2020)$.

Bale, Catherine S.E., Liz Varga, and Timothy J. Foxon (Jan. 2015). "Energy and complexity: New ways forward". en. In: Applied Energy 138, pp. 150-159. ISSN: 03062619. DOI: 10.1016/j . apenergy .2014.10.057. URL: https://linkinghub.elsevier.com/retrieve/pii/S0306261914011076 (visited on $02 / 16 / 2020)$.

Barker, Rocky (Mar. 2018). Idaho Power says solar panels could cost your neighbors. Does the claim hold up? en. Library Catalog: www.idahostatesman.com. URL: https://www. idahostatesman.com/news/ local/environment/article205962334.html (visited on 03/17/2020). 
Bass, Frank M. (Jan. 1969). "A New Product Growth for Model Consumer Durables". en. In: Management Science 15.5, pp. 215-227. ISSN: 0025-1909, 1526-5501. DOI: $10.1287 / \mathrm{mnsc} \cdot 15.5 .215$. URL: http://pubsonline.informs.org/doi/abs/10.1287/mnsc.15.5.215 (visited on $03 / 19 / 2020)$.

Baye, Michael R. and Jeff Prince (2017). Managerial economics and business strategy. Ninth edition. New York, NY: McGraw-Hill Education. ISBN: 978-1-259-29061-9.

Berndt, Ernst R (1991). The practice of econometrics: classic and contemporary. English. OCLC: 22310012. Reading, Mass.: Addison-Wesley Pub. Co.

Blair, Nate et al. (2014). "System Advisor Model, SAM 2014.1.14: General Description". en. In: Renewable Energy, p. 19.

Boswijk, H. Peter and Philip Hans Franses (2005). "On the Econometrics of the Bass Diffusion Model". In: Journal of Business \&6 Economic Statistics 23.3, pp. 255-268. ISSN: 0735-0015. URL: https://www.jstor.org/stable/27638819 (visited on $02 / 14 / 2020)$.

Brigham, Eugene F. and Joel F. Houston (2017). Fundamentals of financial management. Concise 9th edition. OCLC: ocn956380086. Boston: Cengage Learning. ISBN: 978-1-305-63593-7.

Cole, Wesley and A. Will Frazier (Dec. 2018). "Impacts of increasing penetration of renewable energy on the operation of the power sector". en. In: The Electricity Journal 31.10, pp. 24-31. ISSN: 10406190. DOI: 10.1016/j.tej.2018.11.009. URL: https://linkinghub.elsevier.com/retrieve/pii/S1040619018303130 (visited on 12/14/2018).

Damette, Olivier, Philippe Delacote, and Gaye Del Lo (Feb. 2018). "Households energy consumption and transition toward cleaner energy sources". en. In: Energy Policy 113, pp. 751-764. ISSN: 03014215. DOI: 10.1016/j .enpol .2017.10.060. 
URL: https://linkinghub.elsevier.com/retrieve/pii/S0301421517307346 (visited on $12 / 14 / 2018$ ).

Delloite (2019). IDPC 10k.pdf.

Denholm, Paul and Maureen Hand (Mar. 2011). "Grid flexibility and storage required to achieve very high penetration of variable renewable electricity". en. In: Energy Policy 39.3, pp. 1817-1830. ISSN: 03014215. DOI:

10.1016/j.enpol.2011.01.019. URL:

https://linkinghub.elsevier.com/retrieve/pii/S0301421511000292 (visited on 06/08/2019).

Denholm, Paul and Robert M. Margolis (Sept. 2007). "Evaluating the limits of solar photovoltaics (PV) in electric power systems utilizing energy storage and other enabling technologies". en. In: Energy Policy 35.9, pp. 4424-4433. ISSN:

03014215. DOI: 10.1016/j.enpol.2007.03.004. URL:

https://linkinghub.elsevier.com/retrieve/pii/S030142150700095X (visited on 06/08/2019).

Denholm, Paul and Mark Mehos (2011). "Enabling Greater Penetration of Solar Power via the Use of CSP with Thermal Energy Storage". en. In: Renewable Energy, p. 28.

EIA (Feb. 2019). Residential Energy Consumption Survey (RECS) -. URL: https://www.eia.gov/consumption/residential/ (visited on 02/25/2019).

Elsner, Wolfram, Torsten Heinrich, and Henning Schwardt (2015). The microeconomics of complex economies: evolutionary, institutional, neoclassical, and complexity perspectives. OCLC: ocn879349158. Amsterdam ; Boston: Academic Press. ISBN: 978-0-12-411585-9.

Energy, Ide (2019). Boise's Energy Future / City of Boise. en. (Visited on 02/07/2020). 
Filippini, Massimo and Lester C. Hunt (Sept. 2012). "US residential energy demand and energy efficiency: A stochastic demand frontier approach". en. In: Energy Economics 34.5, pp. 1484-1491. ISSN: 01409883. DOI:

10.1016/j.eneco.2012.06.013. URL:

https://linkinghub.elsevier.com/retrieve/pii/S0140988312001193 (visited on $02 / 26 / 2019)$.

Freeman, J. et al. (Aug. 2014). Reference Manual for the System Advisor Model's Wind Power Performance Model. en. Tech. rep. NREL/TP-6A20-60570, 1150800, NREL/TP-6A20-60570, 1150800. DOI: 10.2172/1150800. URL: http://www.osti.gov/servlets/purl/1150800/ (visited on 10/11/2019).

Friedman, Jerome H (1991). "Multivariate Adaptive Regression Splines". English. In: Ann. Statist. 19.1. OCLC: 5721379612, pp. 1-67. ISSN: 0090-5364.

Fumo, Nelson and M. A. Rafe Biswas (July 2015). "Regression analysis for prediction of residential energy consumption". In: Renewable and Sustainable Energy Reviews 47, pp. 332-343. ISSN: 1364-0321. DOI:

10.1016/j.rser.2015.03.035. URL:

http://www.sciencedirect.com/science/article/pii/S1364032115001884 (visited on $03 / 20 / 2019)$.

Gagnon, Pieter et al. (Jan. 2016). Rooftop Solar Photovoltaic Technical Potential in the United States. A Detailed Assessment. en. Tech. rep. NREL/TP-6A20-65298, 1236153, NREL/TP-6A20-65298, 1236153. DOI: 10.2172/1236153. URL: http://www.osti.gov/servlets/purl/1236153/ (visited on 01/07/2020).

Ghaith, Ahmad F., Francis M. Epplin, and R. Scott Frazier (Sept. 2017). "Economics of grid-tied household solar panel systems versus grid-only electricity". en. In: Renewable and Sustainable Energy Reviews 76, pp. 407-424. ISSN: 13640321. DOI: 10.1016/j.rser.2017.02.079. URL: 
https://linkinghub.elsevier.com/retrieve/pii/S1364032117303064 (visited on 12/14/2018).

Gilman, P. (May 2015). SAM Photovoltaic Model Technical Reference. en. Tech. rep. NREL/TP-6A20-64102, 1215213, NREL/TP-6A20-64102, 1215213. DOI: 10.2172/1215213. URL: http://www.osti.gov/servlets/purl/1215213/ (visited on $03 / 15 / 2020)$.

Gonzalez de Durana, Jose and Oscar Barambones (June 2018). "Technology-free microgrid modeling with application to demand side management". en. In: Applied Energy 219, pp. 165-178. ISSN: 03062619. DOI:

10.1016/j . apenergy . 2018.03.024. URL:

https://linkinghub.elsevier.com/retrieve/pii/S0306261918303532 (visited on 06/18/2019).

Hall, Steven (May 2019). Forecasting Structural Energy Demand: Machine Learning Approach.

Harvey, Hal and Robbie Orvis (2018). Designing climate solutions: a policy guide for low-carbon energy. Washington: Island Press. ISBN: 978-1-61091-956-2.

Hernandez, Rebecca R., Madison K. Hoffacker, and Christopher B. Field (Jan. 2014). "Land-Use Efficiency of Big Solar". In: Environmental Science 86 Technology 48.2, pp. 1315-1323. ISSN: 0013-936X. DOI: 10.1021/es4043726. URL: https://doi .org/10.1021/es4043726 (visited on 03/13/2020).

Holland, John Henry (2003). Hidden order: how adaptation builds complexity. eng. 10. print. Helix books. OCLC: 838098590 . Cambridge, Mass.: Perseus Books. ISBN: 978-0-201-44230-4.

Hou, Qingchun et al. (May 2019). Probabilistic duck curve in high PV penetration power system_ Concept, modeling, and empirical analysis in China / Elsevier Enhanced Reader. en. DOI: 10.1016/j.apenergy.2019.03.067. (Visited on $11 / 27 / 2019)$. 
IdaCorp (2018a). Adaptability: 2018 Sustainability Report.

- (2018b). Connecting-2017 Sustainability Report. Tech. rep.

Jenkins, Jesse D and Samuel Thernstrom (Mar. 2017). "DEEP

DECARBONIZATION OF THE ELECTRIC POWER SECTOR INSIGHTS FROM RECENT LITERATURE". en. In: p. 10.

Journal, Electricity (Dec. 2018). "Residential Storage Capacity Moves Rapidly beyond Niche Status in U.S." en. In: The Electricity Journal 31.10, p. 62. ISSN: 10406190. DOI: $10.1016 / j$.tej $\cdot 2018.11 .013$. URL: https://linkinghub.elsevier.com/retrieve/pii/S1040619018303397 (visited on $02 / 18 / 2020$ ).

Kapetanios, George and Tony Yates (2010). "Estimating Time Variatin in Measurement Error fron Data REvisions: An Application to Backcasting and Forecasting in Dynamic Models". In: Journal of Applied Econometrics 25.5. Publisher: Wiley, pp. 869-893. ISSN: 0883-7252. URL: https://www. jstor.org/stable/40865177 (visited on 03/03/2020).

Keen, Steve, Robert U. Ayres, and Russell Standish (Mar. 2019). "A Note on the Role of Energy in Production". In: Ecological Economics 157, pp. 40-46. ISSN: 0921-8009. DOI: $10.1016 / \mathrm{j}$. ecolecon.2018.11.002. URL: http://www.sciencedirect.com/science/article/pii/S0921800917311746 (visited on $02 / 28 / 2019$ ).

Kelton, Stephanie (2011). "Limitations of the government budget constraint: Users vs. issuers of the currency". en. In: Panoeconomicus 58.1, pp. 57-66. ISSN: 1452-595X. DOI: $10.2298 /$ PAN1101057K. URL: http://www.doiserbia.nb.rs/Article.aspx?ID=1452-595X1101057K (visited on $01 / 10 / 2020)$.

Kremers, Enrique, Jose Gonzalez de Durana, and Oscar Barambones (Nov. 2013). "Multi-agent modeling for the simulation of a simple smart microgrid". en. In: 
Energy Conversion and Management 75, pp. 643-650. ISSN: 01968904. DOI:

10.1016/j .enconman.2013.07.050. URL:

https://linkinghub.elsevier.com/retrieve/pii/S0196890413004214

(visited on $02 / 18 / 2020)$.

Kremers, Enrique, Pablo Viejo, et al. (Mar. 2010). "A Complex Systems Modelling Approach for Decentralised Simulation of Electrical Microgrids". In: 2010 15th IEEE International Conference on Engineering of Complex Computer Systems, pp. 302-311. DOI: 10.1109/ICECCS .2010.1.

Kuhn, Max and Kjell Johnson (2013). Applied predictive modeling. OCLC: ocn827083441. New York: Springer. ISBN: 978-1-4614-6848-6.

Kumar, Rajesh and Arun Agarwala (Feb. 2016). "Renewable energy technology diffusion model for techno-economics feasibility". en. In: Renewable and Sustainable Energy Reviews 54, pp. 1515-1524. ISSN: 13640321. DOI: 10.1016/j.rser.2015.10.109. URL: https://linkinghub.elsevier.com/retrieve/pii/S1364032115011880 (visited on $02 / 16 / 2020)$.

Lobel, Ruben and Georgia Perakis (2011). Consumer Choice Model For Forecasting Demand And Designing Incentives For Solar Technology.

Ma, Jun and Jack C. P. Cheng (Dec. 2016a). "Estimation of the building energy use intensity in the urban scale by integrating GIS and big data technology". In: Applied Energy 183, pp. 182-192. ISSN: 0306-2619. DOI:

10.1016/j .apenergy. 2016.08.079. URL:

http://www.sciencedirect.com/science/article/pii/S0306261916311679 (visited on $03 / 07 / 2019)$.

- (Dec. 2016b). "Identifying the influential features on the regional energy use intensity of residential buildings based on Random Forests". In: Applied Energy 183, pp. 193-201. ISSN: 0306-2619. DOI: 10.1016/j .apenergy.2016.08.096. 
URL:

http://www.sciencedirect.com/science/article/pii/S0306261916311941 (visited on $03 / 07 / 2019)$.

Ma, Junchao et al. (Mar. 2017). "Transmission Loss Optimization-Based Optimal Power Flow Strategy by Hierarchical Control for DC Microgrids". In: IEEE Transactions on Power Electronics 32.3, pp. 1952-1963. ISSN: 1941-0107. DOI: 10.1109/TPEL . 2016.2561301.

MacKay, David (2010). Sustainable energy - without the hot air. eng. Reprinted. OCLC: 723546051. Cambridge: UIT Cambridge. ISBN: 978-0-9544529-3-3 978-1-906860-01-1.

Maleki, Akbar and Alireza Askarzadeh (Sept. 2014). "Optimal sizing of a $\mathrm{PV} /$ wind/diesel system with battery storage for electrification to an off-grid remote region: A case study of Rafsanjan, Iran". en. In: Sustainable Energy Technologies and Assessments 7, pp. 147-153. ISSN: 22131388. DOI: 10.1016/j.seta.2014.04.005. URL: https://linkinghub.elsevier.com/retrieve/pii/S2213138814000381 (visited on $02 / 14 / 2020)$.

Mazhari, E. M. et al. (Dec. 2009). "Hybrid simulation and optimization-based capacity planner for integrated photovoltaic generation with storage units". In: Proceedings of the 2009 Winter Simulation Conference (WSC), pp. 1511-1522. DOI: $10.1109 /$ WSC . 2009.5429303.

Mitchell, William (2019). Macroeconomics. en. Macmillan International Higher Education. ISBN: 978-1-137-61067-6.

Mulder, Henk A. J. and Wouter Biesiot (1998). Transition to a sustainable society: a backcasting approach to modelling energy and ecology. Advances in ecological economics. Cheltenham, UK ; Northampton, MA: E. Elgar. ISBN: 978-1-85898-731-6. 
Mohanad, Al-Musaylh, et al. (Jan. 2018). "Short-term electricity demand forecasting with MARS, SVR and ARIMA models using aggregated demand data in Queensland, Australia". en. In: Advanced Engineering Informatics 35, pp. 1-16. ISSN: 1474-0346. DOI: 10.1016/j .aei.2017.11.002. URL:

http://www.sciencedirect.com/science/article/pii/S1474034617301477 (visited on 01/06/2020).

Page, Scott E. (2018). The model thinker: what you need to know to make data work for you. First edition. OCLC: on1028523969. New York: Basic Books. ISBN: 978-0-465-09462-2.

Pérez-Lombard, Luis, José Ortiz, and Christine Pout (Jan. 2008). "A review on buildings energy consumption information". en. In: Energy and Buildings 40.3, pp. 394-398. ISSN: 03787788. DOI: 10.1016/j .enbuild.2007.03.007. URL: https://linkinghub.elsevier.com/retrieve/pii/S0378778807001016 (visited on 02/26/2019).

Pollin, Robert et al. (2008). Green Recovery: A Program to Create Good Jobs \&6 Start Building a Low-Carbon Economy. en. Tech. rep. peri_report. Publication Title: Published Studies. Political Economy Research Institute, University of Massachusetts at Amherst. URL:

https://ideas.repec.org/p/uma/perips/peri_report.html (visited on $03 / 17 / 2020)$.

Ponta, Linda et al. (Mar. 2018). "An Agent-based Stock-flow Consistent Model of the Sustainable Transition in the Energy Sector". en. In: Ecological Economics 145, pp. 274-300. ISSN: 09218009. DOI: 10.1016/j.ecolecon.2017.08.022. URL: https://linkinghub.elsevier.com/retrieve/pii/S0921800916310138 (visited on $12 / 14 / 2018$ ).

Pruckner, Marco and Reinhard German (Dec. 2013). "A hybrid simulation model for large-scaled electricity generation systems". en. In: 2013 Winter Simulations 
Conference (WSC). Washington, DC, USA: IEEE, pp. 1881-1892. ISBN:

978-1-4799-3950-3 978-1-4799-2077-8. DOI: 10.1109/WSC . 2013.6721568. URL: http: //ieeexplore.ieee.org/document/6721568/ (visited on 06/09/2019).

Ptak, Thomas et al. (Dec. 2018). "Rethinking community: Analyzing the landscape of community solar through the community-place nexus". en. In: The Electricity Journal 31.10, pp. 46-51. ISSN: 10406190. DOI: 10.1016/j.tej.2018.11.006.

URL: https://linkinghub.elsevier.com/retrieve/pii/S1040619018302689 (visited on 12/14/2018).

Qudrat-Ullah, H (2016). The physics of stocks and flows of energy systems: applications in energy policy. English. OCLC: 919107592. ISBN: 978-3-319-24827-1.

Rai, Varun and Adam Douglas Henry (June 2016). "Agent-based modelling of consumer energy choices". en. In: Nature Climate Change 6.6, pp. 556-562. ISSN: 1758-678X, 1758-6798. DOI: 10.1038/nclimate2967. URL: http://www. nature.com/articles/nclimate2967 (visited on 02/18/2020).

Raworth, Kate (2017). Doughnut economics: seven ways to think like a 21st century economist. eng. OCLC: 1004662708. White River Junction, Vermont: Chelsea Green Publishing. ISBN: 978-1-60358-796-9 978-1-60358-674-0 978-1-84794-137-4 978-1-84794-138-1 978-1-60358-675-7.

Ruth, Matthias et al. (Mar. 2015). "Dynamics of energy transitions under changing socioeconomic, technological and climate conditions in Northwest Germany". In: Ecological Economics 111, pp. 29-47. ISSN: 0921-8009. DOI:

10.1016/j .ecolecon.2014.12.025. URL:

http://wWw.sciencedirect.com/science/article/pii/S0921800915000117 (visited on $11 / 27 / 2018$ ). 
Sanmen Nuclear Power Station (Dec. 2019). en. Page Version ID: 932688683. URL: https://en.wikipedia.org/w/index.php?title=Sanmen_Nuclear_Power_ Station\&oldid=932688683 (visited on 02/07/2020).

Shellenberger, Michael (Oct. 2018). (13) Why renewables can't save the planet / Michael Shellenberger / TEDxDanubia - YouTube. Budhapest, Hungary. URL: https://www . youtube. com/watch?v=N-yALPEpV4w (visited on 11/15/2019).

Short, W., D.J. Packey, and T. Holt (Mar. 1995). A manual for the economic evaluation of energy efficiency and renewable energy technologies. en. Tech. rep. NREL/TP-462-5173, 35391, NREL/TP-462-5173, 35391. DOI: 10. 2172/35391. URL: http://www. osti.gov/servlets/purl/35391-NqycFd/webviewable/ (visited on 12/13/2019).

Sivaram, Varun (2018). Taming the sun: innovations to harness solar energy and power the planet. Cambridge, MA: The MIT Press.

Sowell, John (Dec. 2019). "Idaho Power wanted to cut payments for solar panel electricity. See what regulators said". en. In: idahostatesman. (Visited on 01/08/2020).

Sterman, John (2000). Business dynamics: systems thinking and modeling for a complex world. English. OCLC: 42771322. Boston: Irwin/McGraw-Hill. ISBN: 978-0-07-231135-8 978-0-07-238915-9 978-0-07-124107-6 978-0-07-238737-7 978-0-07-117989-8.

Stokes, Leah C. and Hanna L. Breetz (Feb. 2018). "Politics in the U.S. energy transition: Case studies of solar, wind, biofuels and electric vehicles policy". en. In: Energy Policy 113, pp. 76-86. ISSN: 03014215. DOI:

10.1016/j .enpol .2017.10.057. URL:

https://linkinghub.elsevier.com/retrieve/pii/S0301421517307322 (visited on $12 / 14 / 2018$ ). 
The Duck Curve - Debunking Renewable Energy Myths, Part 1 (May 2016). en-US. URL: https://cleantechnica.com/2016/05/13/duck-curve-debunkingrenewable-energy-myths-1/ (visited on 12/30/2019).

Till, Charles E. and Yoon Il Chang (2011). Plentiful energy: the story of the integral fast reactor, the complex history of a simple reactor technoloogy, with emphasis on its scientific basis for non-specialists. OCLC: ocn770693738. United States: Charles E. Till and Yoon Il Chang. ISBN: 978-1-4663-8460-6.

Tirole, Jean and Steven Rendall (2017). Economics for the common good. eng. OCLC: ocn958799683. Princeton, New Jersey: Princeton University Press. ISBN: 978-0-691-17516-4.

Wang, Zeyu et al. (July 2018). "Random Forest based hourly building energy prediction". In: Energy and Buildings 171, pp. 11-25. ISSN: 0378-7788. DOI: 10.1016/j.enbuild.2018.04.008. URL: http://www.sciencedirect.com/science/article/pii/S0378778818311290 (visited on $03 / 07 / 2019)$.

Watts, Duncan J. and Steven H. Strogatz (June 1998). "Collective dynamics of 'small-world' networks". en. In: Nature 393.6684, pp. 440-442. ISSN: 0028-0836, 1476-4687. DOI: 10.1038/30918. URL: http://www. nature.com/articles/30918 (visited on 02/16/2020).

Wei, Max, Shana Patadia, and Daniel M. Kammen (Feb. 2010). "Putting renewables and energy efficiency to work: How many jobs can the clean energy industry generate in the US?" en. In: Energy Policy 38.2, pp. 919-931. ISSN: 0301-4215. DOI: $10.1016 / \mathrm{j}$.enpol $2009 \cdot 10 \cdot 044$. URL: http://www.sciencedirect.com/science/article/pii/S0301421509007915 (visited on $03 / 17 / 2020)$.

Wilensky, Uri and William Rand (2015). An introduction to agent-based modeling: modeling natural, social, and engineered complex systems with NetLogo. Cambridge, Massachusetts: The MIT Press. ISBN: 978-0-262-73189-8. 
APPENDIX 


\section{Simulation Data}

\subsection{SAM Algorithm}

From Gilman, 2015, The hourly simulation model performs the following calculations for each of the 8,760 hours in a year:

[1.]For each of up to four subarrays:[A.]

1. (a) Calculate sun angles from date, time, and geographic position data from the weather file.

(b) Calculate the nominal beam and diffuse irradiance incident on the plane of array (POA irradiance). This depends on the solar irradiance data in the weather file, sun angle calculations, user-specified subarray parameters such as tracking and orientation parameters, and backtracking option for one-axis trackers.

(c) Apply the user-specified beam and diffuse near-object shading factors to the nominal POA irradiance.

(d) For subarrays with one-axis tracking and self-shading enabled, calculate and apply the self-shading loss factors to the nominal POA beam and diffuse irradiance.

(e) Apply user-specified monthly soiling factors to calculate the effective POA irradiance on the subarray.

2. If there is a single subarray (Subarray 1) with no tracking (fixed) and self-shading is enabled, calculate the reduced diffuse POA irradiance and 
self-shading DC loss factor.

3. Determine subarray string voltage calculation method (Section 10.1).

4. For each of up to four subarrays, run the module model with the effective beam and diffuse POA irradiance and module parameters as input to calculate the DC output power, module efficiency, DC voltage, and cell temperature of a single module in the subarray.

5. Calculate the subarray string voltage using the method determined in Step 3.

6. Loop through the subarrays to calculate the array DC power:

[A.]For Subarray 1, apply the fixed self-shading DC loss to the module DC power if it applies. For each subarray, calculate the subarray gross DC power by multiplying the module DC power by the number of modules in the subarray. For each subarray, calculate subarray net DC power by multiplying the gross subarray power by the DC loss. For each subarray, calculate the subarray string voltage by multiplying the module voltage by the number of modules per string. Calculate the array net and gross DC power by adding up the subarray values.

(4) Run the inverter submodel to calculate the gross AC power and inverter conversion efficiency.

8. Calculate the net $\mathrm{AC}$ power by applying the $\mathrm{AC}$ loss to the gross $\mathrm{AC}$ power. 
Table 9: Network Supply Demand with Solar Irradiance: July 15,2018

\begin{tabular}{cccccccc}
\hline & Date & Supply & Demand & DHI & DNI & Zenith & GHI \\
\hline \hline 1 & $2018-07-15$ & -0.066 & 60.500 & 0 & 0 & 114.100 & 0 \\
2 & $2018-07-15$ 01:00:00 & -0.066 & 50.277 & 0 & 0 & 113.663 & 0 \\
3 & $2018-07-15$ 02:00:00 & -0.066 & 47.969 & 0 & 0 & 110.426 & 0 \\
4 & $2018-07-15$ 03:00:00 & -0.066 & 50.833 & 0 & 0 & 104.766 & 0 \\
5 & $2018-07-1504: 00: 00$ & -0.066 & 41.343 & 0 & 0 & 97.211 & 0 \\
6 & $2018-07-15$ 05:00:00 & 6.945 & 78.215 & 9 & 80 & 88.457 & 11 \\
7 & $2018-07-15$ 06:00:00 & 75.253 & 78.321 & 33 & 0 & 78.864 & 33 \\
8 & $2018-07-15$ 07:00:00 & 126.848 & 113.373 & 72 & 660 & 68.403 & 315 \\
9 & $2018-07-1508: 00: 00$ & 162.973 & 127.059 & 89 & 765 & 57.612 & 499 \\
10 & $2018-07-15$ 09:00:00 & 185.529 & 140.420 & 100 & 830 & 46.834 & 668 \\
11 & $2018-07-1510: 00: 00$ & 205.647 & 156.115 & 107 & 871 & 36.556 & 807 \\
12 & $2018-07-1511: 00: 00$ & 150.534 & 164.467 & 103 & 910 & 27.753 & 908 \\
13 & $2018-07-1512: 00: 00$ & 135.624 & 172.789 & 102 & 925 & 22.541 & 956 \\
14 & $2018-07-1513: 00: 00$ & 177.421 & 149.182 & 99 & 929 & 23.572 & 950 \\
15 & $2018-07-1514: 00: 00$ & 186.075 & 152.380 & 103 & 908 & 30.197 & 887 \\
16 & $2018-07-1515: 00: 00$ & 186.681 & 157.803 & 98 & 882 & 39.613 & 778 \\
17 & $2018-07-1516: 00: 00$ & 178.198 & 148.177 & 90 & 839 & 50.120 & 628 \\
18 & $2018-07-1517: 00: 00$ & 140.779 & 88.292 & 78 & 768 & 60.950 & 451 \\
19 & $2018-07-1518: 00: 00$ & 63.049 & 80.646 & 62 & 648 & 71.686 & 265 \\
20 & $2018-07-1519: 00: 00$ & 11.458 & 92.339 & 36 & 411 & 81.985 & 93 \\
21 & $2018-07-1520: 00: 00$ & -0.066 & 85.381 & 0 & 0 & 91.189 & 0 \\
22 & $2018-07-1521: 00: 00$ & -0.066 & 85.866 & 0 & 0 & 99.774 & 0 \\
23 & $2018-07-15$ 22:00:00 & -0.066 & 66.882 & 0 & 0 & 106.830 & 0 \\
24 & $2018-07-1523: 00: 00$ & -0.066 & 66.307 & 0 & 0 & 111.826 & 0 \\
\hline \hline
\end{tabular}

Calculated based on typical model year data, 1998:2018 
Table 10: Oscar System Hourly Output: July 15,2018

\begin{tabular}{ccccc}
\hline Date & Supply & Zenith & GHI & Temp_C \\
\hline \hline 2018-07-15 & -0.001 & 114.196 & 0 & 19 \\
2018-07-15 01:00:00 & -0.001 & 113.760 & 0 & 18 \\
2018-07-15 02:00:00 & -0.001 & 110.520 & 0 & 17 \\
2018-07-15 03:00:00 & -0.001 & 104.854 & 0 & 16 \\
2018-07-15 04:00:00 & -0.001 & 97.293 & 0 & 16 \\
2018-07-15 05:00:00 & 0.174 & 88.525 & 12 & 16 \\
2018-07-15 06:00:00 & 2.055 & 78.934 & 148 & 18 \\
2018-07-15 07:00:00 & 3.421 & 68.471 & 331 & 20 \\
2018-07-15 08:00:00 & 4.393 & 57.678 & 520 & 23 \\
2018-07-15 09:00:00 & 4.999 & 46.902 & 677 & 25 \\
2018-07-15 10:00:00 & 5.541 & 36.631 & 831 & 27 \\
2018-07-15 11:00:00 & 4.049 & 27.840 & 676 & 28 \\
2018-07-15 12:00:00 & 3.644 & 22.640 & 637 & 29 \\
2018-07-15 13:00:00 & 4.780 & 23.664 & 801 & 29 \\
2018-07-15 14:00:00 & 5.015 & 30.272 & 803 & 29 \\
2018-07-15 15:00:00 & 5.036 & 39.676 & 743 & 29 \\
2018-07-15 16:00:00 & 4.812 & 50.178 & 633 & 28 \\
2018-07-15 17:00:00 & 3.805 & 61.008 & 435 & 27 \\
2018-07-15 18:00:00 & 1.691 & 71.746 & 191 & 25 \\
2018-07-15 19:00:00 & 0.283 & 82.049 & 47 & 22 \\
2018-07-15 20:00:00 & -0.001 & 91.261 & 0 & 20 \\
2018-07-15 21:00:00 & -0.001 & 99.853 & 0 & 19 \\
2018-07-15 22:00:00 & -0.001 & 106.917 & 0 & 19 \\
2018-07-15 23:00:00 & -0.001 & 111.921 & 0 & 19 \\
\hline \hline
\end{tabular}


Table 11: India System Hourly Output: July 15,2018

\begin{tabular}{ccccc}
\hline Date & Supply & Zenith & GHI & Temp_C \\
\hline \hline 2018-07-15 & -0.005 & 114.196 & 0 & 19 \\
2018-07-15 01:00:00 & -0.005 & 113.760 & 0 & 18 \\
2018-07-15 02:00:00 & -0.005 & 110.520 & 0 & 17 \\
2018-07-15 03:00:00 & -0.005 & 104.854 & 0 & 16 \\
2018-07-15 04:00:00 & -0.005 & 97.293 & 0 & 16 \\
2018-07-15 05:00:00 & 0.426 & 88.525 & 12 & 16 \\
2018-07-15 06:00:00 & 4.795 & 78.934 & 148 & 18 \\
2018-07-15 07:00:00 & 7.996 & 68.471 & 331 & 20 \\
2018-07-15 08:00:00 & 10.291 & 57.678 & 520 & 23 \\
2018-07-15 09:00:00 & 11.726 & 46.902 & 677 & 25 \\
2018-07-15 10:00:00 & 13.016 & 36.631 & 831 & 27 \\
2018-07-15 11:00:00 & 9.477 & 27.840 & 676 & 28 \\
2018-07-15 12:00:00 & 8.523 & 22.640 & 637 & 29 \\
2018-07-15 13:00:00 & 11.207 & 23.664 & 801 & 29 \\
2018-07-15 14:00:00 & 11.766 & 30.272 & 803 & 29 \\
2018-07-15 15:00:00 & 11.816 & 39.676 & 743 & 29 \\
2018-07-15 16:00:00 & 11.283 & 50.178 & 633 & 28 \\
2018-07-15 17:00:00 & 8.903 & 61.008 & 435 & 27 \\
2018-07-15 18:00:00 & 3.948 & 71.746 & 191 & 25 \\
2018-07-15 19:00:00 & 0.676 & 82.049 & 47 & 22 \\
2018-07-15 20:00:00 & -0.005 & 91.261 & 0 & 20 \\
2018-07-15 21:00:00 & -0.005 & 99.853 & 0 & 19 \\
2018-07-15 22:00:00 & -0.005 & 106.917 & 0 & 19 \\
2018-07-15 23:00:00 & -0.005 & 111.921 & 0 & 19 \\
\hline \hline
\end{tabular}


Table 12: Distributed Network-Monthly Supply, Demand and Savings

\begin{tabular}{ccccccc}
\hline & Month & NetOutput & Load & SolarCost & GridCost & Savings \\
\hline \hline 1 & $2020-01-01$ & 390 & 627 & $48,691,994$ & $69,892,792$ & $21,200,798$ \\
2 & $2020-02-01$ & 551 & 566 & $34,962,673$ & $63,299,481$ & $28,336,808$ \\
3 & $2020-03-01$ & 808 & 630 & $31,821,480$ & $70,634,866$ & $38,813,385$ \\
4 & $2020-04-01$ & 1,114 & 668 & $22,743,141$ & $74,371,982$ & $51,628,841$ \\
5 & $2020-05-01$ & 1,327 & 783 & $24,205,819$ & $87,042,753$ & $62,836,935$ \\
6 & $2020-06-01$ & 1,405 & 993 & $39,911,755$ & $123,987,759$ & $84,076,004$ \\
7 & $2020-07-01$ & 1,480 & 1,078 & $42,958,483$ & $133,812,649$ & $90,854,167$ \\
8 & $2020-08-01$ & 1,322 & 1,051 & $50,036,427$ & $131,243,412$ & $81,206,985$ \\
9 & $2020-09-01$ & 1,078 & 865 & $37,518,568$ & $95,106,236$ & $57,587,668$ \\
10 & $2020-10-01$ & 789 & 752 & $40,378,231$ & $83,153,695$ & $42,775,463$ \\
11 & $2020-11-01$ & 487 & 594 & $40,694,491$ & $66,564,072$ & $25,869,581$ \\
12 & $2020-12-01$ & 392 & 621 & $46,421,179$ & $69,188,174$ & $22,766,995$ \\
\hline \hline
\end{tabular}

Output and Load in gWh. Typical model year data, 1998:2018

\section{Financial Incentives}

\subsection{Residential Renewable Energy Tax Credit}

A taxpayer may claim a credit of $30 \%$ of qualified expenditures for a system that serves a dwelling unit located in the United States that is owned and used as a residence by the taxpayer. Expenditures with respect to the equipment are treated as made when the installation is completed. If the installation is at a new home, the "placed in service" date is the date of occupancy by the homeowner. Expenditures include labor costs for on-site preparation, assembly or original system installation, and for piping or wiring to interconnect a system to the home. If the federal tax credit exceeds tax liability, the excess amount may be carried forward to the succeeding taxable year. The maximum allowable credit, equipment requirements and other details vary by technology, as outlined below. Solar-electric property 
- $30 \%$ for systems placed in service by $12 / 31 / 2019$

- $26 \%$ for systems placed in service after $12 / 31 / 2019$ and before $01 / 01 / 2021$

- $22 \%$ for systems placed in service after $12 / 31 / 2020$ and before $01 / 01 / 2022$

There is no maximum credit for systems placed in service after 2008. Systems must be placed in service on or after January 1, 2006, and on or before December 31, 2021. The home served by the system does not have to be the taxpayer's principal residence.

\section{$40.2 \quad$ FHA Energy Efficient Mortgages}

Homeowners can take advantage of energy efficient mortgages (EEM) to either finance energy efficiency improvements to existing homes, including renewable energy technologies, or to increase their home buying power with the purchase of a new energy efficient home. The U.S. federal government supports these loans by insuring them through Federal Housing Authority (FHA) or Veterans Affairs (VA) programs. This allows borrowers who might otherwise be denied loans to pursue energy efficiency, and it secures lenders against loan default. 